\title{
Physical Therapist Assistant Student Success in Traditional 15- versus Seven-Week Courses at a Community College: A Single Institution Case Study
}

Tammy R. Marcin

University of St. Augustine for Health Sciences

DOI: https://doi.org/10.46409/sr.SERB2840

Follow this and additional works at: https://soar.usa.edu/dissertations

Part of the Curriculum and Instruction Commons, and the Vocational Education Commons

\section{Recommended Citation}

Marcin, T. R. (2018). Physical Therapist Assistant Student Success in Traditional 15- versus Seven-Week Courses at a Community College: A Single Institution Case Study. [Doctoral project, University of St Augustine for Health Sciences]. SOAR @ USA: Student Dissertations Collection. https://doi.org/10.46409/ Sr.SERB2840

This Dissertation is brought to you for free and open access by the Student Research at SOAR @ USA. It has been accepted for inclusion in Student Dissertations by an authorized administrator of SOAR @ USA. For more information, please contact soar@usa.edu, erobinson@usa.edu. 
Physical Therapist Assistant Student Success in Traditional 15- versus Seven-Week Courses at a Community College: A Single Institution Case Study

Tammy R. Marcin, DPT, MBA

Doctor of Education

University of St. Augustine for Health Sciences

January 2018 


\begin{abstract}
The reasons why a physical therapist assistant student does not advance in a technical program are multifactorial. The curriculum design of a program is one of many factors that can potentially mitigate against students' progression in a program. The previous literature has only assessed the characteristics of physical therapist assistant students, faculty, and programs in relation to graduates' success in passing the National Physical Therapist Examination. A retrospective program evaluation was performed to investigate how the length of courses (i.e., 7 week vs. 15-week) in the first technical semester of a physical therapist assistant program affected student progression in the program. The population for this study consisted of two cohorts of physical therapist assistant students at one community college. Both cohorts had 34 students. The results for this study suggest that students who participated in the 7-week course had a statistically better retention rate in the first technical term of a physical therapist assistant program, but there was no difference in course or term grade point average than students who participated in a 15-week course. The program studied can utilize the results of this research to validate the benefits and the negative impacts of a compressed course design for a program to improve program retention.
\end{abstract}


Physical Therapist Assistant Student Success in Traditional 15- versus Seven-Week Courses at a Community College: A Single Institution Case Study

\author{
by \\ Tamala, R, Marcin \\ has been approved
}

January, 2018

APPROVED:

ERIC OESTMANN, Ph.D. PT, Faculty Mentor and Chair

MELISSA BATTEN, Ph.D., Committee Member

ACCEPTED AND SIGNED:

Eviclestoncin

ERIC OESTMANN, PhD, PT

Melissa Battran

MELISSA BATTEN, Ph.D.

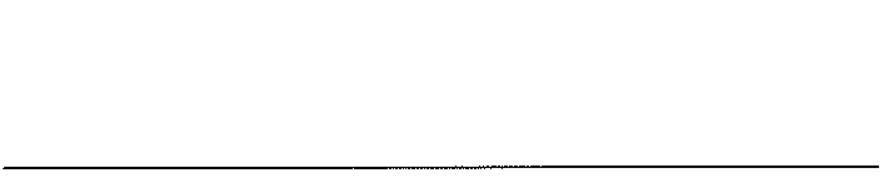

CINDY MATHENA, Ph.D.

Dean of Post Professional Studies 
Copyright Tamala R. Marcin 2018

All Rights Reserved 


\section{Acknowledgement}

This research study would not have been possible without the knowledge that I have gained throughout my educational encounters and my family. This process has allowed me to develop a foundation in teaching methodology and assessment to improve my skill set as both an educator and a physical therapist.

To my mother, Sharon Rose Martin, for instilling in me that all students can learn, as well as the courage to recognize that a child's knowledge is multifactorial.

To my son, Garrett, for his understanding of my absences from some sporting events and tolerance of my studying during family movie nights. I have been in school for a third of his life, and I hope he appreciates the love for knowledge.

To my husband, Jim, for his technical support and sympathetic heart. I cannot thank him enough for setting up my hotspot to allow me to complete schoolwork from my hatchback while watching two-hour peewee football practices. Most important, his understanding that I had to have Wi-Fi when we traveled.

To the faculty at University Saint Augustine, I appreciate the guidance that I have received from all faculty members to develop my skill set as an educator. Before entering this program, I had no formal teaching background. The knowledge that I have gained about teaching philosophy, foundation, and curriculum development has changed me as an educator.

To my dissertation committee: Dr. Eric for prompt, through feedback and belief in the importance of my dissertation topic; and to Dr. Batten for her willingness to provide academic input as well as mental support.

To my current and past students and peers, for being an inspiration to me to seek further knowledge. 


\section{Table of Contents}

Abstract

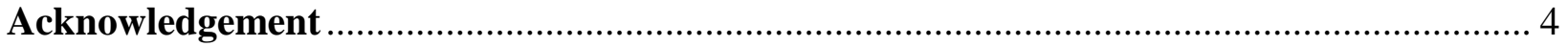

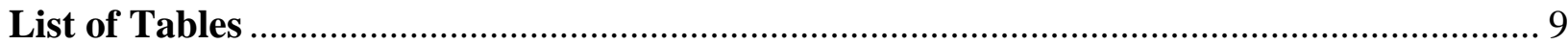

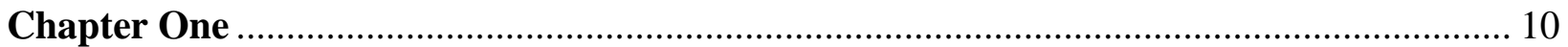

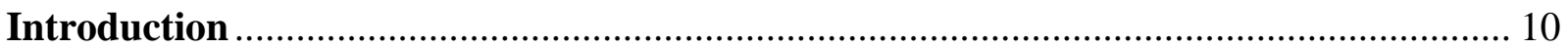

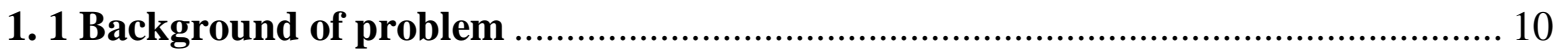

1. 2 Retention

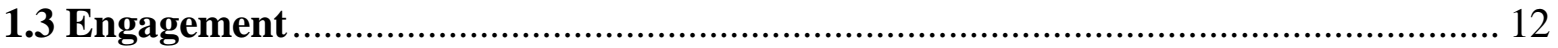

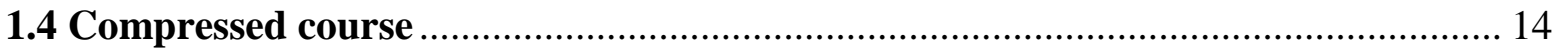

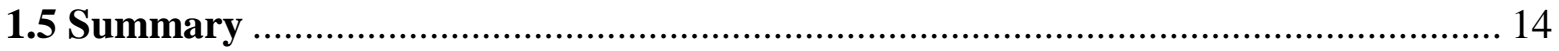

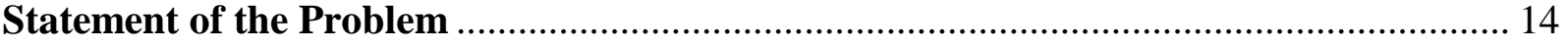

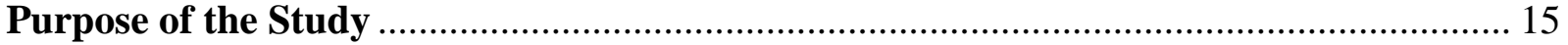

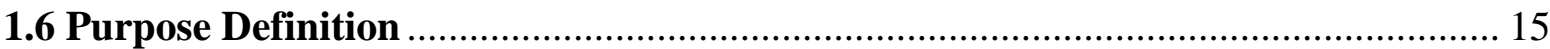

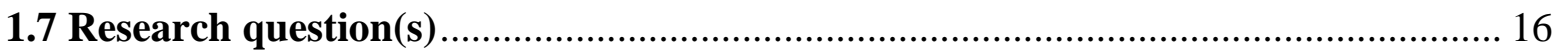

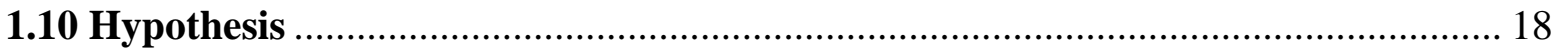

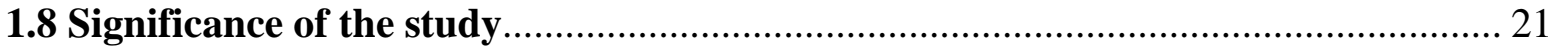

1.9 Definition of key terms ...................................................................................... 22

Chapter Two 


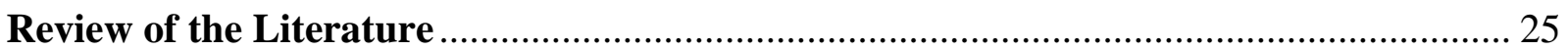

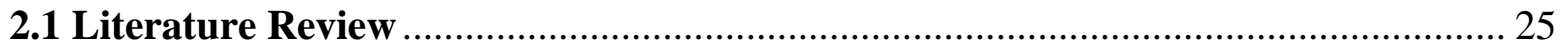

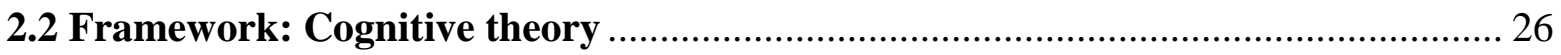

2.3 Framework: Input-Environment-Outcome (I-E-O) Model................................. 27

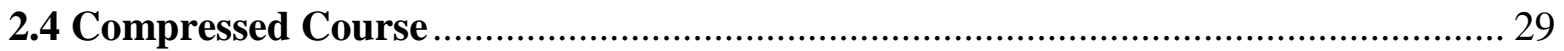

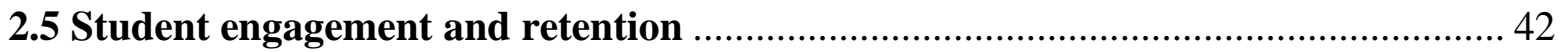

2.6 History, growth, and program outcomes for a PTA program .......................... 46

2.7 Development of Methodology for this Study ................................................. 50

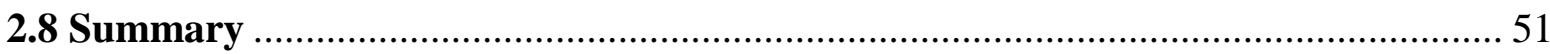

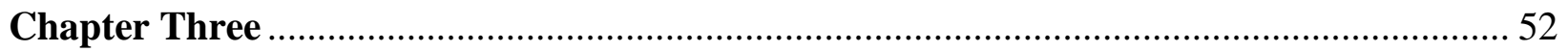

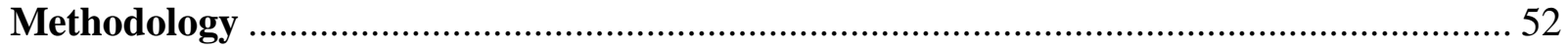

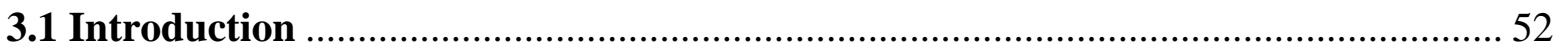

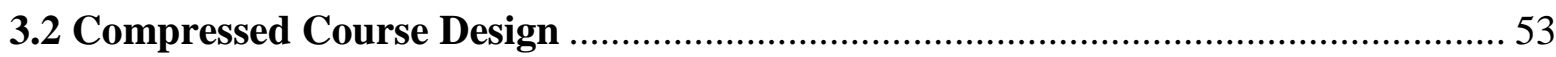

3.3 Definition of the Purpose of the Proposed Study ............................................... 57

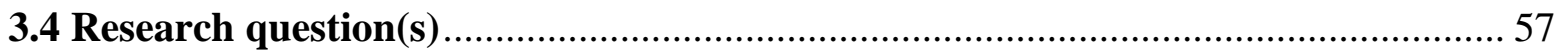

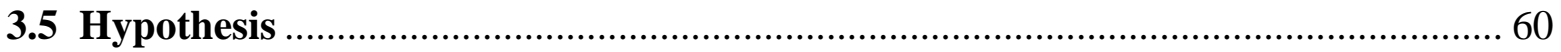

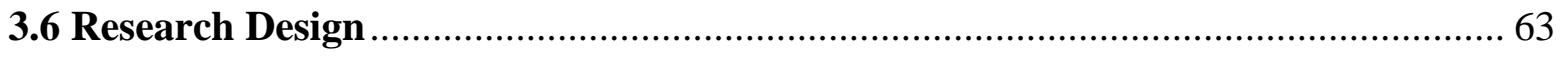

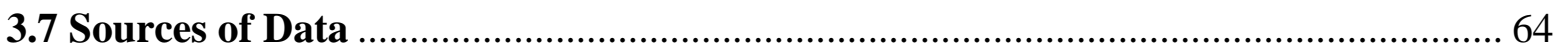

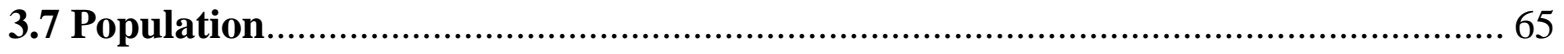

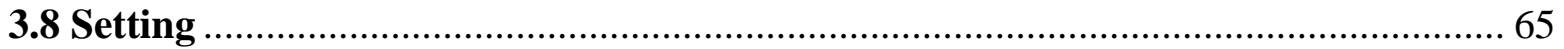


3.9 Recruitment

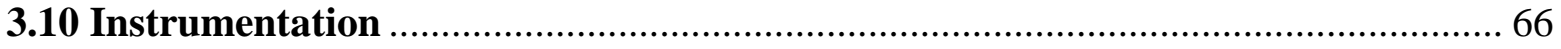

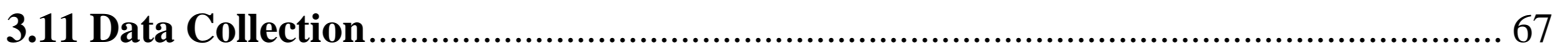

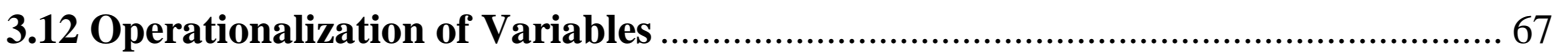

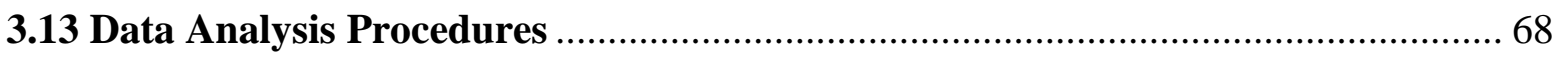

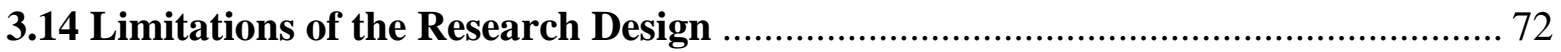

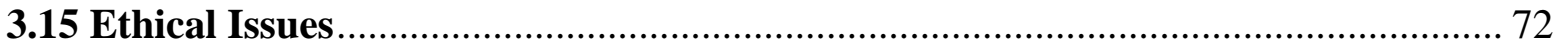

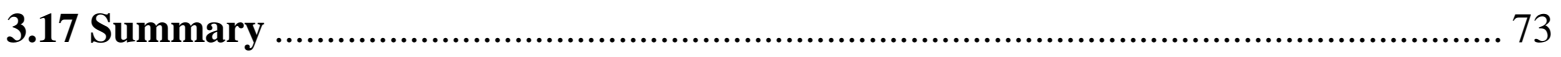

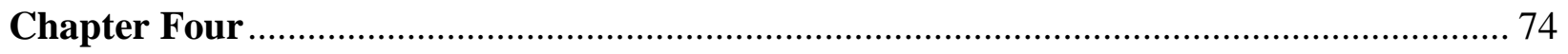

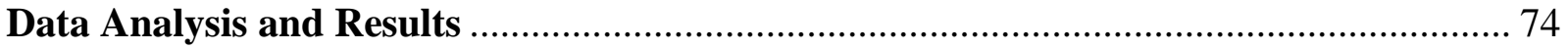

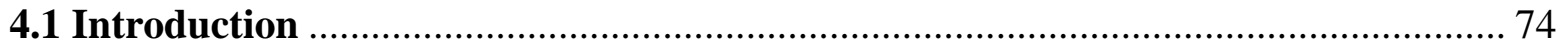

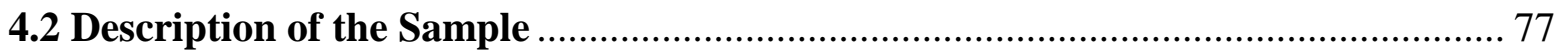

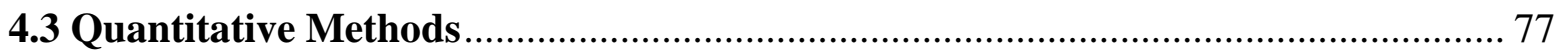

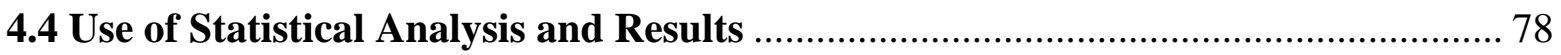

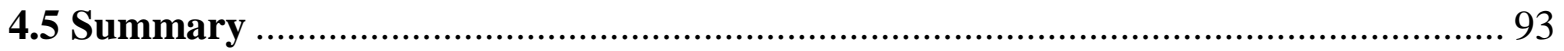

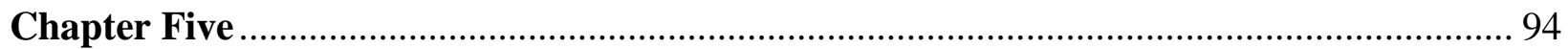

Summary, Conclusions, and Recommendations for Future Research............................... 94

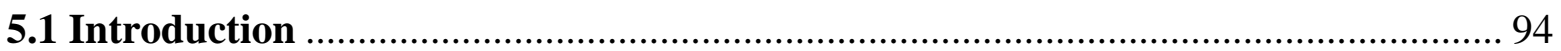

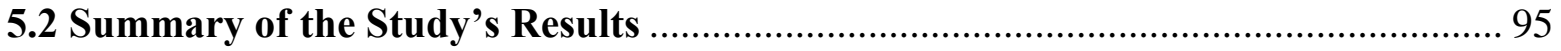

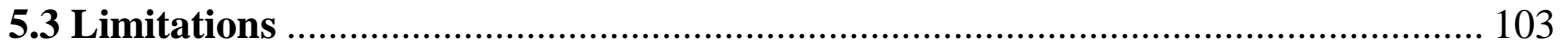


5.4 Implications for Health Sciences

5.5 Recommendations for Future Research 106

5.6 Conclusions. 107

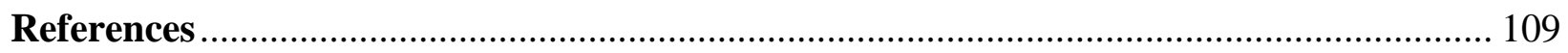

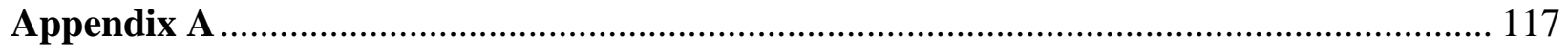




\section{List of Tables}

Table 1. Demographic Statistics of Participants in the Study

Table 2. Course and Term Completion and Withdrawal Results Between Groups

Table 3. Comparison of Course Length to Students' Numeric Term GPA and Course Grade

Table 4. Relationship of Students' Age and Term GPA and Course Length

Table 5. Relationship of Students' Gender and Term GPA and Course Length

Table 6. Relationship of Students' Ethnicity and Term GPA and Course Length

Table 7. Relationship of Students' Highest Degree Earned and Term GPA and Course Length

Table 8. Correlation of Admission GPA and First PTA Technical Term and Course GPA

Table 9. Correlation of TEAS Score and First PTA Technical Term and Course GPA

Table 10. Correlation of TEAS Score and First PTA Technical Term and Course GPA

Table 11. Comparison of PTH 205 Traditional 15-Week to Seven-Week Compressed Numeric Grade

Table 12. Comparison of PTH 270 Traditional 15-Week to Seven-Week Compressed Numeric Grade

Table 13. Comparison of PTH 221 Traditional 15-Week to Seven-Week Compressed Numeric Grade

Table. 14. Comparison of PTH 101 Traditional 15-Week to Seven-Week Compressed Numeric Grade

Table 15. Comparison of PTH 205 Traditional 15-Week to Seven-Week Compressed Numeric Grade

Table 16. Comparison of PTH 270 Traditional 15-Week to Seven-Week Compressed Numeric Grade

Table 17. Comparison of PTH 221 Traditional 15-Week to Seven-Week Compressed Numeric Grade 


\section{Chapter One}

\section{Introduction}

\section{1 Background of problem}

In 2015, the graduation rate for accredited physical therapist assistant (PTA) programs ranged from 25\% to 100\% (Education, 2016a). The large variance in graduation rates among PTA schools needs assessment to improve student success in these programs. The previous literature has assessed the characteristics of PTA students, faculty, and programs in relation to graduates' success in passing the National Physical Therapist Examination (Desmaris, WobleValenski, \& Oestmann, 2011; Gresham, Thompson, Luedtke-Hoffmann, \& Tietze, 2015;

Maring, Costello, Ulfers, \& Zuber, 2013). However, scant research exists in the literature on how a program's academic curriculum impacts PTA students' retention rate.

The reasons why a student may choose to leave a PTA program are multifactorial. One of these reasons is students' failure to achieve academic success in a course. Accordingly, identifying curriculum designs that positively impact the chances of students' academic success in the PTA program would benefit stakeholders.

The director of a PTA program, along with faculty, are responsible for assessing the effectiveness of the curriculum design (Education, 2016b). One benchmark a PTA program uses to assess its effectiveness is student retention rates. The Commission on Accreditation of Physical Therapy Education (CAPTE) requires that PTA programs maintain a $60 \%$ two-year average student retention rate (Education, 2016b). Failure to achieve this two-year average threshold could put the PTA program at risk of losing its accreditation status, which would force the program to be dissolved. 
The PTA program covered in this research study had an overall student retention rate of $67 \%$ for 2015 and 2016. To improve this retention rate, the program has aimed to modify its admission requirements and selection of course materials (Kopelman, 2011; Marcin, 2014a). Nevertheless, the program has been unsuccessful in reaching its program goal of a $70 \%$ student retention rate through these changes. The program's assessment committee has noted that the greatest student attrition in this program occurs in the first technical semester of the PTA program (Marcin, 2014). Through the assessment of student feedback, advisory sessions, and student course evaluations, the program director and faculty speculate that retention rates may be influenced by the number of PTA courses students complete simultaneously. Accordingly, the program director and faculty believe that modifying the initial technical PTA coursework into a compressed course format will improve students' success in the courses in the first technical term of the program.

\section{2 Retention}

In $2014,39 \%$ of students in higher education were enrolled in public community colleges ("Undergraduate Enrollment ", 2016). In 2014, 61\% of first-time, full-time degree-seeking undergraduates retained their enrollment ("Undergraduate retention and graduation rates," 2016). Research has revealed that the main reasons students withdraw from two-year institutions are cost of attendance, lack of student motivation, student work schedules, family obligations, classes not offered at the right times, the gap between students' expectations and the realities of work required for college, college procedures, and dependent care issues (Mertes \& Jankoviak, 2016). It is imperative for institutions to address such issues as student success in completing courses because of their potential to significantly impact the institution's success (Wild \& 
Ebbers, 2002). For instance, student success and enrollment can correlate with the revenue of a college and impact government funding (Roman, 2007).

\subsection{Engagement}

Students enrolled in two-year programs are more likely to have a lower social economic background, work more hours than students at a four-year institution, and be the first generation to enter into higher education (Bonet $\&$ Walters, 2016). These factors may decrease the community college students' ability to engage in a classroom setting, which is directly related to the students' attendance. Students who attend class and collaborate with peers and faculty are more likely to successfully complete the course work. To ensure this happens, some programs employ the mechanism of learning communities to improve student attendance and engagement. Learning communities are small cohorts of students that complete the course in a compressed design format (Bonet $\&$ Walters, 2016). One of the major objectives of learning communities is to embed time management and the development of academic skills into the curriculum. Completing courses in a compressed design allows students to focus on a few courses at one time, and has a positive impact on the students' time-management skills. Students who participate in courses with a compressed design attend longer class sessions over a shorter period. Faculty who teach longer class sessions are more likely to adopt active learning strategies into the long class setting to engage student learning. These tools increase interaction between students and faculty during classes. Active learning activities foster an environment for peer learning and for faculty to motivate students, activities that lead to higher classroom attendance. There is a positive correlation between attendance and grades (Bonet \& Walters, 2016).

Purposeful student and faculty interaction correlate positively with student engagement (DeCiccio, Gross, \& Gross, 2009). A reason why students may not continue at an institution is 
their lack of connection to the institution. A mechanism to improve student retention rates is to have an organized plan of action to reach out to the student population in the first semester of the program. DeCiccio, Gross, and Gross (2009) have determined that if the student population connects with faculty prior to, during, and at the end of the first term, the retention of the student body improves. The authors report that students who are contacted by faculty before the start of the term have higher student retention rates into the next term. They also report that there are better student retention rates if the students' parents were also involved in the orientation process.

Gilardi and Guglielmetti (2011a) analyzed the relationship between a student's university experience and student retention rates for nontraditional and traditional students. They found that students' demographics did not impact students' retention rates, but the type of employment status (permanent versus temporary) was significant. Students who reported temporary positions had a significantly higher attrition rate in the first academic year.

How meaningful the student perceives the interaction with faculty is positively correlated with student retention rates (Gilardi \& Guglielmetti, 2011). Students view the integration of classroom activities that provoke open communication between themselves and faculty in a positive light, and those students who perceive that faculty engage them in the classroom environment have better retention rates. Students believe faculty should plan activities that help them relate their learning content to their personal and professional development. A compressed course requires a longer class period and more sessions over a shorter length of time in an academic term. A longer classroom period enables faculty to incorporate an active teaching methodology, which can foster an environment of meaningful learning (Geltner \& Logan, 2001). 


\subsection{Compressed course}

One potential educational intervention in terms of improving student retention rates is a compressed course design. A compressed course requires a longer class period and/or more sessions over a shorter length of time in an academic term. Some of the research available on compressed course design indicates that it produces higher grades and lower withdrawal rates (Geltner \& Logan, 2001). Other research claims compressed courses offer no advantages above full-term courses (Johnson, Lybecker, \& Taylor, 2011).

\subsection{Summary}

In 2015, the student retention rate for accredited PTA programs ranged from $25 \%$ to $100 \%$ (Education, 2016a). There are many potential factors that cause PTA students to drop out of programs, but research on PTA retention is very sparse. What is known is that student-faculty engagement influences the retention of community college students (Gilardi \& Guglielmetti, 2011a). An intervention research has demonstrated an increase in student-faculty engagement in active learning classroom environments (Geltner \& Logan, 2001). While a curriculum environment may foster active learning for PTA students, research has shown mixed results on compressed learning. Lutes and Davies (2013) claim that the success of a compressed curriculum depends on the type of course. No research has been performed on the effects of PTA students' retention rate and compressed course design.

\section{Statement of the Problem}

Although PTA curriculum design is one of many factors that can potentially mitigate against PTA students' progression in a program, the previous literature has only assessed the characteristics of PTA students, faculty, and programs in relation to graduates' success in passing the National Physical Therapist Examination (Desmaris, Woble-Valenski, \& Oestmann, 
2011); (Gresham, Thompson, Luedtke-Hoffmann, \& Tietze, 2015); (Maring, Costello, Ulfers, \& Zuber, 2013). To date no research has been conducted on how curriculum design can influence such student advancement into the next term of the PTA program.

This study aimed to determine which course length - seven or 15 weeks - in the first technical semester's four courses of a physical therapist assistant program resulted in a higher proportion of students successfully completing the course. Distributions of grades by demographics of physical therapist assistant students (gender, ethnicity, age, and highest degree earned upon entering the program), admission grade point average and the Test of Essential Academic Skills (TEAS) score were provided. Each of these were examined separately to determine whether a difference exists in grades among the students' demographics, admission grade point average and the Test of Essential Academic Skills (TEAS) score.

\section{Purpose of the Study}

\subsection{Purpose Definition}

The study determined: (1) Which course - the seven- or 15-week course - resulted in higher student retention rates in the first technical semester's four courses (PTH 101, PTH 205, PTH 221, PTH 270) of a physical therapist assistant program; (2) which course - the seven- or 15-week course - resulted in a higher numeric term grade point average in the first technical semester's four courses (PTH 101, PTH 205, PTH 221, PTH 270) of a physical therapist assistant program; (3) which course - the seven- or 15-week course - resulted in a higher student numeric grade in the first technical semester's four courses (PTH 101, PTH 205, PTH 221, PTH 270) of a physical therapist assistant program; (4) whether a difference existed in the admission grade point average of students who did the first semester's four courses for the physical therapist assistant program over seven weeks and those who did the 15-week program; (5) 
whether a grade difference existed among the scores of the Test of Essential Academic Skills (TEAS) of students in the seven- and 15-week first technical semester's four courses of a physical therapist assistant program; and (6) whether a grade difference existed among . demographics (gender, ethnicity, age, and highest degree earned upon entering the program) of students in the seven- and 15-week first technical semester four courses of a physical therapist assistant program.

\subsection{Research question(s)}

RQ1: How does the length of a physical therapist assistant course affect a student's retention rate in the four courses taken for a physical therapist assistant program during the first technical semester?

Sub RQ1: How does the length of a PTH 101 affect students' retention rate in the first technical semester of a physical therapist assistant program?

Sub RQ2: How does the length of a PTH 205 affect students' retention rate in the first technical semester of a physical therapist assistant program?

Sub RQ3: How does the length of a PTH 221 affect students' retention rate in the first technical semester of a physical therapist assistant program?

Sub RQ4: How does the length of a PTH 270 affect students' retention rate in the first technical semester of a physical therapist assistant program?

RQ2: How does the length of a physical therapist assistant course affect a student's term numeric grade point average for a physical therapist assistant program during the first technical semester? RQ3: How does the length of a physical therapist assistant course affect a student's numeric grade in the four courses taken for a physical therapist assistant program during the first technical semester? 
Sub RQ1: How does the length of a PTH 101 affect students' numeric grade in the first technical semester of a physical therapist assistant program?

Sub RQ2: How does the length of a PTH 205 affect students' numeric grade in the first technical semester of a physical therapist assistant program?

Sub RQ3: How does the length of a PTH 221 affect students' numeric grade in the first technical semester of a physical therapist assistant program?

Sub RQ4: How does the length of a PTH 270 affect students' numeric grade earned in the first technical semester of a physical therapist assistant program?

RQ4: How does the admission numeric grade point average of physical therapist assistant students' predict their grades earned in the first technical semester's four courses (PTH 101, PTH 205, PTH 221, PTH 270) of a physical therapist assistant program?

Sub RQ1: How does the admission grade point average of physical therapist assistant students predict their numeric grades earned in PTH 101?

Sub RQ2: How does the admission grade point average of physical therapist assistant students predict their numeric grades earned in PTH 205?

Sub RQ3: How does the admission grade point average of physical therapist assistant students predict their numeric grades earned in PTH 221?

Sub RQ4: How does the admission grade point average of physical therapist assistant students predict their numeric grades earned in PTH 270?

RQ5: How does the TEAS score of physical therapist assistant students predict their numeric grades earned in the first technical semester's four courses (PTH 101, PTH 205, PTH 221, PTH 270) of a physical therapist assistant program? 
Sub RQ1: How does the TEAS score of physical therapist assistant students predict their numeric grades earned in PTH 101?

Sub RQ2: How does the TEAS score of physical therapist assistant students predict their numeric grades earned in PTH 202?

Sub RQ3: How does the TEAS score of physical therapist assistant students predict their numeric grades earned in PTH 221?

Sub RQ4: How does the TEAS score of physical therapist assistant students predict their numeric grades earned in PTH 270?

RQ6: How do the demographics of physical therapist assistant students (gender, ethnicity, age, and highest degree earned upon entering the program) predict the students' term numeric grade point average for a physical therapist assistant program during the first technical semester.

Sub RQ1: How does a student's gender predict the student's term numeric grade point average?

Sub RQ2: How does a student's ethnicity predict the student's term numeric grade point average?

Sub RQ2: How does a student's age predict the student's term numeric grade point average?

Sub RQ2: How does a student's highest degree earned upon entering the program predict the student's term numeric grade point average?

\subsection{Hypothesis}

This study considered the problem and purpose by testing four sets of hypotheses.

Hypothesis 1 
Students who complete four physical therapist assistant courses (PTH 101, PTH 205, PTH 221, PTH 270) offered in the seven-week compressed program during the first technical semester of the Horry-Georgetown Technical College will be more successful in progressing to the next term than students who complete the four PTH courses in the traditional 15-week semester.

A. Students enrolled in the seven-week PTH 101 course at Horry-Georgetown Technical College will be more successful in progressing to the next term than students enrolled in the traditional 15-week semester.

B. Students enrolled in the seven-week PTH 205 course at Horry-Georgetown Technical College will be more successful in progressing to the next term than students enrolled in the traditional 15-week semester.

C. A statistically significant number of students enrolled in the seven-week PTH 221 course at Horry-Georgetown Technical College will be more successful in progressing to the next term than students who enrolled in the traditional 15 -week semester.

D. A statistically significant number of students enrolled in the seven-week PTH 270 course at Horry-Georgetown Technical College will be more successful in progressing to the next term than students enrolled in the traditional 15 -week semester.

Hypothesis 2

There are statistically significant differences in grades, but no difference in the admission average grade points between students enrolled in the first technical semester's four physical 
therapist assistant courses (PTH 101, PTH 205, PTH 221, PTH 270) over seven weeks and those enrolled in the traditional 15-week courses at Horry-Georgetown Technical College.

A. There are statistically significant differences in grades, but no difference in the admission average grade points between students enrolled in PTH 101 over seven-weeks and those enrolled in the traditional 15-week PTH 101 course.

B. There are statistically significant differences in grades, but no difference in the admission average grade points of students enrolled in the seven-week PTH 205 course and those enrolled in the traditional 15-week PTH 205 course.

C. There are statistically significant differences in grades, but no difference in the admission average grade points of students enrolled in the seven-week PTH 221 course and those enrolled in the traditional 15-week PTH 221 course.

D. There are statistically significant differences in grades, but no difference in the average grade points of students enrolled in the seven-week PTH 270 course and those enrolled in the traditional 15-week PTH 270 course.

Hypothesis 3

There are statistically significant differences in grades, but no difference between the TEAS scores of students enrolled in the first technical semester's four physical therapist assistant courses (PTH 101, PTH 205, PTH 221, PTH 270) over seven weeks at Horry-Georgetown Technical College and those enrolled in the same courses over 15-weeks at Horry-Georgetown Technical College.

A. There are statistically significant differences in grades, but no difference in TEAS scores, between students enrolled in the seven-week PTH 101 course and those enrolled in the traditional 15-week PTH 101 course. 
B. There are statistically significant differences in grades, but no difference in TEAS scores, between students enrolled in the seven-week PTH 205 course and those enrolled in the traditional 15-week PTH 205 course.

C. There are statistically significant differences in grades, but no difference in TEAS scores, between students enrolled in the seven-week PTH 221 course and those enrolled in the traditional 15-week PTH 221 course

D. There are statistically significant differences in grades, but no difference in TEAS scores between students enrolled in the seven-week PTH 270 course and those enrolled in the traditional 15-week PTH 270 course.

Hypothesis 4

There are statistically significant differences in term numeric grade points, but no difference between the demographics (gender, ethnicity, age, and highest degree, Baccalaureate, Master's, Doctoral, earned upon entering the program) of students enrolled in the first technical semester's four physical therapist assistant courses (PTH 101, PTH 205, PTH 221, PTH 270) over seven weeks at Horry-Georgetown Technical College and those enrolled in the same courses over 15-weeks at Horry-Georgetown Technical College.

\subsection{Significance of the study}

CAPTE determines the content of PTA programs, and is the accreditation body for such programs. The role of CAPTE (Educaiton) is to delineate curriculum content for PTA programs to prepare students for entry-level practice as physical therapist assistants. CAPTE reports that courses in the curriculum need to be designed to prepare program students in the content areas of ethics, values, and responsibilities, patient/client management, plan of care, intervention, tests and measures, documentation, participation in the health care environment, practice, and 
management. Even though CAPTE delineates the curriculum content, this organization does not specify a standard curriculum format (Education, 2016b). They allow programs to choose the curriculum format that best meets the students' and organization's needs. CAPTE does require that the PTA program faculty assesses their program; one such area of assessment is student retention rates. If a program fails to graduate $60 \%$ of students admitted over a two-year period, then their accreditation may be revoked.

Published research is a tool faculty for a PTA program may utilize to assess their curriculum and improve student retention rates. No research has been completed on assessing the retention rate of PTA students. Limited research has been conducted on assessing a PTA curriculum, and the research that has been done has assessed program characteristics and the passing of the National Physical Therapy Examination (Maring et al., 2013). No research is available on PTA program characteristics and student retention rates.

The benefit of assessing how compressed course design impacts student retention rates may change the format in which a PTA curriculum is offered. PTA programs that need to improve student retention rates may review this research to determine whether a compressed course design is an appropriate curriculum modification for their school. It is unknown whether compressed course design positively or negatively impacts PTA students' retention rates. Any modifications to a PTA program that can improve student retention rates are likely to improve the financial welfare of both the college and the student.

\subsection{Definition of key terms}

A wide array of terminology is in use for compressed courses and student outcomes. The list below includes the terminology used in this study. 
Physical Therapist Assistant (PTA) Student - A PTA student is someone completing an entry-level two-year (five-semester) associate degree. The education the student receives prepares him/her for entry-level practice to perform intervention and data collection under the direction and supervision of the physical therapist ("Role of a Physical Therapist Assistant (PTA)," 2016).

PTH 101 - This course introduces the purpose, philosophy, and history of physical therapy and medical/legal documentation (College, p. 190).

PTH 205 - This course introduces the basic concepts and principles of muscles, joints, and motion, including traditional testing procedures (College, 2016, p. 190).

PTH 221 - This course is an introduction to basic pathophysiology of the body with an emphasis on the body's reaction to disease and injury (College, 2016, p. 190).

PTH 270 - This course provides opportunities for the specialized study of selected topics in physical therapy (College, 2016, p. 190).

Community College - This is an institution of higher education that provides two-year collegiate education and workforce development (College, 2016).

Student Retention Rates - This is a measure of students who persist in an academic program (Mansfield, O'Leary, \& Webb, 2011).

Successful Completion of Course - The student must earn a $\mathrm{C}$ in the course to continue to the next term in the PTA program (Marcin \& Martel, 2016).

Grades - The grades earned by students are defined in the Horry-Georgetown Technical College Physical Therapist Assistant Student and Clinical Manual (Marcin \& Martel, 2016):

A: $90 \%-100 \%$ (4 grade points) 
B: $80 \%$ - $89 \%$ (3 grade points)

C: $75 \%-79 \%$ (2 grade points)

D: $60 \%-74 \%$ (1 grade point)

F: below $60 \%$ (0 grade points)

W: Withdraw from the course (0 grade points that do not compute in a student's grade point average).

WF: Withdraw from the course with a failing grade ( 0 grade points, that do compute in a student's grade point average).

Term is a 15-17-week time frame in which classes are scheduled to begin. It is measured in credit or contact hours (Wellman, 2003).

Test of Essential Academic Skills (TEAS) "is a computerized diagnostic instrument to help evaluate academic skills. The TEAS is a 4-hour computer-based test that covers Math, English, and Science ("TEAS (Health Science Tests)," 2017)".

Traditional Fifteen Course is a 15-week course that begins and ends during a term. Seven-Week Course is a seven-week course the begins and ends during a term.

Compressed course is a course that is completed in fewer calendar weeks than the above courses during a term.

Student Advancement in Program is when the student progresses into the next academic term. 


\section{Chapter Two}

\section{Review of the Literature}

The purpose of this chapter is to review the literature on cognitive theory, the inputenvironment-outcome model, compressed course, student engagement and retention, and history, growth, and program outcomes for a PTA program.

\subsection{Literature Review}

To establish the theoretic basis for this research study on the relationship of curriculum design and student advancement in an PTA program, this literature review presents assessment and relevant research in compressed course design, specifically in PTA education. The purpose of this chapter is to review the literature on cognitive theory, the input-environment-outcome model, compressed course, student engagement and retention, and history, growth, and program outcomes for a PTA program. The databases used in the literature search for this study include the Academic Search Premier, CINHAL Complete, CINHAL Full Text, Educational Resource Information Center (ERIC), and Dissertations \& Theses. The period utilized for this search was 2007-2017. The following keywords and phrases were used: physical therapist assistant, PTA, allied health education, nursing, occupational therapist assistant, radiology technician, dental hygiene, retention and undergraduate course length, college retention strategies, compressed courses, semester length, program length and retention, program length and higher education, time factors and learning and higher education, course length, retention strategies and college, block format schedule, spiral curriculum and knowledge, cognitive theory, student engagement and higher education and retention. Due to the sparse research on PTA education, other associate degree health care disciplines were included in this review. To date no research has 
been conducted on how curriculum design can influence such student advancement in the PTA program.

\subsection{Framework: Cognitive theory}

A well-developed curriculum foundation is based on an educational theory that supports the program's pedagogy, and proposes how a student transforms information into knowledge.

A spiral curriculum is a program design that supports a compressed course format. A short-length course design allows students to take fewer courses simultaneously and to complete coursework in a term in a sequential order. A curriculum design that offers courses in a serial order allows students to build and expand on previous knowledge. Knowledge gained in a successive format is more likely to move information from working memory to long-term memory (Tatum, 2010). The educational theory underlying the learning process in which a student transfers information from working to long-term memory is known as cognitive theory. Jerome Bruner (1976), a cognitive theorist, proposed that learning takes place when a task being learned is similar to previously learned information.

A compressed course curriculum design offers students a learning environment that enables them to organize new and current knowledge. As the learner encounters new information, he/she organizes the information based on past experiences. The learner pulls information from long-term memory to shape input from working memory (De Jong, 2010). When learners adopt a curriculum that has a sequential purposeful order of courses, they can transform information into knowledge more readily.

A curriculum that brings into line the prior knowledge of the learner and avoids excessive information will stimulate the processes that lead to deep knowledge (Dick \& Carey, 1990). The deeper knowledge gained is known as germane cognitive load (De Jong, 2010). A teacher can 
hinder students' development in accessing deeper knowledge through poor instructional design, which can cause extraneous cognitive load. Learners may experience extraneous cognitive load if they are required to process information at a higher level than they have knowledge of, or if they are asked to coordinate materials having the same information. A compressed course curriculum format may decrease the extraneous cognitive load on students, as they take fewer courses at the same time. Decreasing the number of topics students are asked to study simultaneously improves the opportunity to teach information in a sequential format. Providing students information in a progressive order allows them to build upon their previous knowledge, which improves the student's ability to organize information in a meaningful and permanent way.

Students' ability to learn is also influenced by the amount of information they attempt to process at a given time. The amount of information an individual processes at one time is influenced by the characteristics of the content to be learned. Most individuals can only manipulate four different types of information in their working memory at one time (Cowan, 2001). If learners receive too much information, they may not be able to process it effectively to long-term memory. In a multicourse design, learners take more courses at one time, which results in the need for them to manipulate more information than they can cognitively process.

In summary, a compressed course design can improve students' ability to process information, enabling them to achieve a germane cognitive load because they are processing less information at one time and have a foundation of knowledge from the sequential course design.

\subsection{Framework: Input-Environment-Outcome (I-E-O) Model}

Students' ability to succeed in persisting to graduation is multifactorial. The Tinto Interactionalist Model of Student Persistence proposes factors that influence a student's 
graduation from college. Tinto's model claims that students' retention in a residential college is influenced by the college's academic and social integration (Braxton, Hirschy, \& McClendon, 2011). This theory proposes that the greater a student's academic and social commitment is, the greater the likelihood the student will graduate. Tinto's Interactionalist Model of Student Persistence embraces 13 propositions that influence a student's departure from college. The validity of Tinto's theory has been assessed for empirical support by institutional type and by student groups. In two-year colleges, only one of Tinto's 13 propositions, student entry characteristics, had empirical affirmation. The validity of Tinto's theory has been questioned at community colleges because institutions with similar student demographics and curricula have significant difference in completion rates of the course work (Schuetz, 2005)

An alternative method for assessing factors that influence a student's persistence to graduation is the input-environment-outcome (I-E-O) model. This model assesses what an educational program is trying to achieve, the characteristics of the student, and what the student experiences in the educational environment (Antonio \& Astin, 2012). The benefit of evaluating a program allows students to align their values with college standards versus universal standards (Hlinka, 2017). This tailored strategy can be evaluated after implementation to ensure the plan meets the needs of the institution and its students (Fike \& Fike, 2008).

The I-E-O model has been successfully adopted in community colleges to improve retention. Fike and Fike (2008) assessed the fall-to-spring and fall-to-fall retention rates for 9,200 first-time college students in one institution. The researchers discovered that students who scored below the college reading level had better retention in college if they participated in reading development courses. Fike and Fike (2008) found that the information collected from this study could be used to improve student retention rates at an institution. Barra (2013), 
assessed how to improve African American practical nursing students retention at a community college. The author identified that the cause of attrition in the program was students being unsuccessful in passing fundamental nursing courses and medical math. The program added an optional intensive tutoring program for the fundamental nursing courses and medical math. They reported statistical significance in retention for all courses in which tutoring was offered. The IE-O model can not only assess the effectiveness of interventions; it can also identify other potential variables that hinder or improve retention. Fontaine (2014) assessed the effect of implementing specific interventions for an associate nursing program, and found that none of the interventions implemented statistically improved retention. However, overall program retention improved statistically during the evaluation period. Fontaine (2014) determined that better retention was recorded among younger students than older ones, which is not consistent with the literature the author assessed. The author reported that the United States was in a recession during the research, and that this recession may have been a reason why older students' retention rate was higher than that of their younger peers.

Assessment of the stakeholders and the environment will enable an institution to develop a specific plan of action for improvement. Institutions can improve retention by investigating the characteristics of successful and unsuccessful students for a specific program of study. In addition, the organization should assess the kinds of environment in which students succeed or fail.

\subsection{Compressed Course}

\section{Introduction}

There were mixed results on the outcome of the research reviewed for the compressed course design. The results ranged from improvement, decline, or no change. Although not clearly 
stated in all research studies, the type of research performed appears to be case study design. A common factor amongst the research presented in this literature review was that all the research was conducted at one institution. All research studies reviewed have the limitation of a bias of geographical location and the constraint of influence of one college/university. Uncommon factors of the research were the research topic, how success was measured, and the population. The uncommon factors identified in the research will be synthesized in this literature review.

\section{Topics: Compressed Course}

Existing research reports that the outcomes of a compressed course format depend upon the type of course, student characteristics, and faculty (Lutes \& Davies, 2013). Research studies have been identified from the following areas of study: accounting, algebra, criminal justice, geology, mathematics, physics, psychology, and chemistry. There were mixed results on the outcomes of the research reviewed for a compressed course design. Student outcomes included improvement, decline, or no change.

According to Dunn and Hooks (2015), students who completed the Principles of Accounting I in a compressed course format had significantly better final results than students who completed the same course over 16 weeks. The authors ruled out the effect of student demographics, time of day the course was offered, and enrollment status. Lloyd and Eckhardt (2010a) found similar results on the benefit of compressed course design for chemistry when they evaluated students who accessed tutoring for the chemistry course. They found that students who completed a compressed chemistry course and took advantage of tutoring had statistically significantly higher grades than those who did not. They also restricted the sample to students who took only two compressed courses at one time. 
Harlow, Harrison, and Honig (2015) reported that a six-week compressed physics course design did not improve students' physics grades compared to a 12-week term. They reported that students in six-week compressed courses demonstrated poor outcomes on the Force Concept Inventory. They completed the assessment before and after the course for both groups, and found that students in the 12-week term scored significantly better. They concluded that physics is a discipline that may not be teachable in a fast-paced environment, and that students need more time to master and apply the information.

The majority of research studies reported that statistically, the outcomes were not significantly different for student grades when comparing a compressed course design with a full-term course design. Hicks (2014a) assessed the impact of a compressed course format on grades and student opinions regarding a criminal justice course. He found no difference in grades or student opinions for the compressed course compared to the full-term course. Fulton-Calkins (2008), in addition to reporting no significant changes in student grades for a compressed mathematics course, also reported no significant impact on student retention. Anastasi (2007) compared a full-term psychology course to a compressed summer term course and found no difference in students' overall academic performance. Shaw, Chametzky, Burrus, and Walters (2013) also assessed a psychology course, but their research looked at online psychology courses offered in both compressed and full-term formats. They found no statistically significant difference between course formats. Caldwell (2012b) compared test scores for geology courses and found no statistical difference between compressed and full-term curriculum test outcomes.

In summary, assessment of the topic of compressed course design is limited because no more than two research studies have been completed on the topic. Further research on multiple 
institutions is needed in replicating studies on the same topic to determine whether topic is a factor that influences student success in a compressed course design.

\section{Measurement of compressed course design success}

The research studies evaluated had a common independent variable of compressed course design but the literature was inconsistent on the dependent variable. Most research has utilized quantitative variables, such as grades, but others have assessed qualitative variables, such as surveys on student preference. Comparing the results of the research studies is problematic because of the inconsistency of dependent variables.

Four of the ten research studies assessed utilized the final numeric grade as a dependent variable. They reported mixed results on compressed course design when final numeric grade was the dependent variable. Anastasi (2007) analyzed the course grades of 506 students enrolled in 16 sections of compressed and undergraduate psychology courses at one undergraduate university. The purpose of this study was to determine whether the compressed course format was equivalent to a full-term class. The 16 psychology sessions included four sections of Effective Thinking, seven sections of Memory \& Cognition, and five sections of Research Methods. The same faculty member taught all 16 sessions and used same content and assessment procedures for each course. The compressed course session was offered in the summer term versus the full-term course, which was offered in the fall and spring. The researcher reported that grades were significantly higher for the summer session. A study by Lloyd and Eckhardt (2010) assessed the effect a compressed general chemistry course and tutoring had on students' retention rate in Associate of Science degree. The purpose of their study was to improve student progression in the science program. Through assessment at one community college, the researchers identified that general chemistry was a common reason students did not progress in 
in the science program. They employed an intervention of a compressed course format and tutoring. They recruited students for the period 2006 to 2008 from one school and gave them a $\$ 300$ stipend for participating in the study. The control group was students who completed a fullterm or compressed term general chemistry course from 2001 to 2008 with no organized tutoring. Lloyd and Eckhardt (2010) concluded that students who completed the compressed course format and tutoring for general chemistry achieved a statistically higher grade in the course and retention rate. Shaw, Chametzky, Burrus, and Walters (2013) analyzed overall the course grade of 115 students who were enrolled in an undergraduate abnormal psychology course at one community college. The purpose of the study was to analyze the correlation between the course length and student achievement. The class setting for all sections was online. Data were collected for three sections of an eight-week compressed course format and three sections of a 16-week full-term format from the fall semester 2011 through the fall semester, 2012. The independent research study variable was course duration, and the dependent variables were student achievement (final grade) and assignment completion. The same instructor coordinated all sections of the course and used the same content and assessment tools for all courses. The researcher controlled for gender in the study. The authors concluded that there was no statistical difference in student achievement and course length. In 2003, a small private undergraduate university began offering online and virtual compressed and full-term criminal justice courses. The rationale for offering criminal justice courses in this format was to recruit adult students. Hicks (2014b) assessed the effectiveness of the new criminal justice curriculum to assess whether program outcomes were met. The research assessed the criminal justice course outcomes and student demographics from 2003 to 2009. A total of 191 students' data were reviewed in the study. A purpose of this study was to determine whether the compressed course 
format for students enrolled in the criminal justice courses were equal to the full-term criminal justice course. Hicks (2014b) assessed the effectiveness of the new criminal justice curriculum to assess whether program outcomes were met. The research assessed the criminal justice course outcomes and student demographics from 2003 to 2009. A total of 191 students' data were reviewed in the study. A purpose of this study was to determine whether the compressed course format for students enrolled in the criminal justice courses were equal to the full-term criminal justice course. The course outcomes assessed were students' overall grades and course preferences, established via a survey. Hicks (2014b) found that there was no difference in numeric course grades between the compressed course format and full term. What she did find was that statistically students preferred the compressed course format to the full term. A reason why the four study results may be inconsistent is that they are not homogenous regarding the topic or setting.

The two research studies cited used letter grade as a dependent variable. Carrington and Houston (2010) assessed what effects the length of a course had on student success in class. The authors' research aimed to assess whether the spacing effect was true for students enrolled in Intermediate Accounting I or Intermediate Accounting II. Carrington and Houston (2010) predicted that based on the spacing effect, students would learn material better over a longer course length. To assess the spacing effect for Accounting I and Intermediate Accounting II, the researchers investigated 2,012 student outcomes in these subjects at one university from fall 2006 through summer 2009. They assessed the results for courses offered in a full term and compressed format. They also examined whether there was a difference in outcome based on the number of times the course was held during the week. The researchers reported that $80 \%$ of the courses that were assessed were taught by two full-time faculty, and all courses used the same 
textbook. The researchers also assessed whether student characteristics impacted course outcomes. The results of their research showed that course length did not impact student outcomes and that courses that lasted less than 50 minutes had lower student outcomes than courses that lasted longer than 50 minutes. The researchers also noted that traditional male students performed worse in all course formats. Carrington and Houston (2010) reported that their research could benefit administrators in determining how to offer Accounting I or Intermediate Accounting II. Reyes (2010) assessed whether the length of a college algebra course (eight weeks and 16 weeks), had an impact on students' grade and student retention rate at a community college. The researcher also assessed whether the students' demographics impacted course outcomes and retention. Four sections of an eight-week and 16-week algebra course were assessed. A total of 231 students was assessed for this study. Reyes (2010) reported that course length did not result in any statistical difference in course grades or retention. While the researcher assessed student retention rates, the author excluded the withdrawal rate (those who voluntarily withdrew from the class) from the course. Why a student withdraws from a course is multifactorial. Both studies reported that letter grade was not statistically significant for compressed course design.

Two studies that were assessed used final exam score and compressed course design as a dependent variable. Both studies reported that final exam score was higher for compressed course design. A faculty member for an undergraduate chemistry course observed that students in a compressed chemistry course achieved better course outcomes than students who completed the course over a full term. Hall, Wilson, and Sanger (2012), investigated a faculty member's assumption that students who took undergraduate chemistry in a compressed format had better outcomes. They reviewed student chemistry courses, demographics, and admission data from fall 
2000 to summer 2004. Student demographic and admission data were reviewed to assess whether students who participated in a compressed curriculum achieved similar results to those who covered the curriculum over a full term. The same faculty member taught all courses that were assessed and used the same content and assessment tools for all courses. The sample population was 136 students for the full-term courses and 95 for the compressed courses. Hall, Wilson, and Sanger (2012) reported that students who completed chemistry in the compressed course format had better course outcomes than those who finished the chemistry course over a full term. They found that student demographics or admission data did not influence student success in a compressed chemistry course. The authors recommended that future studies should assesses student outcomes in future higher level chemistry courses given in an intensive format and to evaluate student motivation. The results from this study will help academic advisors assisting students in course scheduling. In a more recent retrospective study, Dunn and Hooks (2015) assessed whether a compressed course and the time of day the class was offered at the university had an effect on student performance in an introductory accounting course. The rationale for completing the study was to determine whether a short length course could improve student outcomes. The outcomes from this study were that the time of day the course was offered did not impact academic performance, and night students' grades were statistically better for the compressed course than the full-term course. The researchers concluded that student characteristics did not have an impact on outcomes. The content taught was consistent for the compressed and full-time introductory account course. Future research recommendations are to assess the effect of a compressed curriculum on higher level accounting courses and compare the extent to which students who completed the full-term course and the compressed course retained knowledge from the introductory accounting course over the long term. 
One study utilized a standard test score as a dependent variable. Harlow, Harrisona, and, Honig (2015) analyzed the performance of 831 (641 fall term and 190 summer term) students in a physics course, and compared the effects of the compressed term and the traditional term on the academic results. The researchers used the Force Concept Inventory (FCI) to analyze students' assimilation of knowledge both in the pre course and post course. Harlow, Harrisona, and Honig (2015) report that students who completed the full-term fall course had better statistical outcomes than those who attended the summer's compressed course format. A limitation of the study was that faculty teaching pedagogy was not assessed. The faculty member who taught the compressed course was not the same one who taught the full-term class. Student demographics were not assessed in this study. The student sample for the summer course may have had a different population than the fall students.

One study looked at study preference as well as final numeric grade. Hicks (2014b) found that there was no difference in course grades between the compressed course format and the full term. What she did find was that students statistically preferred the compressed course format than the format over the full term. A limitation is that student retention for the compressed course format and the full term was not assessed. Student preference may be positively correlated to motivation.

In summary, the choice of the dependent variable may be a factor in assessing the effectiveness of a compressed course design. Researchers may find it helpful to assess more than one dependent variable for the compressed course design.

\section{Participants in the compressed course}

The participants assessed in the compressed course design studies cited were undergraduate students enrolled in a two- or four-year institution. A limitation in comparing 
these studies is that the demographics of a student enrolled in community college are different than those of students at an undergraduate university. A student enrolled in a two-year program is more likely to have a lower social economic background, work more hours than students at a four-year institution, and be the first generation to enter into higher education (Bonet \& Walters, 2016).

Four out of the ten studies reviewed for this literature review were completed at two-year community colleges. Mixed results were published on the effects of a compressed course design in this institutional setting. Three studies reported no statistical difference in the dependent variable, and one reported an improved outcome. Caldwell (2012) assessed whether a 16-week semester versus a nine-week summer term at a community college had an effect on student performance in general education and physical geology. The authors concluded that there were no statistical differences in the students' test scores for the 16-week semester versus the nineweek summer term. A concern with this research population is that the nine-week course was only offered online and not in a face-to-face format. Not having offered the 16- and nine-week courses in the same setting may have impacted the validity of the data. Lloyd and Eckhardt's (2010) research assessed the effect a compressed general chemistry course and tutoring had on students' retention rate in an Associate of Science degree. Lloyd and Eckhardt (2010) concluded that students who completed the compressed course format and tutoring for general chemistry had a statistically higher grade in the course and a higher retention rate. A concern with this population in the experimental group is that they were provided a $\$ 300$ course material stipend for participation in the study, and the control group was not. Furthermore, the control may not have had access to the same course supplies, which could have influenced student outcomes. Shaw, Chametzky, Burrus, and Walters (2013) analyzed the overall course grades of 115 
students enrolled in an undergraduate online abnormal psychology course at one community college. The purpose of the study was to analyze the correlation between the course length and student achievement. The authors concluded that there was no statistical difference in student achievement and course length. A concern of this study is that gender was the only student demographic controlled. Reyes (2010) assessed whether the length of a college algebra course (eight or 16 weeks) had an impact on students' grades and retention rates at a community college. The researcher also assessed whether student demographics impacted course outcomes and retention. Four sections of eight-week or 16-week algebra courses were assessed. A total of 231 students was assessed for this study. Reyes (2010) reported that course length did not result in a statistical difference in course grades or retention. While the researcher assessed student retention rates, the author excluded the withdrawal rate (those who voluntarily withdrew from the class) from the study. Why a student withdraws from a course is multifactorial. A limitation of this study is that the researcher did not define why students voluntarily withdraw from a course; for example, was the student passing or failing the course at the time of withdrawal? Another limitation is that the author did not discuss whether the curriculum content and assessment tools were consistent in all sections.

Six out of the ten studies reviewed for this literature review were completed at four-year universities. Mixed results were published on the effects of a compressed course design in this institutional setting. Four studies reported no statistical difference in the dependent variable, one reported improvement, and one reported a decline in outcomes. Anastasi (2007) analyzed the course grades of 506 students' enrolled in 16 sections of a compressed and undergraduate psychology course at one undergraduate university. The purpose of this study was to determine whether the compressed course format was equivalent to a full-term class. The 16 psychology 
sessions included the following: four sections of Effective Thinking, seven sections of Memory \& Cognition, and five sections of Research Methods. They concluded that the grades were significantly higher for the summer compressed session. A limitation of this study was that the compressed design format was offered only in the summer term. The reasons why students were taking the compressed summer course vs. the fall or spring full-term course were not assessed. The only student demographic assessed was students' overall GPA. The summer course participants had a lower average overall GPA than the full-term fall or spring students. Another limitation to this study is that the researchers did not exclude participants who were repeating the course. Carrington and Houston (2010) assessed the effects that the length of a course had on student success in class. Their purpose was to assess whether the spacing effect was true for students enrolled in Intermediate Accounting I or Intermediate Accounting II. Based on the spacing effect, Carrington and Houston (2010) predicted that students would learn material better over a longer course. The results of their research showed that course length did not impact student outcomes and that courses that lasted less than 50 minutes had lower student outcomes than courses that lasted longer than 50 minutes. A difference in this study compared to other studies assessed is that the compressed design was four weeks compared to other studies in which the compressed design was seven to nine weeks. Another limitation is that the compressed course design was offered only in the summer term. The authors controlled for student demographics and did not report a statistical difference but did not assess students’ prior academic performance. Hicks (2014b) assessed the effectiveness of the program outcomes for online and virtual compressed and full-term criminal justice courses. The research assessed the criminal justice courses' outcomes and student demographics from 2003 to 2009. A total of 191 students' data was reviewed in the study. Hicks (2014b) found there was no difference in course 
grades between the compressed course format and the full term. Through a mandatory graduation survey, Hicks found that students statistically preferred the compressed course format to the fullterm one. The author did not disclose whether the mandatory survey was a valid tool for assessing student satisfaction. Hall, Wilson, and Sanger (2012) reviewed a student chemistry course, demographics, and admission data from fall 2000 to summer 2004. Student demographics and admission data were reviewed to assess whether the students who participated in the compressed curriculum were equivalent to students in the full-term course. The same faculty member taught all courses that were assessed and utilized the same content and assessment tools for all courses. The sample population was 136 students for the full term and 95 for the compressed course. Hall, Wilson, and Sanger (2012) reported that students who completed chemistry in the compressed course format had better course outcomes than those who finished chemistry in a full-term course. A limitation to this study is that the compressed course was offered only in the summer term. The reasons why students were taking the summer compressed course vs. the fall or spring full-term course were not assessed. Harlow, Harrisona, and Honig (2015) analyzed the performance of 831 (641 fall term and 190 summer term) students in a physics course, and examined the effects of compressed and traditional-length academic terms on performance. The researchers utilized the Force Concept Inventory (FCI) to analyze the extent to which students assimilated knowledge both in the pre course and post course. Harlow, Harrisona, and Honig (2015) reported that students who completed a full-term fall course had better statistical outcomes than those who attended the summer compressed course format. Dunn and Hooks (2015) assessed whether a compressed course and time of day the class was offered at the university had an effect on student performance in an introductory accounting course. The rationale for completing the study was to determine whether a short 
course could improve student outcomes. The outcomes from this study were that the time of day the course was offered did not impact academic performance, and night students' grades were statistically better in the compressed course than they were in the full-term course. The researchers concluded that student characteristics did not have an impact on outcomes

A comparison of the results of the compressed course design among undergraduate university students with those of community college students shows no difference in outcomes. The research completed on both populations is inconsistent for the results. Only one of the ten articles reported that the population assessed demonstrated worse results. A limitation in the literature review is that no topic was assessed among both undergraduate and community college students to correlate the effects of institutional settings.

\subsection{Student engagement and retention}

Learning communities are a mechanism to improve student attendance and engagement. These communities are small cohorts of students completing the course in a compressed design format (Bonet \& Walters, 2016). The structure of the learning community is to embed time management and academic skills development into the curriculum. Completing courses in a compressed design allows students to focus on a few courses at one time and has a positive impact on students' time-management skills. Students who participate in compressed course design attend longer class sessions over a shorter period. Faculty who teach longer class sessions are more likely to adopt active learning strategies in a long class setting to engage student learning. These tools increase interaction between students and faculty during class sessions. Active learning activities foster an environment for peer learning and for faculty to motivate students. Students who have the opportunity to learn with peers and interact with faculty have higher classroom attendance. There is a positive correlation between attendance and grades 
(Bonet \& Walters, 2016). Engagement in the classroom setting is directly related to students' attendance. Students who attend class and collaborate with peers and faculty are more successful in completing the course work.

Purposeful student and faculty interactions are positively correlated to student engagement (DeCiccio et al., 2009). A reason students may not continue at an institution is their lack of connection to the institution. A mechanism to improve retention is to have an organized plan of action to reach out to the student population in the first semester of the program.

DeCiccio, Gross, and Gross (2009) have determined that if the student population connects with faculty prior to, during, and at the end of the first term, the student body's retention rate improves. They report that students contacted by faculty before the start of term have a higher retention rate in the next term. One out of five community college students reports that they do not feel welcome the first time they come to campus (Sander, 2008). A mechanism to improve a new student's initial perception of a college is to have formal and informal interaction with faculty and staff. The interactions should consist of informing students of services the college offers to improve a students' success.

The student retention rate improves when the institution identifies students who are at risk of attrition. Nelson, Quinn, Marrington, and Clarke (2012) report that student success in the first academic year statistically improves when the institution offers to help at-risk students and when students accept such assistance. They report that higher education institutes that have a formal plan on how faculty can communicate with at-risk students improves course grades and retention. Those in the faculty who are aware of students who are at risk should intervene early in the term to access student feedback and provide support to the students. These measures will increase a students' success and improve grades. Students who receive ongoing purposeful 
formative feedback from faculty will demonstrate a higher level of interest (Crosling, Heagne, \& Thomas, 2009). A compressed course design curriculum will decrease the number of courses a faculty teaches simultaneously. The fewer courses a faculty teaches at once increases the availability of faculty and can improve engagement opportunities with students (Lloyd \& Eckhardt, 2010a).

A compressed course design can provide an environment in which the teacher utilizes active learning as a mode of the curricular delivery method. Richardson and Radloff (2014) reported that faculty who have more time to devote to the pedagogy of teaching are more likely to use active learning strategies in the class setting. Students have proposed that an academic environment that engages them to ask questions and seek advice from faculty is an active environment (Richardson \& Radloff, 2014). Students who report an environment as active are less likely to consider withdrawing from a course. Students have suggested that passive lectures create disengaging environments. Compressed course designs have longer class periods and are more likely to have active learning activities (Lloyd \& Eckhardt, 2010a).

Gilardi and Guglielmetti (2011a) analyzed the relationship between a student's university experience and retention rate for nontraditional and traditional students. They found that students' demographics did not impact students' retention, but the type of employment status (permanent versus temporary) was significant. Students who reported temporary positions had a significantly higher attrition rate in the first academic year. How meaningful the student perceives the interaction with faculty is positively correlated with student retention (Gilardi \& Guglielmetti, 2011). Students viewed a positive interaction as faculty integrating classroom activities that provoked open communication between faculty and students. Students who perceived that faculty engaged them in the classroom environment had a better retention rate. 
Gilardi and Guglielmetti (2011a) concluded that faculty should plan activities which ensure that the content relates to their personal and professional development. An engaging curriculum foundation is built upon a student's current level of knowledge (Crosling, Heagne, \& Thomas, 2009). To motivate students in progressing their knowledge a teacher needs to develop scaffolding-learning activities. This type of curriculum framework places the student at the center of learning. Student-centered learning involves the student in the learning process. A curriculum will engage students when it is relevant to their interests and offers applicable examples. A compressed course requires a longer class period and more sessions over a shorter length of time in an academic term. A longer classroom period warrants time for faculty to incorporate active learning. Lee and Horsfall (2010) reported that students state that a compressed course design increases faculty-student engagement in the class setting. An active teaching methodology can foster an environment of meaningful learning (Geltner \& Logan, 2001). Students report that in a compressed course format they have more peer interaction than in a full-term course (Herrmann \& Berry, 2016). The students report that greater peer interaction is a positive aspect of a compressed course format.

A challenge in engaging students in a compressed format is that students are required to understand information faster (Herrmann \& Berry, 2016). Teachers report that success in engaging students in a compressed curriculum depends on removing superfluous content and focusing on the basics (Kops, 2014).

To develop an engaging learning environment, faculty should consider the student population enrolled in a course (Wyatt, 2011). Students are categorized as traditional and nontraditional. The traditional student population age range is between 18 and 24 , and nontraditional is 25 years or older. Nontraditional students typically work more hours and have 
greater family obligations. This population of students is driven by their educational goals. Their classroom engagement increases when classroom activities are linked to their educational interest. They are more likely to ask questions and appreciate group peer activities. They will respond best when treated like adults. Faculty need to consider flexible learning environments to adapt to the nontraditional student's hectic schedule demands. Nontraditional students have limited time on campus so faculty and college officials need to develop clear mechanisms of communication to keep the students informed of campus activities. Students who engage in the institution are more likely to continue their academic journey. Faculty can improve students' retention by developing a classroom culture that fosters open communication, peer modeling, and reassurance of the student's capabilities (Rendon \& National Center on Postsecondary Teaching, 1994).

\subsection{History, growth, and program outcomes for a PTA program}

Horry Georgetown Technical College (HGTC) has had authority from the State of South Carolina to grant degrees since 1966. The local Area Commission granted approval for the college to offer the Associate in Health Science degree with a major in Physical Therapist Assistant (PTA) on August 11, 2005. Subsequently, on July 25, 2006, The State Board for Technical and Comprehensive Education granted approval for the college to offer the Associate in Health Science degree majoring in PTA. On December 7, 2006, HGTC was authorized to offer an Associate in Health Science degree, majoring in Physical Therapist Assistant by the South Carolina Commission on Higher Education. The South Carolina Technical College System, with the approval of the Commission on Higher Education, implemented the degree's name change to Associate in Applied Science Physical Therapist Assistant effective fall 2009. The researcher for this study has been a member of the faculty of the PTA program since 2008, 
serving as the academic clinical coordinator of education (ACCE) from April 2008 to August 2012 and transitioning to program director in August 2012. The PTA founder program director was a faculty at HGTC from August 2007 to August 2012.

In 2011, the director and founder of the PTA program identified that the pass rate of the graduate National Physical Therapist Examination (NPTE) was 82\%, which was below the program's goal of 90\% The NPTE's three-year average and the program's student retention rates of $65 \%$ were also below the program's goal of $90 \%$. The founder program director submitted a curriculum change request to modify the program's admission status to improve the outcomes of the NPTE and the program's student retention rates (Kopelman, 2011). To support the admission change the PTA founder program director cited research related to requests for curriculum changes. The two research studies cited to support the proposed program admission changes were "Education program and student characteristics associated with pass rates on the National Physical Therapy Examination for physical therapist assistants" (Maring \& Costello, 2009) and "Factors influencing physical therapist assistant licensure examination success" (Desmaris et al., 2011). The purpose of Maring and Costello's research was to assess the characteristics of physical therapist assistant students and the program in relation to the success of the NPTE pass rate. The rationale for this study was to provide PTA schools with recommendations for curriculum changes to improve the programs' outcomes. The independent variables were accreditation status, program setting, faculty qualifications, curriculum design, student demographics, and graduation rate. The dependent variable was the NPTE program pass rate. The researchers had a $24 \%$ response rate to a survey sent to all accredited physical therapist assistant program directors in the United States. The authors concluded that the following variables: program inception date, institutional setting, number of clinical hours in the program, 
and percentage of general education requirements, were statistically associated with the NPTE pass rate. The authors found no association between student characteristics and success in the NPTE. A limitation of this study was the low response rate. The researchers did not report that the survey tool utilized to collect data was assessed for validity. The purpose of the research by Desmaris Woble-Valenski, and Oestmann was to assess the relation of the characteristics of PTA students to the success of the NPTE pass rate. The rationale for this study was to examine the relationship between scores in the NPTE and anatomy and physiology grades, grade point average in physical therapist assistant coursework, and scores on the physical therapist assistant clinical performance instrument (CPI). The researchers surveyed PTA schools in the New England geographic area. The researchers concluded that there was a strong correlation between a student's anatomy and physiology grade and grade point average but not the CPI score. A limitation to this study was that it was based on one geographical area and featured a small sample of the population.

The founder program director of the PTA program utilized cited research studies that supported changes in admission application for the PTA program (Kopelman, 2011). The founder program director modified the weighted admission criteria to improve students' NPTE board pass rate. The director speculated that admitting students into the program who had more potential to pass the NPTE would be more likely to progress in the program and improve the retention rate. The new admission criteria were implemented in fall 2012.

In the spring of 2013, the current PTA program director established the Assessment Committee for the Physical Therapist Assistant program at the college. This committee, in conjunction with program faculty, annually reviews the PTA program policies and procedures to clarify the impact of the program's policies and procedures on the achievement of its mission, 
goals, and objectives. The tools the committee may use are admission demographics of the PTA class, admission scores for the program, NPTE board scores, student course surveys, student clinical site evaluations, faculty input, faculty curriculum review form-course level, employer surveys, and clinical instructor input.

The PTA program's assessment data related to the curriculum are reviewed a minimum of three times a year by the College Physical Therapist Assistant Assessment Committee, and annually by the Physical Therapist Assistant Curriculum Advisory Committee. To assess the program's curriculum, the committees use information from the Normative Model of Physical Therapist Assistant Education, the Commission Accreditation Physical Therapy Education (CAPTE) Handbook, the Federation of State Board of Physical Therapy (FSBPT) data gathered from the program stakeholders (students, graduates, employers, faculty, and clinical sites), and course educational outcomes. The curriculum assessment process provides an effective mechanism for continuously improving the learning experience for students and identifying competency of the students to safely progress through the curriculum. The PTA program director and faculty members of the PTA program assess it on an ongoing basis.

Since $2012,100 \%$ of the students who were admitted that year and who graduated from the PTA program passed the NPTE. The PTA program has seen a significant increase in NPTE success. However, what has not improved significantly is the student retention rates since fall 2012. Prior to the admission change, the retention rate of students in the PTA program was $65 \%$, and after the change it was 67\%. Since 2012, the Physical Therapist Assistant Assessment Committee has made changes to the curriculum with the goal of improving student retention rates. Changes have consisted of modifying course material, especially in courses that had a high attrition rate. These curriculum changes improved student retention rates in a course but the 
changes did not improve the program's overall success rate. The Physical Therapist Assistant Assessment Committee has identified that the greatest attrition occurs in the first technical semester of the program. Following student feedback, faculty have reported that students who withdraw from the program in the first semester report being overwhelmed by the number of new topics. The program faculty have reported that they believe all courses offered in the first technical semester are warranted but the program should consider how many courses the students take simultaneously in the first technical term. Faculty accordingly recommended offering the course in the first technical term in a compressed format. The rationale behind this curriculum modification is to improve students' retention rates without impacting the program's board pass rate (Marcin, 2016).

\subsection{Development of Methodology for this Study}

A literature review was used to develop the methodology for this study. From the literature review, it was determined that PTA course grades were an appropriate dependent variable, but data relating to student withdrawal rate would be collected. Research has revealed that the main reasons students withdraw from two-year institutions are the cost of attendance, lack of student motivation, student work schedules, family obligations, classes not offered at the right times, the gap between students' expectations and the realities of work required for college, college procedures, and dependent care issues (Mertes \& Jankoviak, 2016). In developing the methodology for this paper, the study drew on research by Reyes (2010), who assessed students' retention rates at a community college but excluded the withdrawal rate (those who voluntarily withdrew from the class) from the study, which may have skewed Reyes' results. Clarification on how a compressed course design influences students' academic performance and willingness to continue in a program may be beneficial in helping this program assess the curriculum plan. 
Hicks (2014b) also found there was no difference in the numeric course grades between a compressed course format and full term. What Hicks did find was that, statistically, students preferred a compressed course format to the full term. Assessing the student withdrawal rate, as well as academic achievement, may be beneficial in determining whether curriculum design impacts students' willingness to progress in an academic program.

\subsection{Summary}

This chapter presented a history of a PTA program's student retention rates and a review of the literature on compressed course design and student engagement and retention. The PTA program reviewed showed that student retention rates have not improved, regardless of the changes the program has made in admission status and course content. The program's goal is to improve student retention rates without jeopardizing the program's NPTE rates. Student retention rates improve when the students actively engage with peers and faculty in the classroom (Gilardi \& Guglielmetti, 2011a). A compressed course design may foster an active learning environment (Herrmann \& Berry, 2016). The literature review for compressed course design results ranged from improvement to decline to no change. There was inconsistency in the research article reviews on how success was measured, and the population for compressed course design. 


\section{Chapter Three}

\section{Methodology}

\subsection{Introduction}

Many factors can potentially cause PTA students to drop out of programs, but research on PTA retention is very sparse. This research studied reviewed the literature on cognitive theory, the input-environment-outcome model, compressed course, student engagement and retention, and history, growth, and program outcomes for a PTA program. The databases used in the literature search for this study include the Academic Search Premier, CINHAL Complete, CINHAL Full Text, Educational Resource Information Center (ERIC), and Dissertations \& Theses. The period utilized for this search was 2007-2017. No research has been performed on the effects of a compressed course design on PTA students' retention rate. What is known is that student-faculty engagement influences the retention of community college students (Gilardi \& Guglielmetti, 2011b). An intervention research has demonstrated an increase in student-faculty engagement in active learning classroom environments (Geltner \& Logan, 2001). While a curriculum environment may foster active learning for PTA students, research has shown mixed results on compressed learning. According to Dunn and Hooks (2015), students who completed the Principles of Accounting I in a compressed course format had significantly better final results than students who completed the same course over 16 weeks. The authors ruled out the effect of student demographics, time of day the course was offered, and enrollment status. Harlow, Harrison, and Honig (2015) reported that a six-week compressed physics course design did not improve students' physics grades compared to a 12-week term. They concluded that physics is a discipline that may not be teachable in a fast-paced environment, and that students need more 
time to master and apply the information. Lutes and Davies (2013) claimed that the success of a compressed curriculum depends on the type of course.

\subsection{Compressed Course Design}

A compressed course design is a potential educational intervention aimed at improving student progression in a program. A compressed course requires a longer class period and/or more sessions over a shorter length of time during an academic term. Some of the research available on compressed course design indicates that it produces higher grades and lower withdrawal rates (Geltner \& Logan, 2001). Other research claims that compressed courses offer no advantages above full-term courses (Johnson, Lybecker, \& Taylor, 2011).

Existing research reports that the outcomes of a compressed course format depend upon the type of course, student characteristics, and faculty (Lutes \& Davies, 2013). Research studies have been identified from the following areas of study: accounting, algebra, criminal justice, geology, mathematics, physics, psychology, and chemistry. According to Dunn and Hooks (2015), students who completed the Principles of Accounting I in a compressed course format had significantly better final results than students who completed the same course over 16 weeks. Lloyd and Eckhardt (2010b) found similar results on the benefit of compressed course design for chemistry when they evaluated students who accessed tutoring for the chemistry course. Harlow, Harrison, and Honig (2015) reported that a six-week compressed physics course design did not improve students' physics grades compared to a 12-week term.

There were mixed results on the outcomes of the research reviewed for a compressed course design. The majority of research studies reported that statistically, the outcomes were not significantly different for student grades when comparing a compressed course design with a full-term course design. Hicks (2014a) assessed the impact of a compressed course format on 
grades and student opinions regarding a criminal justice course. He found no difference in grades or student opinions for the compressed course compared to the full-term course. Fulton-Calkins (2008), in addition to reporting no significant changes in student grades for a compressed mathematics course, also reported no significant impact on student retention. Anastasi (2007) compared a full-term psychology course to a compressed summer term course and found no difference in students' overall academic performance. Shaw, Chametzky, Burrus, and Walters (2013) also assessed a psychology course, but their research looked at online psychology courses offered in both compressed and full-term formats. They found no statistically significant difference between course formats. Caldwell (2012a) compared test scores for geology courses and found no statistical difference between compressed and full-term curriculum test outcomes. The assessment of the topic of compressed course design is limited because no more than two research studies have been completed on the topic. Further research on multiple institutions is needed to replicate studies on the same topic to determine whether the topic is a factor that influences student success in a compressed course design.

The research studies evaluated for this dissertation had a common independent variable of compressed course design, but the literature was inconsistent on the dependent variable. Anastasi (2007) analyzed the course grades of 506 students enrolled in 16 sections of compressed and undergraduate psychology courses at one undergraduate university. A study by Lloyd and Eckhardt (2010b) assessed the effect a compressed general chemistry course and tutoring had on students' retention rate in Associate of Science degree. Shaw, Chametzky, Burrus, and Walters (2013) analyzed overall the course grade of 115 students who were enrolled in an undergraduate abnormal psychology course at one community college. The purpose of the study was to analyze the correlation between the course length and student achievement. 
Carrington and Houston (2010) assessed what effects the length of a course had on student success in class. The authors' research aimed to assess whether the spacing effect was true for students enrolled in Intermediate Accounting I or Intermediate Accounting II. Carrington and Houston (2010). Reyes (2010) assessed whether the length of a college algebra course (eight weeks and 16 weeks), had an impact on students' grade and student retention rate at a community college. The researcher also assessed whether the students' demographics impacted course outcomes and retention. Most research has utilized quantitative variables, such as grades, but others have assessed qualitative variables, such as surveys on student preference. Comparing the results of the research studies is problematic because of the inconsistency of the dependent variables.

A comparison of the results of the compressed course design among undergraduate university students with those of community college students shows no difference in outcomes. The research completed on both populations is inconsistent for the results. Caldwell (2012a) assessed whether a 16-week semester versus a nine-week summer term at a community college had an effect on student performance in general education and physical geology. The authors concluded that there were no statistical differences in the students' test scores for the 16-week semester versus the nine-week summer term. Shaw, Chametzky, Burrus, and Walters (2013) analyzed the overall course grades of 115 students enrolled in an undergraduate online abnormal psychology course at one community college. The purpose of the study was to analyze the correlation between the course length and student achievement. The authors concluded that there was no statistical difference in student achievement and course length. Anastasi (2007) analyzed the course grades of 506 students' enrolled in 16 sections of a compressed and undergraduate psychology course at one undergraduate university. The purpose of this study was to determine 
whether the compressed course format was equivalent to a full-term class. The 16 psychology sessions included the following: four sections of Effective Thinking, seven sections of Memory \& Cognition, and five sections of Research Methods. They concluded that the grades were significantly higher for the summer compressed session. Harlow, Harrisona, and Honig (2015) analyzed the performance of 831 (641 fall term and 190 summer term) students in a physics course, and examined the effects of compressed and traditional-length academic terms on performance. The researchers utilized the Force Concept Inventory (FCI) to analyze the extent to which students assimilated knowledge both in the pre course and post course. Harlow, Harrisona, and Honig (2015) reported that students who completed a full-term fall course had better statistical outcomes than those who attended the summer compressed course format. Dunn and Hooks (2015) assessed whether a compressed course and time of day the class was offered at the university had an effect on student performance in an introductory accounting course. The rationale for completing the study was to determine whether a short course could improve student outcomes. The outcomes from this study were that the time of day the course was offered did not impact academic performance, and night students' grades were statistically better in the compressed course than they were in the full-term course. A limitation in comparing these studies is that the demographics of students enrolled in community college are different to those of students at an undergraduate university. A student enrolled in a two-year program is more likely to have a lower socio-economic background, work more hours than students at a four-year institution, and be the first generation to enter into higher education (Bonet \& Walters, 2016).

In summary, there were mixed results on the outcome of the research reviewed for the compressed course design. The results ranged from improvement, decline, to no change. From 
the review of the literature cited in this dissertation, factors that were considered for this study's development were how success was measured, and the population.

\subsection{Definition of the Purpose of the Proposed Study}

The study determined: (1) Which course - the seven- or 15-week course - resulted in higher student retention rates in the first technical semester's four courses (PTH 101, PTH 205, PTH 221, PTH 270) of a physical therapist assistant program; (2) which course - the seven- or 15-week course - resulted in a higher numeric term grade point average in the first technical semester's four courses (PTH 101, PTH 205, PTH 221, PTH 270) of a physical therapist assistant program; (3) which course - the seven- or 15-week course - resulted in a higher student numeric grade in the first technical semester's four courses (PTH 101, PTH 205, PTH 221, PTH 270) of a physical therapist assistant program; (4) whether a difference existed in the admission grade point average of students who did the first semester's four courses for the physical therapist assistant program over seven weeks and those who did the 15-week program; (5) whether a grade difference existed among the scores of the Test of Essential Academic Skills (TEAS) of students in the seven- and 15-week first technical semester's four courses of a physical therapist assistant program; and (6) whether a grade difference existed among . demographics (gender, ethnicity, age, and highest degree earned upon entering the program) of students in the seven- and 15-week first technical semester four courses of a physical therapist assistant program.

\subsection{Research question(s)}

RQ1: How does the length of a physical therapist assistant course affect a student's retention rate in the four courses taken for a physical therapist assistant program during the first technical semester? 
Sub RQ1: How does the length of a PTH 101 affect students' retention rate in the first technical semester of a physical therapist assistant program?

Sub RQ2: How does the length of a PTH 205 affect students' retention rate in the first technical semester of a physical therapist assistant program?

Sub RQ3: How does the length of a PTH 221 affect students' retention rate in the first technical semester of a physical therapist assistant program?

Sub RQ4: How does the length of a PTH 270 affect students' retention rate in the first technical semester of a physical therapist assistant program?

RQ2: How does the length of a physical therapist assistant course affect a student's term numeric grade point average for a physical therapist assistant program during the first technical semester? RQ3: How does the length of a physical therapist assistant course affect a student's numeric grade in the four courses taken for a physical therapist assistant program during the first technical semester?

Sub RQ1: How does the length of a PTH 101 affect students' numeric grade in the first technical semester of a physical therapist assistant program?

Sub RQ2: How does the length of a PTH 205 affect students' numeric grade in the first technical semester of a physical therapist assistant program?

Sub RQ3: How does the length of a PTH 221 affect students' numeric grade in the first technical semester of a physical therapist assistant program?

Sub RQ4: How does the length of a PTH 270 affect students' numeric grade earned in the first technical semester of a physical therapist assistant program? 
RQ4: How does the admission numeric grade point average of physical therapist assistant students'predict their grades earned in the first technical semester's four courses (PTH 101, PTH 205, PTH 221, PTH 270) of a physical therapist assistant program?

Sub RQ1: How does the admission grade point average of physical therapist assistant students predict their numeric grades earned in PTH 101 ?

Sub RQ2: How does the admission grade point average of physical therapist assistant students predict their numeric grades earned in PTH 205?

Sub RQ3: How does the admission grade point average of physical therapist assistant students predict their numeric grades earned in PTH 221 ?

Sub RQ4: How does the admission grade point average of physical therapist assistant students predict their numeric grades earned in PTH 270?

RQ5: How does the TEAS score of physical therapist assistant students predict their numeric grades earned in the first technical semester's four courses (PTH 101, PTH 205, PTH 221, PTH 270) of a physical therapist assistant program?

Sub RQ1: How does the TEAS score of physical therapist assistant students predict their numeric grades earned in PTH 101 ?

Sub RQ2: How does the TEAS score of physical therapist assistant students predict their numeric grades earned in PTH 202?

Sub RQ3: How does the TEAS score of physical therapist assistant students predict their numeric grades earned in PTH 221?

Sub RQ4: How does the TEAS score of physical therapist assistant students predict their numeric grades earned in PTH 270? 
RQ6: How do the demographics of physical therapist assistant students (gender, ethnicity, age, and highest degree earned upon entering the program) predict the students' term numeric grade point average for a physical therapist assistant program during the first technical semester.

Sub RQ1: How does a student's gender predict the student's term numeric grade point average?

Sub RQ2: How does a student's ethnicity predict the student's term numeric grade point average?

Sub RQ2: How does a student's age predict the student's term numeric grade point average?

Sub RQ2: How does a student's highest degree earned upon entering the program predict the student's term numeric grade point average?

\subsection{Hypothesis}

This study considered the problem and purpose by testing four sets of hypotheses.

Hypothesis 1

Students who complete four physical therapist assistant courses (PTH 101, PTH 205, PTH 221, PTH 270) offered in the seven-week compressed program during the first technical semester of the Horry-Georgetown Technical College will be more successful in progressing to the next term than students who complete the four PTH courses in the traditional 15-week semester.

A. Students enrolled in the seven-week PTH 101 course at Horry-Georgetown Technical College will be more successful in progressing to the next term than students enrolled in the traditional 15-week semester. 
B. Students enrolled in the seven-week PTH 205 course at Horry-Georgetown Technical College will be more successful in progressing to the next term than students enrolled in the traditional 15-week semester.

C. A statistically significant number of students enrolled in the seven-week PTH 221 course at Horry-Georgetown Technical College will be more successful in progressing to the next term than students who enrolled in the traditional 15 -week semester.

D. A statistically significant number of students enrolled in the seven-week PTH 270 course at Horry-Georgetown Technical College will be more successful in progressing to the next term than students enrolled in the traditional 15 -week semester.

Hypothesis 2

There are statistically significant differences in grades, but no difference in the admission average grade points between students enrolled in the first technical semester's four physical therapist assistant courses (PTH 101, PTH 205, PTH 221, PTH 270) over seven weeks and those enrolled in the traditional 15-week courses at Horry-Georgetown Technical College.

A. There are statistically significant differences in grades, but no difference in the admission average grade points between students enrolled in PTH 101 over seven-weeks and those enrolled in the traditional 15-week PTH 101 course.

B. There are statistically significant differences in grades, but no difference in the admission average grade points of students enrolled in the seven-week PTH 205 course and those enrolled in the traditional 15-week PTH 205 course.

C. There are statistically significant differences in grades, but no difference in the admission average grade points of students enrolled in the seven-week PTH 221 course and those enrolled in the traditional 15-week PTH 221 course. 
D. There are statistically significant differences in grades, but no difference in the average grade points of students enrolled in the seven-week PTH 270 course and those enrolled in the traditional 15-week PTH 270 course.

Hypothesis 3

There are statistically significant differences in grades, but no difference between the TEAS scores of students enrolled in the first technical semester's four physical therapist assistant courses (PTH 101, PTH 205, PTH 221, PTH 270) over seven weeks at Horry-Georgetown Technical College and those enrolled in the same courses over 15-weeks at Horry-Georgetown Technical College.

A. There are statistically significant differences in grades, but no difference in TEAS scores, between students enrolled in the seven-week PTH 101 course and those enrolled in the traditional 15-week PTH 101 course.

B. There are statistically significant differences in grades, but no difference in TEAS scores, between students enrolled in the seven-week PTH 205 course and those enrolled in the traditional 15-week PTH 205 course.

C. There are statistically significant differences in grades, but no difference in TEAS scores, between students enrolled in the seven-week PTH 221 course and those enrolled in the traditional 15-week PTH 221 course

D. There are statistically significant differences in grades, but no difference in TEAS scores between students enrolled in the seven-week PTH 270 course and those enrolled in the traditional 15-week PTH 270 course.

Hypothesis 4 
There are statistically significant differences in term numeric grade points, but no difference between the demographics (gender, ethnicity, age, and highest degree, Baccalaureate, Master's, Doctoral, earned upon entering the program) of students enrolled in the first technical semester's four physical therapist assistant courses (PTH 101, PTH 205, PTH 221, PTH 270) over seven weeks at Horry-Georgetown Technical College and those enrolled in the same courses over 15-weeks at Horry-Georgetown Technical College.

\subsection{Research Design}

The quantitative method used for this study was a retrospective program evaluation. A program evaluation research is a study that uses standard research methodology to evaluate a social program by means of assessment (Powell, 2006). A retrospective program evaluation study is helpful as it can assess what an educational program is trying to achieve, the characteristics of the student, and what the student experiences in the educational environment (Antonio \& Astin, 2012). This research study has been designed primarily to increase knowledge on how to improve student retention rates in a PTA program. The current study compared two intact groups of students, who received the same content and forms of assessment in four PTA courses by the same full-time faculty in fall 2016 and 2017. The independent variables will be course length, prerequisite grade point average, and Test of Essential Academic Skills (TEAS) score. The control variables are student demographics (age, gender, highest degree earned, and ethnicity). The dependent variables will be the numeric grade for PTH 101, PTH 205, PTH 270, PTA 221 and term grade average, which was chosen as the dependent variables as the students must achieve academic success in a course to progress in the program. 


\subsection{Sources of Data}

The researcher for this study is the program director at the college in which the data are being collected. The program director's role is to perform ongoing assessment of the program's curriculum and student outcomes (Education, 2016a). As the program director, this researcher is not required to submit an assessment of the program's curriculum to the program's accreditation body until the program's next self-study in 2024 . This research study was conducted strictly for the purpose of completing the dissertation process. As the director of the program, the researcher has access to all student and program data that will be utilized for this study for assessment. The researcher will only be assessing student and program data within the scope of the program director's role. As no data will be collected outside the scope of the program director's job responsibilities, informed consent will not be solicited from the students among whom data were collected.

A role of the PTA program director is to design the program's curriculum (Educaiton, 2016). The PTA program director, with input from the Physical Therapist Assistant Assessment Committee, has chosen to modify the first technical semester of the PTA in the fall of 2017 for the 2018 cohort (Marcin, 2016). In the spring of 2017, the PTA program director submitted a curriculum change request to the Horry-Georgetown Technical College Curriculum Committee, which reported that approval for modification of the full-term course to a compressed course design was not required, as this change offered during the same term is at the discretion of the PTA program director (Marcin, 2017a).

As discussed in the Physical Therapist Assistant Assessment Committee meeting (Marcin, 2016), the PTA program director submitted the 2017 fall schedule with all the first technical semester courses in a compressed course design. Two courses, PTH 205 Physical 
Therapy Functional Anatomy and PTH 221 Pathology I, will be offered in the first seven weeks of the term, and PTH 270 Special Topics in Physical Therapy and PTH 101 Physical Therapy Professional Preparation will be offered the last seven weeks of the term.

\subsection{Population}

The target population for this study were PTA students in an Associate of Applied Science program at a community college in South Carolina. The population for this study consisted of a two cohorts of PTA students. The fall 2017 cohort completed the first technical semester's four courses in the PTA program in a traditional 15-week term, and the fall 2018 cohort completed the first technical semester's four courses in a seven-week compressed design; two courses in the first seven weeks and two in the second seven weeks. All students enrolled in both cohorts were taught by the same full-time faculty member for lectures and lab. Both cohorts had 34 students. No students were excluded from the study as the data collected were utilized for program assessment.

\subsection{Setting}

The PTA program is accredited with awarding an Associated Applied Science (AAS) program, with an emphasis on physical therapist assistants (College, 2016). The study participants were students who had enrolled in all PTA course in the first semester of the PTA program.

\subsection{Recruitment}

All students enrolled in the 2017 and 2018 cohorts were included in the study. Both cohorts had 34 students. No students were excluded from the study as the data collected were utilized for program assessment. Both cohorts' data were collected retrospectively. As the director of the program, the researcher has access to all student and program data that will be 
utilized for this study for assessment. The researcher will only be assessing student and program data within the scope of the program director's role. As no data will be collected outside the scope of the program, the director's job responsibilities, and without identifiable student markers, informed consent will not be solicited from the students among whom data were collected.

\subsection{Instrumentation}

The demographic data collected included gender, ethnicity, age, and highest degree (Baccalaureate, Master's, Doctoral) earned upon entering the program. These data were collected on a form from students during orientation by the program director for each cohort. The program director assigned each student a program identification number and matched it with the student's associated demographics. The program collects this demographic information annually as a requirement for the program's annual accreditation report (Education, 2016a). The required grade point average and TEAS score were independent variables. The program receives this information annually for each cohort from the college's admission coordinator on an Excel spreadsheet. The students' numeric grade for each course is the dependent variable. At the end of each term, faculty for each course are required to submit the grade book to the program director. The grade book contains all forms of assessment used for the course and final grade. The grade book is stored on the program's secured external drive provided by the college. Retrospective data were collected on the groups that completed the course during the 15- and seven-week term. 


\subsection{Data Collection}

The President of the College in which the data were collected granted permission for such collection, refer to appendix A. The Institutional Review Board of the University of Saint Augustine granted approval for the researcher to collect data for this study, refer to appendix B.

All student data collected from the admission coordinator were stored in the program's shared secured shard network drive. The program director used a college-assigned computer to access the data. The computer was used only by the program director and is secured in the program director's private office.

The students who completed the courses in the 15 weeks course format were coded as traditional and students who completed the courses in seven weeks course format were coded as compressed. A numerical number coded students in the traditional and compressed group. The number assigned was based on alphabetical order of the student's last name. The data was stored in an excel spreadsheet in the program director's private computer.

\subsection{Operationalization of Variables}

The students' demographic data (gender, ethnicity, age, and highest degree earned upon entering the program) were utilized as controlled variables to conclude that both cohorts were similar. Admission variables, required grade point average and TEAS score were the independent variables to conclude that both cohorts were alike. The students who completed the courses in the 15 weeks course format were coded as traditional and students who completed the courses in seven weeks course format were coded as compressed. Students demographics were coded as follow: male $=1$, female $=2$, white $=1$, nonwhite $=2$, age in years, no bachelor's degree earned $=1$, and bachelor's degree or higher earned $=2$. Admission variables, required grade point average and TEAS score, were coded as a numeric number. 
The curriculum course length was the independent variable that different among the two cohorts. The construct to be measured was students' success at progressing to the next term in the physical therapy program.

\subsection{Data Analysis Procedures}

Statistical Package for the Social Sciences (SPSS) was utilized to analyze the data collected. The data analyzed were the term numeric grade point average and course numeric grades the students earned in the seven- and 15-week physical therapist assistant courses (PTH 101, PTH 205, PTH 221, PTH 270) in the first technical semester of the PTA program. The analyzed data also included the grade distribution by age, gender, ethnicity, highest degree earned, admission average grade points, and admission TEAS score.

The demographic data of gender, highest degree earned, and ethnicity were analyzed through descriptive statistics. Descriptive data were collected to assess the characteristics of the seven- and 15-week physical therapist assistant cohorts. The rationale of this assessment was to compare the similarities and differences of the cohorts in the study. The mean and standard deviation were collected on the following variables for both cohorts; number of students' withdrawal from the term, number of students withdrawing from a course (PTH 101, PTH 205, PTH 221, PTH 270), term numeric grade point average, course numeric grade, admission average grade points, and admission TEAS score, gender, ethnicity, and highest degree earned.

The t-tests were utilized to determine whether the values of the variables in this study were significantly different from each other (Woodwell, 2013). A probability value of $<.05$ was utilized to state the strength of a relationship between variables. The variables assessed with the t-test were course numeric grade, term grade point average, course length, type of course, gender, ethnicity, and highest degree earned. A combination of variables was utilized to assess 
whether there was a statistical difference between the overall numeric course grade and the variables.

The first group of variables assessed was the student's numeric term grade point average for each course (PTH 101, PTH 205, PTH 221, and PTH 270) in the term according to the length of the course. The overall comparison was performed to assess whether one group, the sevenversus the 15-week cohort achieved a different term numeric grade point average.

The second group of variables assessed was the numeric grade of each course, PTH 101, PTH 205, PTH 221, and PTH 270, according to course length. This assessment was made to assess whether the students in the seven- versus 15 -week cohorts performed differently in a course with regard to numeric grade.

The third group of variables assessed was the students' numeric term grade point average for each course (PTH 101, PTH 205, PTH 221, and PTH 270) in the term, according to the students' TEAS score and length of course. An overall comparison was performed to assess whether the seven- versus 15 -week cohorts performed differently in terms of term numeric grade point average.

The fourth group of variables assessed was the student's numeric grade for each course, PTH 101, PTH 205, PTH 221, and PTH 270, according to the students' TEAS score and course length. This assessment was made to determine whether students in the seven-week cohort performed differently to the 15 -week cohort in relation to the numeric grade for the course.

The fifth group of variables assessed were the student's numeric term grade point average for the term in relation to students' age. Students were classified either as traditional or nontraditional. Age is a variable that is used to differentiate between nontraditional and traditional college students (Kim, 2002). Students of 25 years or older are defined as 
nontraditional students. An overall comparison was performed to assess whether the traditional and nontraditional students performed differently with regard to numeric term grade point average.

The sixth group of variables assessed was the student's numeric term grade point average for the term in relation to students' age and cohort. This comparison was performed to assess whether there was any difference in performance between nontraditional and traditional students with regard to the numeric term grade point average in a seven- or 15 -week term.

The seventh group of variables assessed was the students' numeric term grade point average for the term in relation to gender. Students were classified either as male or female. The overall comparison was performed to assess whether males and females performed differently with regard to their numeric term grade point average.

The eighth group of variables assessed was the student's numeric term grade point average for the term in relation to gender and cohort. This comparison was performed to assess whether males and females performed differently with regard to numeric term grade point average in a seven- or 15-week term.

The ninth group of variables assessed was the student's numeric term grade point average for the term in relation to ethnicity. Students were classified as either minority or majority. Two categories for ethnicity were utilized because of the small sample size of 34 students per cohort. An overall comparison was performed to assess whether one group, minority or majority, performed differently with regard to numeric term grade point average.

The tenth group of variables assessed was the students' numeric term grade point average for the term in relation to their ethnicity and cohort. This comparison was performed to assess 
whether one group, minority or majority, performed differently with regard to the numeric term grade point average in a seven- or 15 -week term.

The $11^{\text {th }}$ group of variables assessed were the students' numeric term grade point average for the term in relation to level of education. Students were classified as either having completed a bachelor's degree or higher or not. Two categories were utilized because of the small sample size of 34 students per cohort. An overall comparison was performed to assess whether one group performed differently with regard to numeric term grade point average for the term.

The $12^{\text {th }}$ group of variables assessed were the students' numeric term grade point average for the term in relation to students' level of education and cohort. This comparison was performed to assess whether one group performed differently with regard to numeric term grade point average for the term in a seven- or 15 -week course format.

A Pearson $\mathrm{R}$ test was performed to assess how strong the predictive relationship was between variables (Woodwell, 2013). The first group of variables assessed was the students' numeric grade earned per course (PTH 101, PTH 205, PTH 221, and PTH 270) and the admission grade point average, TEAS score, and age. The second group of variables assessed was the students' numeric grade points earned for the term and the admission grade point average, TEAS score, and age. The Pearson R test was performed for both the seven- and 15week cohorts. The data collected for both groups of variables were presented as r-squared. Rsquared explains the total percentage of change in a variable due to interaction with the other variables (Woodwell, 2013).

A multiple regression model was performed to predict numeric course grade based on all the independent variables assessed, student gender, highest degree earned, ethnicity, grade point average, TEAS score, and age. A multiple linear regression model was presented for the four 
seven-week courses (PTH 101, PTH 205, PTH 221, and PTH 270) in both the seven-week and 15-week term.

\subsection{Limitations of the Research Design}

The limitations of the research design were that it was based on one geographical area, it featured a small sample of the population, and the limited control of data. Each limitation will be addressed

The variables that influence the success of a student progressing in a PTA program are multifactorial. Generalizing the results of this retrospective program evaluation to another PTA may be limited as the student population may not be similar. However, a program may benefit from understanding how program evaluation assesses the effect of curriculum design on student success. The aim this study focus was to assess a program curriculum and its effect on retention.

The program assessed had only two cohorts, both of which had identical curricula, but one group completed the course work in a 15-week term and the other in a seven-week term. Assessing additional cohorts may have benefited the program, but due to curriculum modifications for previous cohorts, only two cohorts received identical curricula.

This program evaluation was completed retrospectively. A challenge with a retrospective study is controlling data. Although the content was consistent between cohorts, the instructors may have modified the frequency of assessment to accommodate the change in term length.

\subsection{Ethical Issues}

All data for this study were secured in the program director's office. All students received an assigned identification number, and only the program director knew which identification numbers were assigned to the students for the purposes of identifying them for data 
entry. Permission to complete the retrospective program evaluation was approved by the college leadership of the PTA programs and the University of Saint Augustine.

\subsection{Conflict of Interest Assessment}

The researcher who completed this retrospective program evaluation is the program director. The program director did not receive additional financial compensation for completing this retrospective program evaluation as a requirement for a dissertation.

\subsection{Summary}

The purpose of the research study was to determine whether there is a significant difference in the academic success of PTA students who participated in a seven- or 15-week PTA course. The reasons why some PTA students do not succeed in a PTA program are multifactorial. A retrospective program evaluation was completed to assess the effects a curricular change in a program had on students' grades and retention. 


\section{Chapter Four}

\section{Data Analysis and Results}

\subsection{Introduction}

The purpose of this chapter is to present the data analysis and answer the following research questions:

RQ1: How does the length of a physical therapist assistant course affect a student's retention rate in the four courses taken for a physical therapist assistant program during the first technical semester?

Sub RQ1: How does the length of a PTH 101 course affect students' retention rate in the first technical semester of a physical therapist assistant program?

Sub RQ2: How does the length of a PTH 205 course affect students' retention rate in the first technical semester of a physical therapist assistant program?

Sub RQ3: How does the length of a PTH 221 course affect students' retention rate in the first technical semester of a physical therapist assistant program?

Sub RQ4: How does the length of a PTH 270 course affect students' retention rate in the first technical semester of a physical therapist assistant program?

RQ2: How does the length of a physical therapist assistant course affect a student's term numeric grade point average in a physical therapist assistant program during the first technical semester?

RQ3: How does the length of a physical therapist assistant course affect a student's numeric grades in the four courses taken for a physical therapist assistant program during the first technical semester? 
Sub RQ1: How does the length of a PTH 101 course affect students' numeric grades in the first technical semester of a physical therapist assistant program? Sub RQ2: How does the length of a PTH 205 course affect students' numeric grades in the first technical semester of a physical therapist assistant program? Sub RQ3: How does the length of a PTH 221 course affect students' numeric grades in the first technical semester of a physical therapist assistant program? Sub RQ4: How does the length of a PTH 270 course affect students' numeric grades in the first technical semester of a physical therapist assistant program?

RQ4: How does the admission numeric grade point averages of physical therapist assistant students' predict their grades in the first technical semester's four courses (PTH 101, PTH 205, PTH 221, PTH 270) of a physical therapist assistant program?

Sub RQ1: How does the admission grade point average of physical therapist assistant students predict their numeric grades in PTH 101 ?

Sub RQ2: How does the admission grade point average of physical therapist assistant students predict their numeric grades in PTH 205?

Sub RQ3: How does the admission grade point average of physical therapist assistant students predict their numeric grades in PTH 221 ?

Sub RQ4: How does the admission grade point average of physical therapist assistant students predict their numeric grades in PTH 270?

RQ5: How does the TEAS score of physical therapist assistant students predict their numeric grades in the first technical semester's four courses (PTH 101, PTH 205, PTH 221, PTH 270) of a physical therapist assistant program? 
Sub RQ1: How does the TEAS score of physical therapist assistant students predict their numeric grades in PTH 101?

Sub RQ2: How does the TEAS score of physical therapist assistant students predict their numeric grades in PTH 202?

Sub RQ3: How does the TEAS score of physical therapist assistant students predict their numeric grades in PTH 221?

Sub RQ4: How does the TEAS score of physical therapist assistant students predict their numeric grades in PTH 270?

RQ6: How do the demographics of physical therapist assistant students (gender, ethnicity, age, and highest degree earned upon entering the program) predict the students' term numeric grade point average for a physical therapist assistant program during the first technical semester?

Sub RQ1: How does a student's gender predict the student's term numeric grade point average?

Sub RQ2: How does a student's ethnicity predict the student's term numeric grade point average?

Sub RQ2: How does a student's age predict the student's term numeric grade point average?

Sub RQ2: How does a student's highest degree earned upon entering the program predict the student's term numeric grade point average?

To answer the research questions, statistical analysis, results, and a summary of research findings are presented. 


\subsection{Description of the Sample}

The target population for this study were PTA students in an Associate of Applied Science program at a community college in South Carolina. The population for this study consisted of two cohorts of PTA students. The Fall 2016 cohort completed the first technical semester's four courses in the PTA program in a traditional 15-week term, and the Fall 2017 cohort completed the first technical semester's four courses in a seven-week compressed design, two courses in the first seven weeks and two in the second seven weeks. All students enrolled in both cohorts were taught by the same full-time faculty member for lectures and lab. Both cohorts comprised 34 students. No students were excluded from the study, as the data collected were utilized for program assessment.

\subsection{Quantitative Methods}

The quantitative method used for this study was a retrospective program evaluation. The current study compared two separate groups of students who received the same content instruction and forms of assessment in four PTA courses from the same full-time faculty in fall 2016 and 2017. There was a total of 68 students, 34 participants in each group.

The independent variable in this study was the length of courses in the first technical semester. Prerequisite GPA and TEAS scores were investigated as predictor variables for their impact on the dependent measures. The dependent variables were the numeric grades for PTH 101, PTH 205, PTH 270, PTA 221 and term grade point averages, which were chosen as the dependent variables because the students must achieve academic success in a course to progress in the program. Demographic data were collected from participants (age, gender, highest degree earned, and ethnicity), and this data was also used to determine if they had a differential impact on the dependent measures. 


\subsection{Use of Statistical Analysis and Results}

All descriptive and inferential statistics were analyzed using the Statistical Package for Social Sciences Version 24.0 (SPSS, 2016).

The demographic data of gender, highest degree earned, and ethnicity were analyzed through descriptive statistics. Descriptive data were collected to assess the characteristics of the seven- and 15-week physical therapist assistant cohorts (Table 1). Chi-square tests of independence were calculated comparing student demographics (age, gender, highest degree earned, and ethnicity) by group, and the distribution of student demographics in the two groups were not statistically different except for gender. An independent samples t-test was calculated comparing student admission GPA and TEAS by group, and the distribution of these two variables in the two groups were not statistically different.

\section{Table 1}

Demographic Statistics of Participants in the Study

\begin{tabular}{|c|c|c|c|c|c|c|}
\hline \multirow{2}{*}{ Variables } & \multicolumn{2}{|c|}{ Traditional 15-Week } & \multicolumn{2}{|c|}{ Seven-Week } & & \\
\hline & \multicolumn{6}{|c|}{ Compressed } \\
\hline Participants & & 34 & & & & \\
\hline Age & $\mathrm{M}=27.79$ & $\mathrm{SD}=7.04$ & $M=29.79$ & $\mathrm{SD}=9.32$ & $x^{2}(26)=23.6$ & $\mathrm{p}=.65$ \\
\hline Gender & & & & & $x^{2}(1)=5.92$ & $\mathrm{p}=.02$ \\
\hline Female & $\mathrm{N}=30$ & $44.1 \%$ & $\mathrm{~N}=27$ & $39.7 \%$ & & \\
\hline Male & $\mathrm{N}=4$ & $5.9 \%$ & $\mathrm{~N}=7$ & $10.3 \%$ & & \\
\hline Highest Degree & & & & & $x^{2}(1)=.08$ & $\mathrm{p}=.78$ \\
\hline No Bachelor's & $\mathrm{N}=26$ & $38.2 \%$ & $\mathrm{~N}=25$ & $36.8 \%$ & & \\
\hline Bachelor's & $\mathrm{N}=8$ & $11.8 \%$ & $\mathrm{~N}=9$ & $13.2 \%$ & & \\
\hline
\end{tabular}


Ethnicity

$$
x^{2}(1)=.976 \quad \mathrm{p}=.32
$$

White $\quad \mathrm{N}=30 \quad 44.1 \% \quad \mathrm{~N}=27 \quad 39.7 \%$

Nonwhite $\quad \mathrm{N}=4 \quad 5.9 \% \quad \mathrm{~N}=7 \quad 10.3 \%$

TEAS $\quad \mathrm{M}=68.27 \quad \mathrm{SD}=10.68 \quad \mathrm{M}=71.71 \quad \mathrm{SD}=9.44 \quad \mathrm{t}(66)=1.41 \quad \mathrm{p}=.17$

Admission GPA $\quad \mathrm{M}=3.45 \quad \mathrm{SD}=.29 \quad \mathrm{M}=3.58 \quad \mathrm{SD}=.30 \quad \mathrm{t}(66)=1.84 \quad \mathrm{p}=.07$

A Fishers Exact Test was calculated comparing student cohorts in terms of the number of students' withdrawing from the term and number of students withdrawing from a course (PTH 101, PTH 205, PTH 221, PTH 270). The variables by group and the distribution of these variables in the two groups were statistically different; see Table 2.

Table 2

Course and Term Completion and Withdrawal Results Between Groups

\begin{tabular}{cccc}
\hline Progression & Traditional 15-Week & Seven-Week Compressed & $\mathrm{p}$ \\
\hline PTH 101 & $\mathrm{N}$ & $\mathrm{N}$ & .005 \\
Satisfactory Completion & 30 & 26 & 0 \\
Academic Withdrawal & 0 & 8 & .048 \\
Other Withdrawal & 0 & & \\
PTH 205 & & 30 & \\
Satisfactory Completion & 26 & 2 & .027 \\
Academic Withdrawal & 0 & 2 &
\end{tabular}


Academic Withdrawal

Other Withdrawal

PTH 270

Satisfactory Completion

Academic Withdrawal

Other Withdrawal

Term

Satisfactory Completion

Academic Withdrawal

Other Withdrawal
0

8

$\mathrm{N}$

26

0

8

$\mathrm{N}$

29

3

2
1

1

$\mathrm{N}$

29

.005

1

8

$\mathrm{N}$

.008

24

0

10

The mean and standard deviations were collected for both cohorts for the variables of term numeric grade point average and course (PTH 101, PTH 205, PTH 221, PTH 270), numeric grade (Table 3). Using a probability value of $<.05$, an independent- samples t-test was calculated comparing these variables by group, and the distribution of these variables in the two groups were not statistically different.

Table 3

Comparison of Course Length to Students' Numeric Term GPA and Course Grade

\begin{tabular}{lcccccccc}
\hline \multicolumn{7}{c}{ Traditional 15-Week } & \multicolumn{2}{l}{ Seven-Week Compressed } \\
& N & M & SD & N & M & SD & t(df) & $\mathrm{p}$ \\
PTH 101 & 26 & .84 & .04 & 30 & .87 & .03 & $2.76(54)$ & .08 \\
PTH 205 & 26 & .83 & .05 & 32 & .83 & .06 & $.319(56)$ & .751
\end{tabular}




$\begin{array}{lcccccccc}\text { PTH 221 } & 26 & .81 & .05 & 33 & .83 & .05 & 1.424(57) & .160 \\ \text { PTH 270 } & 26 & .84 & .03 & 30 & .85 & .04 & 1.458(54) & .151 \\ \text { Term } & 26 & 2.87 & .41 & 30 & 3.00 & .39 & 1.294(54) & .201 \\ \end{array}$

Using a probability value of $<.05$, an independent samples t-test was conducted to measure the degree of relationship between traditional and nontraditional students enrolled in the Fall 2016 and 2017 term numeric grade point average. There was not a significant difference in traditional $(\mathrm{M}=2.937, \mathrm{SD}=.378)$ and nontraditional $(\mathrm{M}=2.951, \mathrm{SD}=.424)$ students' first technical term numeric grade point average; $\mathrm{t}(54)=.133, \mathrm{p}=.895$.

Using a probability value of $<.05$, an independent samples t-test was conducted to measure the degree of relationship between traditional and nontraditional students enrolled in the traditional 15-week and seven-week compressed format in the first technical courses (PTH 101, PTH 205, PTH 221, and PTH 270) and term numeric grade point average; see Table 4. There was not a significant difference in these groups and the first technical term numeric grade point average.

Table 4

Relationship of Students' Age and Term GPA and Course Length

\begin{tabular}{lcccccccc}
\hline \multicolumn{8}{c}{ Traditional 15-Week } & \multicolumn{7}{l}{ Seven-Week Compressed } \\
& $\mathrm{N}$ & $\mathrm{M}$ & $\mathrm{SD}$ & $\mathrm{N}$ & $\mathrm{M}$ & $\mathrm{SD}$ & $\mathrm{t}(\mathrm{df})$ & $\mathrm{p}$ \\
Traditional & 12 & 2.810 & .348 & 14 & 3.046 & .381 & $1.636(24)$ & .11
\end{tabular}




$\begin{array}{lllllllll}\text { Nontraditional } & 14 & 2.923 & .460 & 16 & 2.976 & .405 & .328(28) & .74\end{array}$

Using a probability value of $<.05$, an independent samples t-test was conducted to measure the degree of relationship between the gender of students enrolled in the Fall 2016 and 2017 term numeric grade point average. There was a significant difference between female $(\mathrm{M}=3.108, \mathrm{SD}=.401)$ and male $(\mathrm{M}=2.879, \mathrm{SD}=.359)$ students' first technical term numeric grade point average; $\mathrm{t}(54)=.1985, \mathrm{p}=.05$.

Using a probability value of $<.05$, an independent samples t-test was conducted to measure the degree of relationship between genders in the traditional 15-week and seven-week compressed format in the first technical courses (PTH 101, PTH 205, PTH 221, and PTH 270) and term numeric grade point average; see Table 5. There was not a significant difference in these groups and the first technical term numeric grade point average.

\section{Table 5}

Relationship of Students' Gender and Term GPA and Course Length

\begin{tabular}{|c|c|c|c|c|c|c|c|c|}
\hline & \multicolumn{3}{|c|}{ Traditional 15-Week } & \multicolumn{3}{|c|}{ Seven-Week Compressed } & \multirow[b]{2}{*}{$t(d f)$} & \multirow[b]{2}{*}{$\mathrm{p}$} \\
\hline & $\mathrm{N}$ & $\mathrm{M}$ & $\mathrm{SD}$ & $\mathrm{N}$ & $\mathrm{M}$ & SD & & \\
\hline Female & 23 & 2.827 & .398 & 17 & 2.951 & .405 & $.976(38)$ & .34 \\
\hline Male & 3 & 3.213 & .370 & 13 & 3.084 & .367 & $-.550(14)$ & .51 \\
\hline
\end{tabular}

Using a probability value of $<.05$, an independent samples t-test was conducted to measure the degree of relationship between the genders of students enrolled in the Fall 2016 and 
2017 term numeric grade point average. There was not a significant difference between the majority $(\mathrm{M}=2.944, \mathrm{SD}=.372)$ and minority $(\mathrm{M}=2.950, \mathrm{SD}=.554)$ students' first technical term numeric grade point average; $\mathrm{t}(54)=.043, \mathrm{p}=.966$.

Using a probability value of $<.05$, an independent samples t-test was conducted to measure the degree of relationship between ethnicity in the traditional 15 -week and seven-week compressed format in the first technical courses (PTH 101, PTH 205, PTH 221, and PTH 270) and term numeric grade point average; see Table 6 . There was not a significant difference in these groups and the first technical term numeric grade point average.

\section{Table 6}

Relationship of Students' Ethnicity and Term GPA and Course Length

\begin{tabular}{|c|c|c|c|c|c|c|c|c|}
\hline & \multicolumn{3}{|c|}{ Traditional 15-Week } & \multicolumn{3}{|c|}{ Seven-Week Compressed } & \multirow[b]{2}{*}{$t(d f)$} & \multirow[b]{2}{*}{$\mathrm{p}$} \\
\hline & $\mathrm{N}$ & $\mathrm{M}$ & $\mathrm{SD}$ & $\mathrm{N}$ & $\mathrm{M}$ & SD & & \\
\hline Majority & 23 & 2.909 & .411 & 24 & 2.977 & .335 & $.619(45)$ & .54 \\
\hline Minority & 3 & 2.577 & .280 & 6 & 3.137 & .578 & $-.550(7)$ & .165 \\
\hline
\end{tabular}

Using a probability value of $<.05$, an independent samples t-test was conducted to measure the degree of relationship between the highest degree earned of students enrolled in the Fall 2016 and 2017 term numeric grade point average. There is a significant difference in bachelor's degree or higher $(\mathrm{M}=3.136, \mathrm{SD}=.438)$ and no bachelor's degree $(\mathrm{M}=2.868, \mathrm{SD}=.362)$ students' first technical term numeric grade point average; $t(54)=-2.358, \mathrm{p}=.02$. 
Using a probability value of $<.05$, an independent samples t-test was conducted to measure the degree of relationship between highest degree earned in the traditional 15 -week and seven-week compressed format in the first technical courses (PTH 101, PTH 205, PTH 221, and PTH 270) and term numeric grade point average; see Table 7. There was not a significant difference between these groups and the first technical term numeric grade point average.

\section{Table 7}

Relationship of Students' Highest Degree Earned and Term GPA and Course Length

\begin{tabular}{|c|c|c|c|c|c|c|c|c|}
\hline & \multicolumn{3}{|c|}{ Traditional 15-Week } & \multicolumn{3}{|c|}{ Seven-Week Compressed } & \multirow[b]{2}{*}{$t(d f)$} & \multirow[b]{2}{*}{$\mathrm{p}$} \\
\hline & $\mathrm{N}$ & $\mathrm{M}$ & SD & $\mathrm{N}$ & $\mathrm{M}$ & $\mathrm{SD}$ & & \\
\hline No Bachelor's & 18 & 2.808 & .374 & 22 & 2.917 & .353 & $.942(38)$ & .352 \\
\hline \multicolumn{9}{|l|}{ Degree } \\
\hline Bachelor's & 8 & 3.011 & .473 & 8 & 3.261 & .390 & $1.154(14)$ & .268 \\
\hline \multicolumn{9}{|l|}{ Degree or } \\
\hline Higher & & & & & & & & \\
\hline
\end{tabular}

A Pearson R Correlation test was performed to assess how strong the predictive relationship was between TEAS scores and the numeric grades earned in the first technical semester's four courses (PTH 101, PTH 205, PTH 221, PTH 270) and admission numeric GPA and the numeric grades earned in the first technical semester's four courses (PTH 101, PTH 205, PTH 221, PTH 270). The Pearson R test was performed for both the seven- and 15-week 
cohorts; see Tables 8 and 9. The variables that demonstrated a significant positive correlation between variables are designated with*.

\section{Table 8}

Correlation of Admission GPA and First PTA Technical Term and Course GPA

\begin{tabular}{lcccccc}
\hline & \multicolumn{3}{c}{ Traditional 15-Week } & \multicolumn{3}{c}{ Seven-Week Compressed } \\
& $r_{2}=$ & $N=$ & $p=$ & $r_{2}=$ & $N=$ & $p=$ \\
Term GPA & .310 & 26 & .123 & $.369 *$ & 30 & $.044^{*}$ \\
PTH 101 & .329 & 26 & .101 & $.453 *$ & 30 & $.012^{*}$ \\
PTH 221 & .500 & 26 & .009 & $.449 *$ & 33 & $.009 *$ \\
PTH 205 & .356 & 26 & .075 & .328 & 34 & .067 \\
PTH 270 & .274 & 26 & .175 & $.490 *$ & 30 & $.006 *$ \\
\hline
\end{tabular}

\section{Table 9}

Correlation of TEAS Score and First PTA Technical Term and Course GPA

\begin{tabular}{lcccccc}
\hline & \multicolumn{3}{c}{ Traditional 15-Week } & \multicolumn{3}{c}{ Seven-Week Compressed } \\
& $r_{2}=$ & $N=$ & $p=$ & $r_{2}=$ & $N=$ & $p=$ \\
Term GPA & .280 & 26 & .165 & .299 & 30 & .109 \\
PTH 101 & .353 & 26 & .077 & .080 & 30 & .674 \\
PTH 221 & .063 & 26 & .761 & .152 & 33 & .397 \\
PTH 205 & .073 & 26 & .725 & .194 & 32 & .288 \\
PTH 270 & .183 & 26 & .372 & .334 & 30 & .071 \\
\hline
\end{tabular}


Scattergrams were completed to check data for extreme outliers that strongly influence the regression line (Brace, Kemp, \& Snelgar, 2006). No extreme outliers were identified with this descriptive statistic test, see Appendix A.

A multiple modified linear regression model was performed to predict numeric course grade, a dependent variable, based on the four independent and control variables that were closest to statistically significant for the multiple regression model performed. This model was performed to assess if any of the controlled variables were statistically significant as predictor variables. The four variables utilized were highest degree earned, ethnicity, admission grade point average, and age. A multiple modified linear regression model was presented for the four courses (PTH 101, PTH 205, PTH 221, and PTH 270) in both the seven-week and 15-week term format.

Using the enter method for the PTH 101 seven-week compressed format, an insignificant model emerged: $F(6,23)=1.828, p=.138$. The model explains $15 \%$ of the variance (adjusted $\mathrm{R}^{2}$ $=.146)$. The same method was utilized for PTH 10115 weeks. Using the enter method, an insignificant model emerged: $F(6,19)=1.750, p=.164$. The model explains $15 \%$ of the variance (adjusted $\left.\mathrm{R}^{2}=.152\right)$. Table 10 gives information for the predictor variables entered into the model. The only variable that was a significant predictor $(\mathrm{p}<.05)$ was preadmission GPA for the seven-week course format.

\section{Table 10}

Comparison of PTH 101 Traditional 15-Week to Seven-Week Compressed Numeric Grade

Variable $\quad$ Traditional 15-Week $\quad$ Seven-Week Compressed




\begin{tabular}{lcccccc}
\hline & B & SE B & $\beta$ & B & SE B & $\beta$ \\
Gender & -.006 & .029 & -.047 & -.003 & .012 & -.051 \\
Ethnicity & -.048 & .035 & -.392 & -.014 & .015 & -.163 \\
Age & .001 & .002 & .143 & .000 & .001 & .112 \\
Highest Degree Earned & .004 & .017 & .046 & .024 & .014 & .313 \\
TEAS Score & .001 & .001 & .344 & .000 & .001 & -.044 \\
Admission GPA & .041 & .030 & .308 & .049 & .019 & $.444 *$ \\
\end{tabular}

Using the enter method for the PTH 205 seven-week compressed format, an insignificant model emerged: $\mathrm{f}(6,25)=1.415, \mathrm{p}=.248$. The model explains $8 \%$ of the variance $\left(\right.$ adjusted $\mathrm{R}^{2}=$ .074). The same method was utilized for PTH 205 in the 15-week format. Using the enter method, an insignificant model emerged: $F(6,19)=1.398, p=.266$. The model explains $9 \%$ of the variance (adjusted $\mathrm{R}^{2}=.087$ ). Table 11 gives information for the predictor variables entered into the model. The only variable that was a significant predictor $(\mathrm{p}<.05)$ was preadmission GPA for the seven-week course format.

\section{Table 11}

Comparison of PTH 205 Traditional 15-Week to Seven-Week Compressed Numeric Grade

\begin{tabular}{lcccccc}
\hline Variable & \multicolumn{3}{c}{ Traditional 15-Week } & \multicolumn{3}{c}{ Seven-Week Compressed } \\
& $\mathrm{B}$ & SE B & $\beta$ & $\mathrm{B}$ & SE B & $\beta$ \\
Gender & -.035 & .038 & .231 & .003 & .021 & .026 \\
Ethnicity & -.080 & .046 & .046 & -.012 & .027 & -.081 \\
Age & .002 & .002 & .002 & -.002. & .001 &.-.314
\end{tabular}




\begin{tabular}{lcccccc} 
Highest Degree Earned & .024 & .022 & .022 & .012 & .026 & .085 \\
TEAS Score & .000 & .001 & .001 & .001 & .001 & .119 \\
Admission GPA & .031 & .040 & .182 & .077 & .036 & $.372^{*}$ \\
\hline
\end{tabular}

Using the enter method for the PTH 270 seven-week compressed format, an insignificant model emerged: $F(6,23)=2.859, p=.031$. The model explains $28 \%$ of the variance (adjusted $\mathrm{R}^{2}$ $=.278$ ). The same method was utilized for the 15-week PTH 270. Using the enter method, an insignificant model emerged: $F(6,19)=1.318, p=.297$. The model explains $7 \%$ of the variance (adjusted $\left.\mathrm{R}^{2}=.071\right)$. Table 12 gives information for the predictor variables entered into the model. The only variable that was a significant predictor $(\mathrm{p}<.05)$ was preadmission GPA for the seven-week course format.

\section{Table 12}

Comparison of PTH 270 Traditional 15-Week to Seven-Week Compressed Numeric Grade

\begin{tabular}{lcccccc}
\hline Variable & \multicolumn{3}{c}{ Traditional 15-Week } & \multicolumn{3}{c}{ Seven-Week Compressed } \\
& B & SE B & $\beta$ & B & SE B & $\beta$ \\
Gender & -.036 & .023 & .023 & -.010 & .014 & -.118 \\
Ethnicity & -.043 & .028 & .028 & -.003 & .018 & -.025 \\
Age & .002 & .001 & .356 & $8.178 \mathrm{E}-5$ & .001 & .017 \\
Highest Degree Earned & .011 & .013 & .167 & .021 & .016 & .219 \\
TEAS Score & $7.169 \mathrm{E}-5$ & .001 & .023 & .001 & .001 & .273 \\
Admission GPA & .005 & .024 & .050 & .071 & .022 & $.509 *$ \\
\end{tabular}


Using the enter method for the PTH 221 seven-week compressed format, an insignificant model emerged: $F(6,26)=2.080, p=.090$. The model explains $17 \%$ of the variance (adjusted $\mathrm{R}^{2}$ $=.168$ ). The same method was utilized for the 15-week PTH 101. Using the enter method, an insignificant model emerged: $F(6,19)=2.05, p=.108$. The model explains $20 \%$ of the variance (adjusted $\mathrm{R}^{2}=.202$ ). Table 13 gives the information for the predictor variables entered into the model. The only variable that was a significant predictor $(\mathrm{p}<.05)$ was preadmission GPA for the seven-week course format.

\section{Table 13}

Comparison of PTH 221 Traditional 15-Week to Seven-Week Compressed Numeric Grade

\begin{tabular}{lcccccc}
\hline Variable & \multicolumn{3}{c}{ Traditional 15-Week } & \multicolumn{3}{c}{ Seven-Week Compressed } \\
& B & SE B & $\beta$ & B & SE B & $\beta$ \\
Gender & -.001 & .033 & -.009 & .001 & .015 & .006 \\
Ethnicity & -.069 & .040 & -.481 & -.009 & .020 & -.082 \\
Age & .002 & .002 & .328 & -.001 & .001 & -.143 \\
Highest Degree Earned & -.014 & .019 & -.140 & .033 & .019 & .315 \\
TEAS Score & .001 & .001 & .142 & $2.237 \mathrm{E}-6$ & .001 & .000 \\
Admission GPA & 076 & .034 & .489 & .074 & .026 & $.466 *$ \\
\end{tabular}

A multiple modified linear regression model was performed to predict numeric course grade, a dependent variable, based on the four independent and control variables that were closest to statistically significant for the multiple regression model performed. This model was performed to assess if any of the controlled variables were statistically significant as predictor 
variables. The four variables utilized were highest degree earned, ethnicity, admission grade point average, and age. A multiple modified linear regression model was presented for the four courses (PTH 101, PTH 205, PTH 221, and PTH 270) in both the seven-week and 15-week term format.

Using the enter method for the PTH 101 seven-week compressed format, a significant model emerged: $F(4,25)=3.384, p=.024$. The model explains $35 \%$ of the variance (adjusted $\mathrm{R}^{2}$ $=.351)$. The same method was utilized for PTH 10115 weeks. Using the enter method, an insignificant model emerged: $F(4,21)=1.628, p=.205$. The model explains $24 \%$ of the variance (adjusted $\mathrm{R}^{2}=.237$ ). Table 14 gives information for the predictor variables entered into the model. The only variable that was a significant predictor $(\mathrm{p}<.05)$ was preadmission GPA for the seven-week course format.

\section{Table 14}

Comparison of PTH 101 Traditional 15-Week to Seven-Week Compressed Numeric Grade

\begin{tabular}{lllllll}
\hline Variable & \multicolumn{7}{l}{ Traditional 15-Week } & \multicolumn{3}{l}{ Seven-Week Compressed } \\
& $\mathrm{B}$ & SE B & $B$ & $\mathrm{~B}$ & SE B & $\beta$ \\
Ethnicity & -.053 & .036 & -.427 & -.012 & .014 & -.140 \\
Age & .001 & .002 & .129 & .000 & .001 & .109 \\
Highest Degree Earned & .012 & .016 & .135 & .022 & .012 & .300 \\
Admission GPA & .036 & .026 & .271 & .049 & .018 & $.445^{*}$ \\
\end{tabular}

Using the enter method for the PTH 205 seven-week compressed format, an insignificant model emerged: $f(4,27)=2.153, p=.102$. The model explains $24 \%$ of the variance (adjusted $\mathrm{R}^{2}$ $=.242$ ). The same method was utilized for PTH 205 in the 15-week format. Using the enter 
method, an insignificant model emerged: $F(4,21)=1.973, p=.136$. The model explains $27 \%$ of the variance (adjusted $\mathrm{R}^{2}=.273$ ). Table 15 gives information for the predictor variables entered into the model. The only variable that was a significant predictor $(\mathrm{p}<.05)$ was preadmission GPA for the seven-week course format.

\section{Table 15}

Comparison of PTH 205 Traditional 15-Week to Seven-Week Compressed Numeric Grade

\begin{tabular}{lllllll}
\hline Variable & \multicolumn{2}{l}{ Traditional 15-Week } & \multicolumn{3}{l}{ Seven-Week Compressed } \\
\hline & B & SE B & $\beta$ & B & SE B & $\beta$ \\
Ethnicity & -.074 & .044 & -.475 & -.017 & .025 & -.116 \\
Age & .002 & .002 & .223 & -.002 & .001 & -.328 \\
Highest Degree Earned & .022 & .020 & .200 & .018 & .023 & .135 \\
Admission GPA & .50 & .032 & .293 & .076 & .035 & $.372 *$ \\
\end{tabular}

Using the enter method for the PTH 270 seven-week compressed format, a significant model emerged: $F(4,53)=3.384, p=.024$. The model explains $35 \%$ of the variance (adjusted $\mathrm{R}^{2}$ $=.351)$. The same method was utilized for the 15-week PTH 270. Using the enter method, an insignificant model emerged: $F(4,21)=1.099, p=.383$. The model explains $17 \%$ of the variance (adjusted $\mathrm{R}^{2}=.173$ ). Table 16 gives information for the predictor variables entered into the model. Two variables were significant predictors $(\mathrm{p}<.05)$, preadmission GPA for the 15weel and seven-week course format and highest degree earned for the seven-week course format.

\section{Table 16}


Comparison of PTH 270 Traditional 15-Week to Seven-Week Compressed Numeric Grade

\begin{tabular}{lllllll}
\hline Variable & \multicolumn{3}{c}{ Traditional 15-Week } & \multicolumn{3}{l}{ Seven-Week Compressed } \\
& $\mathrm{B}$ & SE B & $\beta$ & $\mathrm{B}$ & SE B & $\beta$ \\
Ethnicity & -.038 & .028 & -.413 & -.007 & .017 & -.070 \\
Age & .001 & .001 & .250 & $-3.467 \mathrm{E}-5$ & .001 & -.007 \\
Highest Degree Earned & .010 & .013 & .162 & .032 & .015 & $.332 *$ \\
Admission GPA & .023 & .020 & $.226 *$ & .069 & .023 & $.500 *$ \\
\end{tabular}

Using the enter method for the PTH 221 seven-week compressed format, an significant model emerged: $F(4,28)=3.360, p=.023$. The model explains $32 \%$ of the variance (adjusted $\mathrm{R}^{2}$ $=.324$ ). The same method was utilized for the 15-week PTH 101. Using the enter method, an significant model emerged: $F(4,21)=3.144, p=. .036$. The model explains $38 \%$ of the variance (adjusted $\mathrm{R}^{2}=.375$ ). Table 13 gives the information for the predictor variables entered into the model. The only variable that was a significant predictor $(\mathrm{p}<.05)$ was preadmission GPA for the 15-week and seven-week course format.

\section{Table 17}

Comparison of PTH 221 Traditional 15-Week to Seven-Week Compressed Numeric Grade

\begin{tabular}{lllllll}
\hline Variable & \multicolumn{3}{l}{ Traditional 15-Week } & \multicolumn{3}{l}{ Seven-Week Compressed } \\
\hline & B & SE B & $\beta$ & B & SE B & $\beta$ \\
Ethnicity & -.071 & .038 & -.497 & -.010 & .018 & -.083 \\
Age & .002 & .002 & .325 & -.001 & .001 & -.144 \\
Highest Degree Earned & -.010 & .017 & -.103 & .033 & .017 & .316
\end{tabular}




$\begin{array}{lllllll}\text { Admission GPA } & .073 & .027 & .469 * & .074 & .025 & .466^{*}\end{array}$

\subsection{Summary}

Based on the data analysis results, the research question was answered in that the length of a PTA course affects student retention rate in the four courses (PTH 101, PTH 221, PTH 205, and PTH 270) taken during the first technical semester. Students who participated in the compressed curriculum design had a higher retention rate in the first technical semester than students who participated in the traditional 15-week course format.

Based on the data analysis results, the research question was answered in that the length of the any of the four physical therapist assistant courses had no significant impact on the term or four courses' (PTH 101, PTH 221, PTH 205, and PTH 270) GPA. Students who participated in the compressed curriculum design had no negative or positive effect on either course or term GPA, as compared to students who participated in the traditional 15-week course format.

Based on the data analysis results, the research question was answered in that the admission numeric grade point average of the PTA students predicts their grades earned in the first technical semester's four courses (PTH 101, PTH 205, PTH 221, PTH 270) of a PTA program. Students who participated in the seven-week compressed curriculum design term and three (PTH 101, PTH 221, and PTH 270) of the four courses GPA were positively statistically correlated to admission GPA. There was no statistical correlation of the term or course GPA to the preadmission GPA for the traditional 15-week course format.

Based on the data analysis results, the research question was answered in that the TEAS scores of the PTA students' predict their grades in the first technical semester's four courses (PTH 101, PTH 205, PTH 221, PTH 270) of a physical therapist assistant program. There was no 
statistical correlation of the term or the four courses' GPA to the TEAS score for the traditional 15-week or seven-week course format.

From the data analysis, the research question was answered in that the students' demographic data, admission numeric grade point averages, and TEAS scores did not predict their grades in the first technical semester's four courses (PTH 101, PTH 205, PTH 221, PTH 270) of a physical therapist assistant program.

\section{Chapter Five}

\section{Summary, Conclusions, and Recommendations for Future Research}

\subsection{Introduction}

This study used quantitative methods to understand how course length of PTA courses in the first technical semester impacted retention rate and GPA, and how student demographics, admission GPA, and TEAS predicted student GPA. The findings support and further illuminate results of the small body of research specific to curriculum design for PTA education. Key findings for the seven-week compressed course format in the first PTA technical term include a higher statistical retention rate, no negative impact of term or course GPA, and admission GPA as a good predictor of term and course GPA. This retrospective evaluation of the program supports the I-E-O model in which an educational program needs to identify a problem solution and assess the outcomes of the intervention (Antonio \& Astin, 2012). The results of this study indicate that the type of intervention will obviously influence the outcomes of a compressed course design (Lutes \& Davies, 2013).

The following will provide the summary of the study results, strengths and limitations of the study, and discussion of the results. The chapter will also review the implications of the findings for health sciences, recommendations for further research, and conclusions. 


\subsection{Summary of the Study's Results}

The purpose of this retrospective study was to determine whether the length of a course (seven- or 15-week) resulted in higher student retention rates in the first technical semester's four courses (PTH 101, PTH 205, PTH 221, PTH 270) of a PTA program, and if the seven- or 15week course resulted in a higher numeric term grade point average in the first technical semester.

The population for this study consisted of two cohorts of PTA students. The Fall 2016 cohort completed the first technical semester's four courses in the PTA program in a traditional 15-week term, and the Fall 2017 cohort completed the first technical semester's four courses in a seven-week compressed design, two courses in the first seven weeks and two in the second seven weeks. The students' demographic data (gender, ethnicity, age, and highest degree earned prior to entering the program) were utilized as controlled variables to conclude that both cohorts were similar. Admission variables, required grade point averages, and TEAS scores were the independent variables to conclude that both cohorts were similar. Data collected on these variables revealed that the traditional and compressed group was similar except in terms of gender. The difference in gender between groups was a surprising finding. A plausible explanation for the finding was that fewer males were accepted into the PTA program in Fall 2016 than is norm in the program. The average ratio of female to male for the program was 3 to 1 (Marcin, 2016). The ratio for the traditional group was 7.5/1, compared to 3.9/1 for the compressed cohort. The lower number of males admitted in Fall 2016 was unusual for this program.

The PTA program assessed had an overall student retention rate of $67 \%$ for 2015 and 2016. The program's assessment committee has noted that the greatest student attrition in this program occurs in the first technical semester of the PTA program (Marcin, 2014). One method 
for assessing factors that influence a student's persistence to graduation is the I-E-O model. This model assesses what an educational program is trying to achieve, the characteristics of the student, and the student's experiences in the educational environment (Antonio \& Astin, 2012). This tailored strategy can be evaluated after implementation to ensure that the plan meets the needs of both the institution and its students (Fike \& Fike, 2008). Through the assessment of student feedback, advisory sessions, and student course evaluations, the program director and faculty speculate that retention rates may be influenced by the number of PTA courses students complete simultaneously. Accordingly, the program director and faculty believed that modifying the initial technical PTA coursework into a compressed course format would improve students' success in the courses in the first technical term of the program. There were mixed results on the outcome of the research reviewed for the compressed course design for this study. Existing research assessed reports that the outcomes of a compressed course format depend upon the type, student characteristics, and faculty (Lutes \& Davies, 2013). The results of this study demonstrated that there was a significant difference in the retention rate (85\% vs. $76 \%)$ of students who participated in the seven-week compressed or 15-week traditional courses design; see Table 2. Through the assessment of student feedback, advisory sessions, and student course evaluations, the program director and faculty speculated that retention rates might be influenced by the number of PTA courses students complete simultaneously (Marcin, 2016). The faculty perceived that the students were overwhelmed with processing multiple courses at the same time. Most individuals can only manipulate four different types of information in their working memory at one time (Cowan, 2001). The compressed design format decreased how much content the students were required to learn in a given time period and thus decreased cognitive overload. The faculty perceived that the students received too much information at once in the 15 -week 
traditional term, and they may not have been able to process the knowledge effectively in terms of long-term memory and could become disengaged (Marcin, 2016). One of the major objectives of a compressed course format is to embed time management and the development of academic skills into the curriculum (Bonet \& Walters, 2016). Completing courses in a compressed design allowed students to focus on a few courses at one time, and faculty observed that the compressed design had a positive impact on the students' engagement and time-management skills, which ultimately may in turn have improved retention (Marcin, 2017b).

Most of the research studies reviewed reported that statistically, the student grades were not significantly different when comparing a compressed course design with a full-term course design (Hicks, 2014; Fulton-Calkins, 2008; Anastasi, 2007; Shaw, Chametzky, Burrus, \& Walters, 2013; Caldwell, 2012). The results of this study were consistent with previous research in that there was no significant difference in the course or term GPA of students who participated in seven- or 15-week courses; see Table 3. Students who participated in the compressed curriculum design experienced no negative or positive effect on course or term GPA as compared to students who participated in the traditional 15-week course format. Although no improvement in GPA was noted, the faculty reported better student success in the seven-week compressed design, with a greater number of students successfully completing the term compared to the 15-week traditional format (Marcin, 2017b).

There is a large variance in graduation rates among PTA schools; in 2015, the graduation rate ranged from ranged from 25\% to 100\% (Education, 2016a). The previous literature has assessed the characteristics of PTA students, faculty, and programs in relation to graduates' success in passing the National Physical Therapist Examination (Desmaris, Woble-Valenski, \& Oestmann, 2011; Gresham, Thompson, Luedtke-Hoffmann, \& Tietze, 2015; Maring, Costello, 
Ulfers, \& Zuber, 2013). However, scarce research exists in the literature on how a program's academic curriculum impacts PTA students' retention rate. From previous program assessments, the program studied had evaluated its admission qualifications. As part of this study, the researcher questioned if the student demographics and admission standards, admission GPA and TEAS scores were statistically different for the two cohorts studied. Data collected on these variables revealed one student demographic correlation and admission standard to term GPA for only the seven-week compressed course format.

Data collected on these variables revealed that the correlation of the term GPA and three (PTH 101, PTH 221, \& PTH 270) and admission GPA was statistically significant for only the seven-week compressed design, which was a surprising finding. A plausible explanation for this finding exists, in that a compressed course curriculum is faster than a traditional course, and the short learning period requires the students to learn information at a faster pace. Students who have a better foundation of knowledge are more likely to absorb new information more easily. The educational theory underlying the learning process in which a student transfers information from working to long-term memory is known as cognitive theory. Jerome Bruner (1976), a cognitive theorist, proposed that learning takes place when the task being learned is similar to previously learned information. A compressed course curriculum design offers students a learning environment that enables them to organize new and current knowledge. As the learner encounters new information, they organize the information based on past experiences. The learner pulls information from long-term memory to shape input from working memory (De Jong, 2010). When learners adopt a curriculum that has a sequential purposeful order of courses, they can transform information into knowledge more readily. 
The interesting correlation for student demographics were with students who had already earned a bachelor's degree or higher. A reasonable explanation for this finding is that students who have completed a bachelor's or higher degree have most likely already acquired time management skills. A compressed course design assists students in developing time management skills (Bonet \& Walters, 2016). Students who possess more academic experiences may possess better time management skills and may thus initially excel in a compressed course environment. In comparison, a longer curriculum may assist a student with lower academic skills in developing better study habits for the information presented. A reason no correlation between term GPA and previous academic experience for the traditionally designed course may be due to students having more time to develop working knowledge (De Jong, 2010).

One surprising finding of this research study was the lack of correlation between the TEAS score and first PTA technical term and course GPA. One factor that could have influenced these results was that there was less variability in the numeric grade score than anticipated. There was consistency between both cohorts in terms of course numeric grades. The numeric course grade difference between cohorts was 0-3\%; see Table 2. The largest variation in numeric grade was between cohorts was 3\% for the PTH 101 15-week course. There was a close significant positive correlation among TEAS score and first PTA technical term and course GPA ( $\mathrm{r}_{2}=.353, \mathrm{~N}=26, \mathrm{p}=.077$, two-tailed). Another factor that may have influenced a lack of correlation among the TEAS score and first PTA technical term and course GPA was the small population (Brace et al., 2006). One factor that could have influenced a closer significant positive correlation for a 15 -week versus a seven-week course is that during the full-term semester the students are required to take four courses. A TEAS “is a computerized diagnostic instrument to help evaluate academic skills. The TEAS is a 4-hour computer-based test that 
covers Math, English, and Science” ("TEAS (Health Science Tests)," 2017). This exam assesses student reading levels. Students who are reading at a higher level may have better abilities to read and comprehend materials for multiple courses.

A multiple modified linear regression model was performed to predict numeric course grade, a dependent variable, based on the four independent and control variables that were closest to statistically significant for the multiple regression model performed; see Tables 14-17. This model was performed to assess changes in the dependent variable when controlled variables with the least correlation were removed (Brace et al., 2006). The removal of TEAS score and gender increased the strength of the correlation of preadmission GPA for all seven-week courses and two 15-week courses. Prior to the removal of these two variables, only three of the sevenweek courses were statistically significant for preadmission GPA and course numeric grade. Only one variable of highest degree earned for one course, PTH 221, was statistically significant for correlation for course numeric grades. The results of the modified linear regression are helpful in validating that the best admission variable for the program of study seven-week course design is admission GPA. Assessing the effects of the control variables is supported by the I-EO model. A goal of this program is to improve retention rate, so the program identified a problem, evaluated the cause, implemented an intervention, and assessed the outcome (Antonio \& Astin, 2012). This tailored strategy can be evaluated after implementation to ensure that the plan meets the needs of the program and its students (Fike \& Fike, 2008).

This study considered the problem and purpose by testing four sets of hypotheses, see table 18 .

\section{Table 18}

Summary of Retrospective Program Evaluation Hypothesis 
$\underline{\text { Hypothesis } 1}$

Students who complete four physical therapist assistant courses (PTH 101, PTH 205, PTH 221, PTH 270) offered in the seven-week compressed program during the first technical semester of the Horry-

Georgetown Technical College will be more successful in progressing to the next term than students who complete the four PTH courses in the traditional 15 -week semester.

\section{$\underline{\text { Hypothesis } 2}$}

There are statistically significant differences in grades, but no difference in the admission average grade points between students enrolled in the first technical semester's four physical therapist assistant courses (PTH 101, PTH 205, PTH 221, РTH 270) over seven weeks and those enrolled in the traditional 15-week courses at HorryGeorgetown Technical College.
Accepted

- A Fishers Exact Test was calculated comparing student cohorts in terms of the number of students' withdrawing from the term and number of students withdrawing from a course (PTH 101, PTH 205, PTH 221, PTH 270). The variables by group and the distribution of these variables in the two groups were statistically different; see

Table 2.

\section{$\underline{\text { Rejected }}$}

- The mean and standard deviations were collected for both cohorts for the variables of term numeric grade point average and course (PTH 101, PTH 205, PTH 221, PTH 270), numeric grade (Table 3). Using a probability value of $<.05$, an independent- samples t-test was calculated comparing these variables by group, and the distribution of these variables in the two groups were not statistically different.

- An independent samples t-test was calculated comparing student admission 
GPA by group, and the distribution of these two variables in the two groups were not statistically different, see Table 1.

Hypothesis 3

There are statistically significant differences in grades, but no difference between the TEAS scores of students enrolled in the first technical semester's four physical therapist assistant courses (PTH 101, PTH 205, PTH 221, PTH 270) over seven weeks at HorryGeorgetown Technical College and those enrolled in the same courses over 15 -weeks at Horry-Georgetown Technical College.
Rejected

- The mean and standard deviations were collected for both cohorts for the variables of term numeric grade point average and course (PTH 101, PTH 205, PTH 221, PTH 270), numeric grade (Table 3). Using a probability value of $<.05$, an independent- samples t-test was calculated comparing these variables by group, and the distribution of these variables in the two groups were not statistically different.

- An independent samples t-test was calculated comparing student TEAS score by group, and the distribution of these two variables in the two groups were not statistically different, see Table 1. 


\section{Hypothesis 4}

There are statistically significant differences in term numeric grade points, but no difference between the demographics (gender, ethnicity, age, and highest degree, Baccalaureate, Master's, Doctoral, earned upon entering the program) of students enrolled in the first technical semester's four physical therapist assistant courses (PTH 101, PTH 205, PTH 221, PTH 270) over seven weeks at Horry-Georgetown Technical College and those enrolled in the same courses over 15-weeks at Horry-Georgetown Technical College.

\section{$\underline{\text { Rejected }}$}

- The mean and standard deviations were collected for both cohorts for the variables of term numeric grade point average and course (PTH 101, PTH 205, PTH 221, PTH 270), numeric grade (Table 3). Using a probability value of $<.05$, an independent- samples t-test was calculated comparing these variables by group, and the distribution of these variables in the two groups were not statistically different.

- Chi-square tests of independence were calculated comparing student demographics (age, gender, highest degree earned, and ethnicity) by group, and the distribution of student demographics in the two groups were not statistically different except for gender, see Table 1.

\subsection{Limitations}

Not unlike previous research on this topic, the limitations of the research design were that it was based on one geographical area, it featured a small sample of the population, and there was limited control of data. Each limitation will be addressed. 
The variables that influence the success of a student progressing in a PTA program are multifactorial. Generalizing the results of this retrospective program evaluation to another PTA may be limited, as the student population may not be similar. However, a program may benefit from understanding how program evaluation assesses the effect of curriculum design on student success. The aim of this study was to assess a program curriculum and its effect on retention.

The program assessed had only two cohorts with identical curricula, but one group completed the coursework in a 15-week term and the other in a seven-week term. The small sample size could skew the data or prevent a correlation from being detected (Brace et al., 2006). Assessing additional cohorts may have benefited the program, but due to curriculum modifications for previous cohorts, only two cohorts received identical curricula.

This program evaluation was completed retrospectively, and a challenge with a retrospective study is controlling data. Although the content was consistent between cohorts, the instructors may have modified the frequency of assessment to accommodate the change in term length.

\subsection{Implications for Health Sciences}

The results of this study may be of interest to educators in PTA or related disciplines, as well as, administrators, students, CAPTE, and the public. Previous research on how curriculum design or course length affects PTA program outcomes is scarce, but there are several suggestions that program stakeholders can implement to assure better that students progress in a PTA program curriculum. With a better understanding of what contributes to program retention rate, program directors and faculty may more productively examine curriculum design and admission requirements. 
If the program offers the curriculum format in a compressed design, the program stakeholders may want to consider the program admission requirements. This may include giving preference for admission into the PTA program to students who already have a bachelor's degree and to students who have a higher admission grade point average. The program may also want to consider interventions to assist students who do not have a bachelor's degree in developing study skills; for example, giving preference for admission into the PTA program to students who do not possess a bachelor's or higher degree to attend study skills training.

Advisors may consider reviewing students' admission GPA and previous education level before starting the PTA technical program. Awareness of the student's academic level may assist advisors in identifying students who may be a risk of not progressing to the next technical term. Advisors may want to request advising sessions with students at risk before the start of the term to offer study and/or time management interventions.

CAPTE currently requires PTA programs to report program length as an evaluative criterion (Education, 2016c). CAPTE may want to consider requiring program reports to also report course length. Adding this criterion may allow future research to compare multiple programs' outcomes and course lengths. A larger and more diverse sample for retrospective study of compressed course designs and program outcomes for PTA programs may benefit program directors in identifying how curriculum design may impact program outcomes.

The purpose of this retrospective study was to determine whether the length of a course (seven- or 15-week) resulted in higher student retention rates in the first technical semester's four courses (PTH 101, PTH 205, PTH 221, PTH 270) of a PTA program, and if the seven- or 15week course resulted in a higher numeric term grade point average in the first technical term. The program that was studied can utilize the results of this research to validate the benefits and 
the negative impacts of a compressed course design for a program in order to improve program retention. For example, the program may consider assessing if the admission requirements are based on the data results. The current admission policy for the program studied allows the student to be weighted based on preadmission GPA or TEAS score (Marcin \& Martel, 2016). The program may assess the benefits of the TEAS score as an admission tool due to the lack of statistical correlation to term GPA. The TEAS test is a standardized test that the students pay a fee to complete ("TEAS (Health Science Tests)," 2017). The removal of this admission cost could improve student access by decreasing costs at this community college (Mertes \& Jankoviak, 2016).

\subsection{Recommendations for Future Research}

This study focused on assessing how course length impacted a program's retention rate in the first PTA technical term of a program. This study concluded that students' preadmission GPA was positively correlated to the first term GPA. Previous research has shown that anatomy and physiology grades are weakly correlated to licensure examination scores for PTA technical courses GPA (Desmarais, Woble-Valenski, \& Oestmann, 2011). Future research recommendations are to assess the effect of a compressed curriculum on licensure board pass rate and graduation rate.

The population for this study was small and isolated to one geographical location and assessed only two cohorts of students. Future research could be a longitudinal study at the same institution that assesses a larger population of students who have completed a compressed course design. A longer observational study with a larger population at the same PTA program may benefit the program to validate admission and program standards, as variables that influence the success of a student progressing in a PTA program are multifactorial. 
From this study, program stakeholders can concluded that no more than $35 \%$ of the PTA numeric course grades in a compressed design are related to admission grade point average. Lack of academic progress is a reason why students may withdraw or be removed from a program. Additional studies assessing how other independent variables impact PTA course numeric grades may be beneficial. Other factors that could be included are teaching philosophy-i.e. active learning interventions.

This study did not assess the students' opinions of the compressed course design. Purposeful student and faculty interactions are positively correlated to student engagement (DeCiccio et al., 2009). DeCiccio, Gross, and Gross (2009) have determined that if the student population connects with faculty prior to, during, and at the end of the first term, the student body's retention rate improves. Further research on student perception of how faculty interaction affects their academic progress may be useful in developing interventions to improve student success.

\subsection{Conclusions}

The retrospective program evaluation evaluated the impact that a compressed course design had on students' course and term GPA and retention rate for students enrolled in the first technical term of a PTA program. The study compared two discrete groups of students who received the same content and forms of assessment in four PTA courses from the same full-time faculty member in Fall 2016 and 2017. Data was reviewed for both groups to ensure that student demographics (age, gender, highest degree earned, and ethnicity) and admission data (prerequisite grade point average and TEAS score) for both groups were not statistically different. There was no statistical difference in the groups for student demographics or admission data, except for gender. This study indicates that students who participated in the 
seven-week course had statically better retention rate, but there was no difference in course or term GPA than students who participated in a 15-week course. A student's admission GPA may be a better indicator of GPA for a seven-week course format than for a 15-week course format. 


\section{References}

Anastasi, J. S. (2007). Methods and techniques: Full-Semester and abbreviated summer courses: An evaluation of student performance. Teaching of Psychology, 34(1), 19-22.

Antonio, A. L., \& Astin, A. W. (2012). Assessment for excellence : the philosophy and practice of assessment and evaluation in higher education: Lanham, MD Rowman \& Littlefield Publishers c2012 2nd ed.

Barra, M. (2013). The effect of medical mathematics retention strategies in decreasing attrition rate among African American licensed practical nursing students in a community college. Journal of Cultural Diversity, 20(3), 125-133.

Bonet, G., \& Walters, B. R. (2016). High impact practices: Student engagement and retention. College Student Journal, 50(2), 224-235.

Brace, N., Kemp, R., \& Snelgar, R. (2006). SPSS for psychologists: a guide to data analysis using SPSS for Windows (versions 12 and 13) (3rd ed.). Basingstoke, UK.: Palgrave Macmillan.

Braxton, J. M., Hirschy, A. S., \& McClendon, S. A. (2011). Understanding and reducing college student departure. ASHE-ERIC Higher Education Report, 30(3), 7-20.

Caldwell, M. (2012a). Assessment of student achievement in introductory physical geology: A three-year study on delivery method and term length. University of South Florida,

Caldwell, M. (2012b). Assessment of student achievement in introductory physical geology: A three-year study on delivery method and term length., University of South Florida,

Carrington, L. G. (2010). The impact of course scheduling on student success in intermediate accounting. American Journal of Business Education, 3(4), 51-60. 
College, H.-G. T. (2016). 2016-2017 College Catalog \& Student Handbook. Horry-Georgetown Technical College.

Cowan, N. (2001). The magical number 4 in short-term memory: A

reconsideration of mental storage capacity. Behavioral and Brain Sciences, 24(1), 87-114.

Crosling, G., Heagne, M., \& Thomas, L. (2009). Improving student retention in higher education. Australian Universities' Review, 51(2), 9-18.

De Jong, T. (2010). Cognitive load theory, educational research, and instructional design: some food for thought. Instructional science, 38(2), 105-134.

DeCiccio, A., Gross, A. H., \& Gross, K. (2009). Creating a retention quilt: Southern Vermont College reports on results from the trenches. New England Journal of Higher Education, 23(5), 24-25.

Desmarais, L., Woble-Valenski, M. A., \& Oestmann, E. (2011). Factors influencing physical therapist assistant licensure examination success. Journal of Physical Therapy Education, 25(2), 36-41.

Desmaris, L., Woble-Valenski, M. A., \& Oestmann, E. (2011). Factors influencing physical therapist assistant licensure examination success. Journal of Physical Therapy Education, 25(2), 36-41.

Dick, W., \& Carey, L. (1990). The systematic design of instruction (3rd ed.). New York: Harper Collins College Publishers.

Dunn, K., \& Hooks, K. (2015). Course scheduling and student learning: An empirical investigation. Global Perspectives on Accounting Education, 12.

Educaiton, C. A. P. T. (4/22/2015). Who we are. Retrieved from http://www.capteonline.org/WhoWeAre/ 
Educaiton, C. A. P. T. (2016). PT standards and required elements. Retrieved from http://www.capteonline.org/Faculty/AccreditedPrograms/

Education, C. A. P. T. (2016a). Aggregate program data. Retrieved from http://www.capteonline.org/uploadedFiles/CAPTEorg/About_CAPTE/Resources/Aggreg ate_Program_Data/AggregateProgramData_PTAPrograms.pdf

Education, C. A. P. T. (2016b). Physical therapist assistant standards and required elements. Retrieved from Commission Accreditation Physical Therapy Education website: http://www.capteonline.org/Faculty/AccreditedPrograms/

Education, C. A. P. T. (2016c). The rules of practice and procedures. Retrieved from http://www.capteonline.org/uploadedFiles/CAPTEorg/About_CAPTE/Resources/Accredi $\underline{\text { tation_Handbook/RulesofPracticeandProcedure.pdf }}$

Fike, D. S., \& Fike, R. (2008). Predictors of first-year student retention in the community college. Community College Review, 36(2), 68-88.

Fontaine, K. (2014). Effects of a retention intervention program for associate degree nursing students. Nursing Education Perspectives (National League for Nursing), 35(2), 94-99. doi:10.5480/12-815.1

Fulton-Calkins, P. (2008). Comparing and contrasting college algebra success rates in traditional versus eight-week courses at a specific community college: A single institution case study. (Doctoral dissertation, ), University of North Texas,

Geltner, P., \& Logan, P. (2001). The influence of term length on student success. (ERIC Document Reproduction Service No. ED455858).

Gilardi, S., \& Guglielmetti, C. (2011a). University life of non-traditional students: Engagement styles and impact on attrition. Journal of Higher Education, 82(1), 33-53. 
Gilardi, S., \& Guglielmetti, C. (2011b). University life of nontraditional students: Engagement styles and impact on attrition. Journal of Higher Education, 82(1), 33-53.

Gresham, B. B., Thompson, M., Luedtke-Hoffmann, K., \& Tietze, M. (2015). Institutional and program factors predict physical therapist assistant program graduation rate and ilcensure examination pass rate. Journal Physical Therapy Education, 29(4), 27-36.

Harlow, J. J., Harrison, D. M., \& Honig, E. (2015). Compressed-format compared to regularformat in a first-year university physics course. American Journal of Physics, 83(3), 272277.

Herrmann, M., \& Berry, K. (2016). An investigation into graduate student preference for compressed courses. Academy of Educational Leadership Journal, 20(2), 23-32.

Hicks, W. L. (2014a). Pedagogy in the twenty-first century: An analysis of accelerated courses in criminal justice. Journal of Criminal Justice EducationJournal of Criminal Justice Education, 25(1), 69-83.

Hicks, W. L. (2014b). Pedagogy in the twenty-first century: An analysis of accelerated courses in criminal justice. Journal of Criminal Justice Education, 25(1), 69-83.

Hlinka, K. R. (2017). Tailoring retention theories to meet the needs of rural Appalachian community college students. Community College Review, 45(2), 144-164. doi:10.1177/0091552116686403

Johnson, D. K. N., Lybecker, K. M., \& Taylor, C. H. (2011). Retention of economics principles by undergraduates on alternative curricular structures. Journal of Education for Business, 86, 332-338. doi:10.1080/08832323.2010.53224

Kim, K. A. (2002). Exploring the meaning of "nontraditional" at the community college. Community College Review, 30(1), 74-89. 
Kopelman, L. (2011). Curriculum Change Request. Horry-Georgetown Technical College.

Kops, W. J. (2014). Teaching compressed-format courses: Teacher-based best practices. Canadian Journal of University Continuing Education, 40(1).

Lee, N., \& Horsfall, B. (2010). Accelerated learning: A study of faculty and student experiences. Innovative Higher Education, 35(3), 191-202.

Lloyd, P. M., \& Eckhardt, R. A. (2010a). Strategies for improving retention of community college students in the cciences. Science Educator, 19(1), 33-41.

Lloyd, P. M., \& Eckhardt, R. A. (2010b). Strategies for improving retention of community college students in the sciences. Science Educator, 19(1), 33-41.

Lutes, L., \& Davies, R. (2013). Comparing the rigor of compressed format courses to their regular semester counterparts. Innovative Higher Education, 38(1), 19-29.

Mansfield, M., O'Leary, E., \& Webb, S. (2011). Retention in higher education: Faculty and student perceptions of retention programs and factors impacting attrition rates. Online Submission, Retrieved from http://storm.hgtc.edu:2048/login?url=http://search.ebscohost.com/login.aspx?direct=true $\underline{\& \mathrm{db}=e r i c \& A N=E D 521416 \& \text { site }=\text { ehost-live } \& \text { scope }=\text { site }}$ Available from EBSCOhost eric database.

Marcin, T. (2014). PTA Spring Assessment Committee Meeting Minutes. Physical Therapist Assistant. Horry-Georgetown Techncial College.

Marcin, T. (2016). PTA Fall Assessment Committee Meeting Minutes. Horry-Georgetown Technical College.

Marcin, T. (2017a). Curriculum Change Request. Horry-Georgetown Technical College. Marcin, T. (2017b). Faculty meeting Minutes 12/1 1/2017. Horry-Georgetown Technical College. 
Marcin, T., \& Martel, S. (2016). Student and Clinical Manual. Physical Therapist Assistant, Horry Georgetown Technical College. Myrtle Beach, SC. Retrieved from http://www.hgtc.edu/documents/academics/programs/pta/studentmanual.pdf

Maring, J., \& Costello, E. (2009). Education program and student characteristics associated with pass rates on the National Physical Therapy Examination for physical therapist assistants. Journal of Physical Therapy Education, 23(1), 3-11 19p.

Maring, J., Costello, E., Ulfers, M., \& Zuber, E. (2013). Curriculum, faculty, and cohort variables predicting physical therapist assistant program graduate success on the national physical therapy examination. Journal of Physical Therapy Education, 27(2), 33-40 38p.

Mertes, S. J., \& Jankoviak, M. W. (2016). Creating a college-wide retention program: A mixed methods approach. Community College Enterprise, 22(1), 9-27.

Nelson, K. J., Quinn, C., Marrington, A., \& Clarke, J. A. (2012). Good practice for enhancing the engagement and success of commencing students. Higher Education: The International Journal of Higher Education and Educational Planning, 63(1), 83-96.

Powell, R. R. (2006). Evaluation research: An overview. Library Trends, 55(1), 101-120.

Reyes, C. (2010). Success in algebra among community college students. Community College Journal of Research and Practice, 34(3), 256-266.

Richardson, S., \& Radloff, A. (2014). Allies in learning: critical insights into the importance of staff-student interactions in university education. Teaching in Higher Education, 19(6), 603-615. doi:10.1080/13562517.2014.901960

Role of the physical therapist assistant. (2016, 4/15/2016). Retrieved from http://www.apta.org/PTACareers/RoleofaPTA/ 
Roman, M. A. (2007). Community College Admission and Student Retention. Journal of College Admission(194), 18-23.

Sander, L. (2008). At community colleges, a call to meet new students at the front dood. Chronicle of Higher Educaiton, 54(29), 1-4.

Shaw, M., Chametzky, B., Burrus, S. W., \& Walters, K. J. (2013). An evaluation of student outcomes by course duration in online higher education. Online Journal of Distance Learning Administration, 16(3).

SPSS. (2016). IBM SPSS Statistics for Windows (Version 24.0 ed.). Armonk,NY: IBM Corp.

Tatum, B. C. (2010). Acclerated learning. Journal of Research in Innovative Teaching, 3(1), 3450.

TEAS (Health Science Tests). (2017). Retrieved from http://www.hgtc.edu/admissions/testing_center/teas.html

Undergraduate Enrollment (2016). The Condition of Education. Retrieved from National Center for Education Statistics.

Undergraduate retention and graduation rates. (2016). The Condiiton of Education. Retrieved from National Center for Education Statistics.

Wellman, J. V. (2003). Of time and the feds: The federal interest in enforcing the credit hour. New Directions for Higher Education, 122.

Wild, L., \& Ebbers, L. (2002). Rethinking student retention in community colleges. Community College Journal of Research and Practice, 26(6), 503-519.

Woodwell, D. (2013). Research Foundations: How Do We Know what We Know? Los Angeles: SAGE Publications. 
Wyatt, L. G. (2011). Nontraditional student engagement: Increasing adult student success and retention. Journal of Continuing Higher Education, 59(1), 10-20. 


\section{Appendix A}

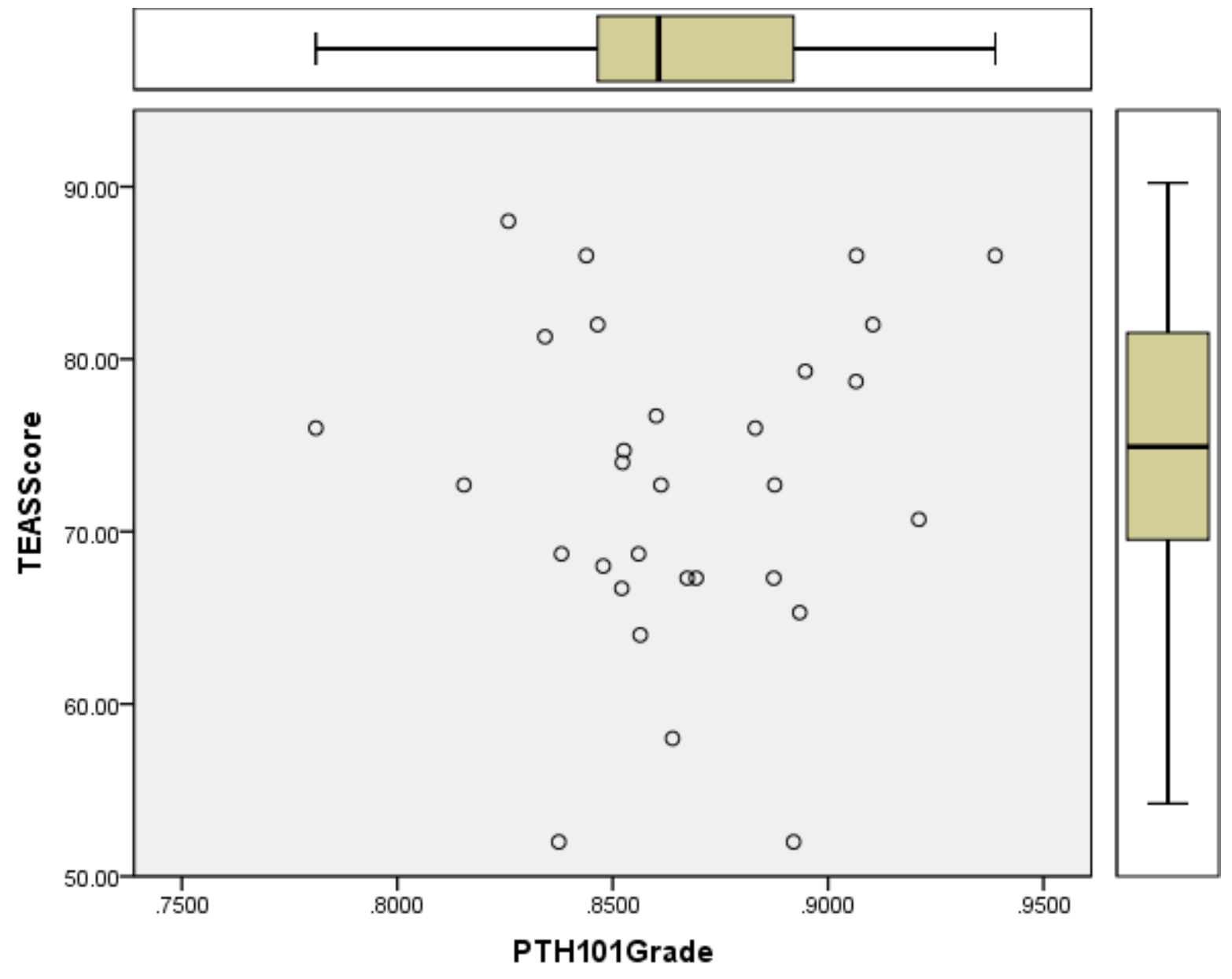

Figure 1: 7-Week Course Format 


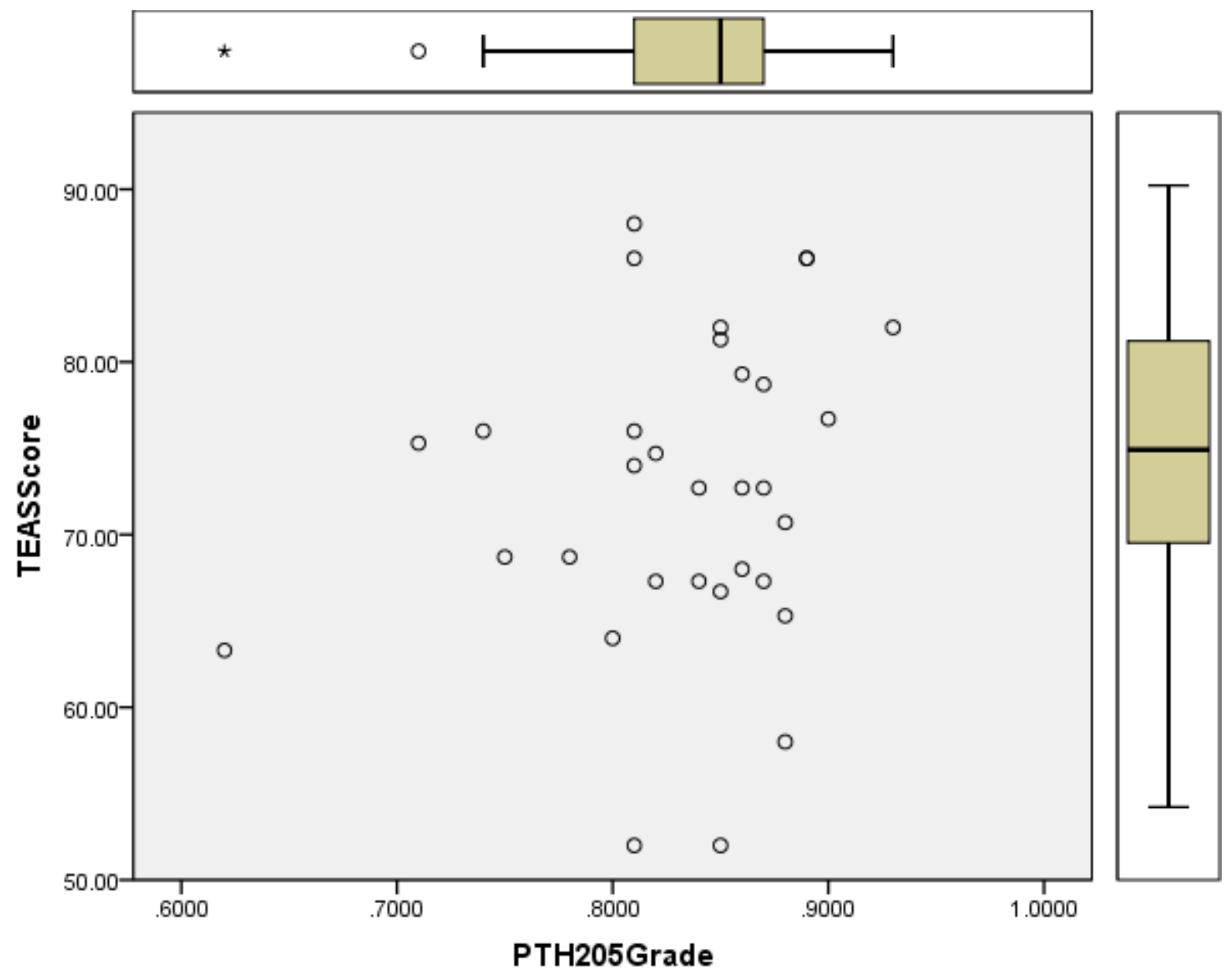

Figure 2: 7-Week Course Format 


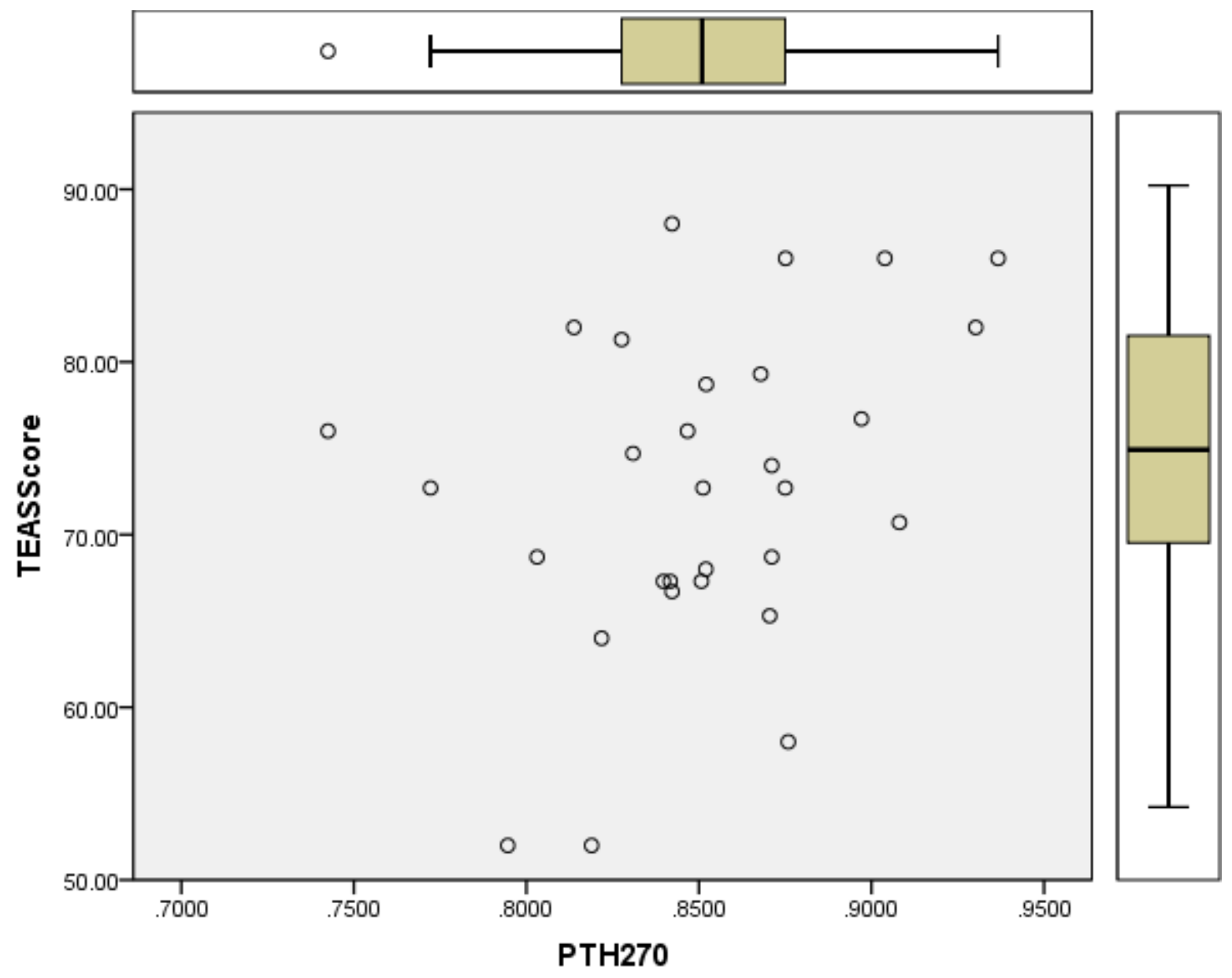

Figure 3: 7-Week Course Format 


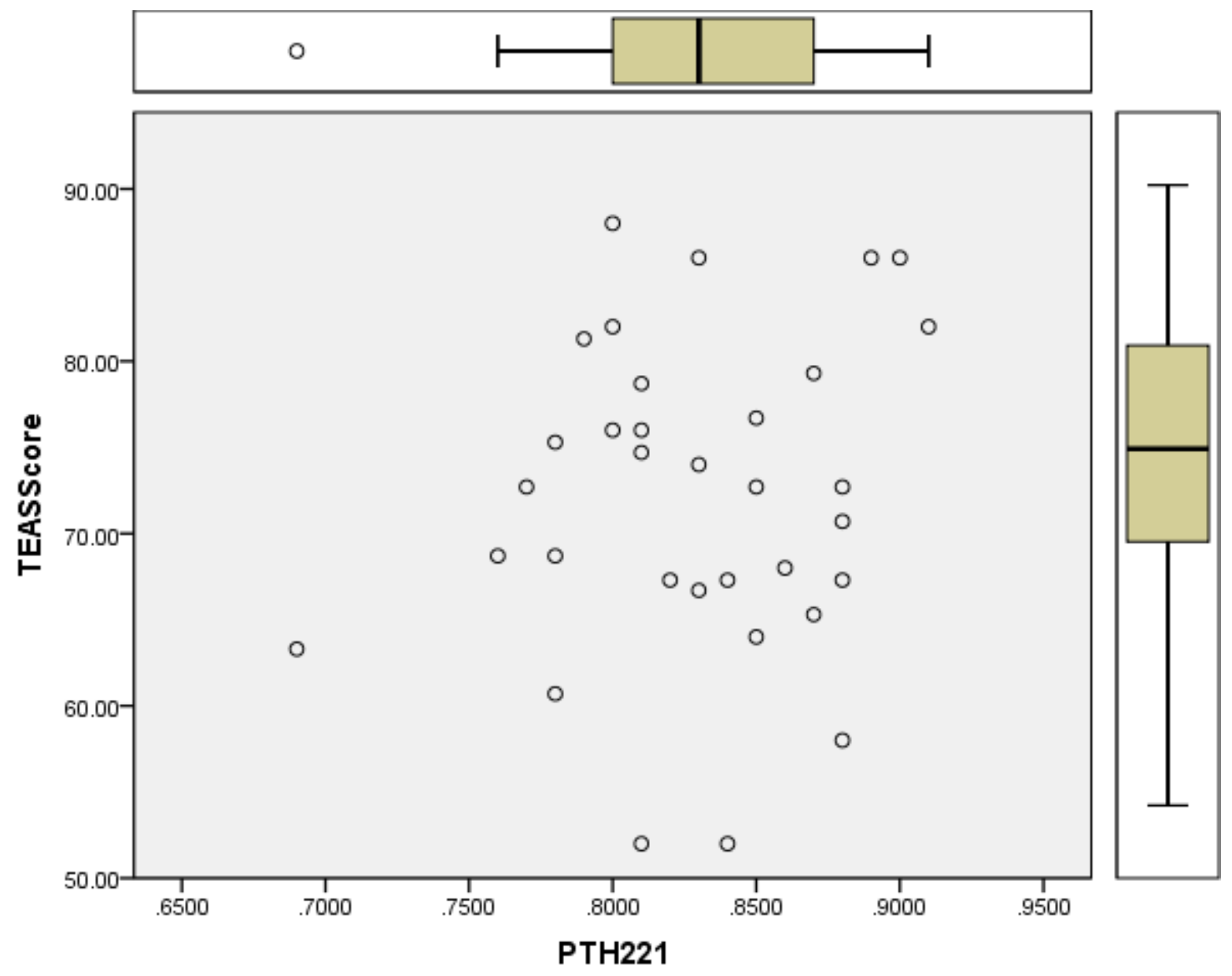

Figure 4: 7 Week Course Format 


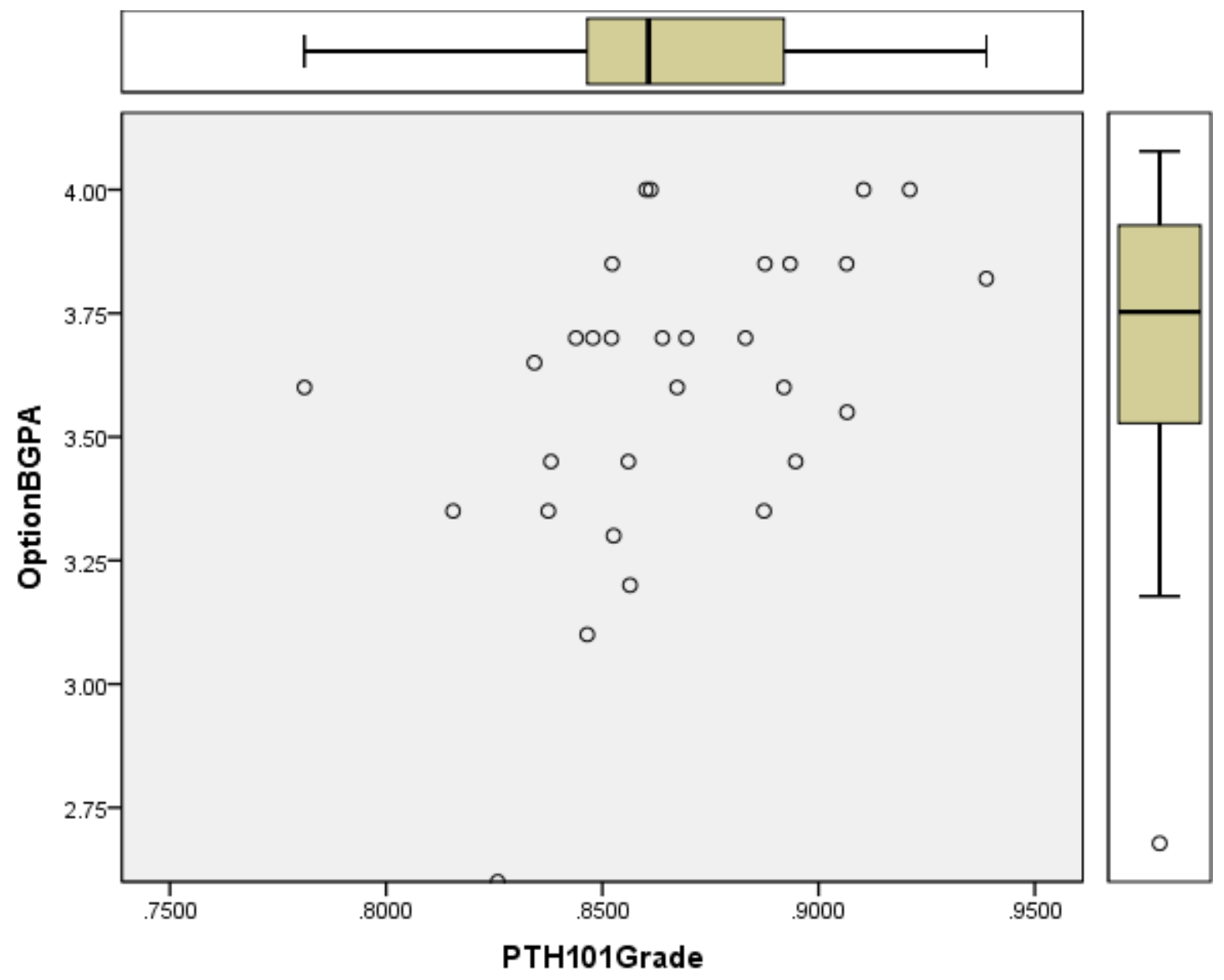

Figure 5: 7-Week Course Format 


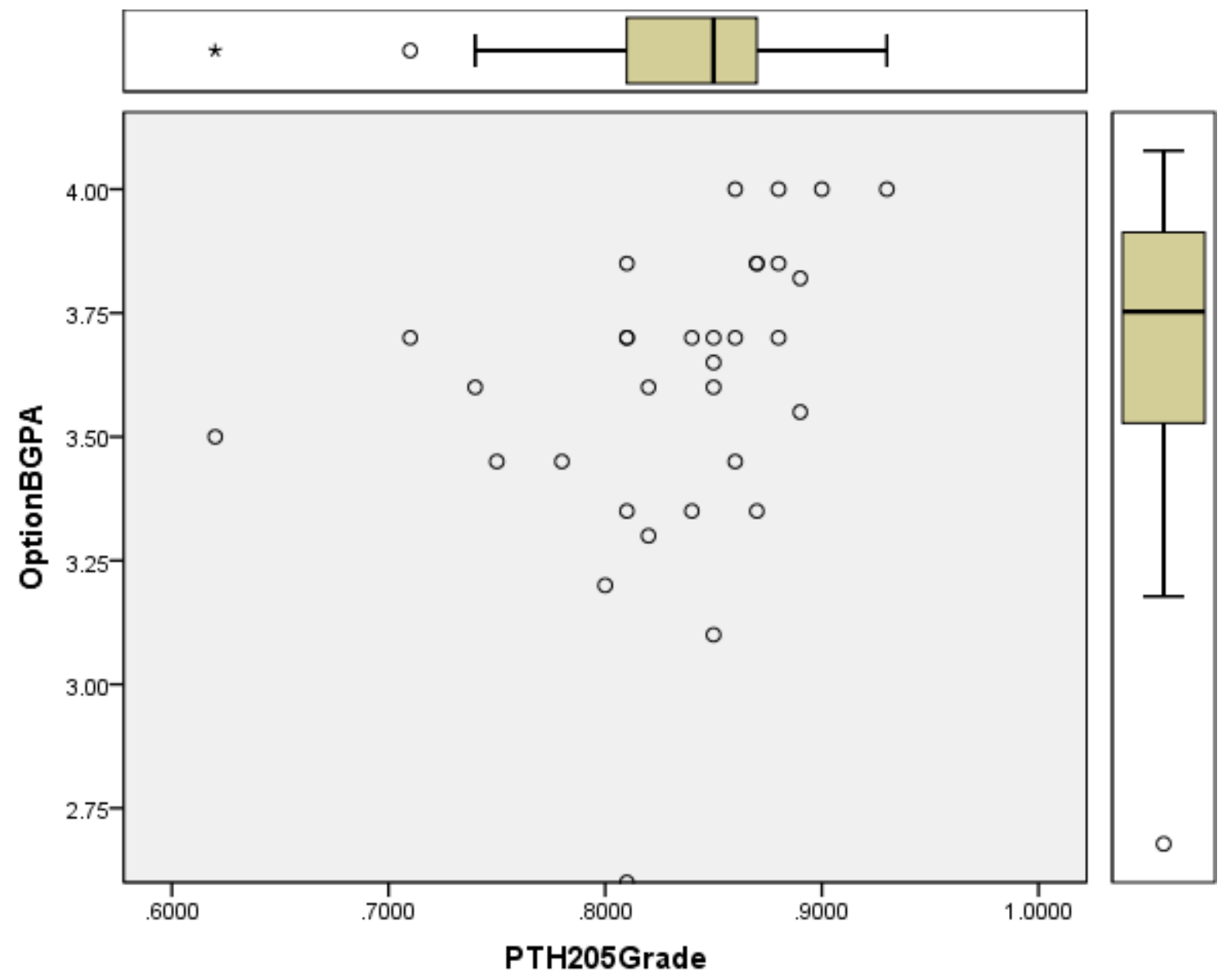

Figure 6: 7 Week Course Format 


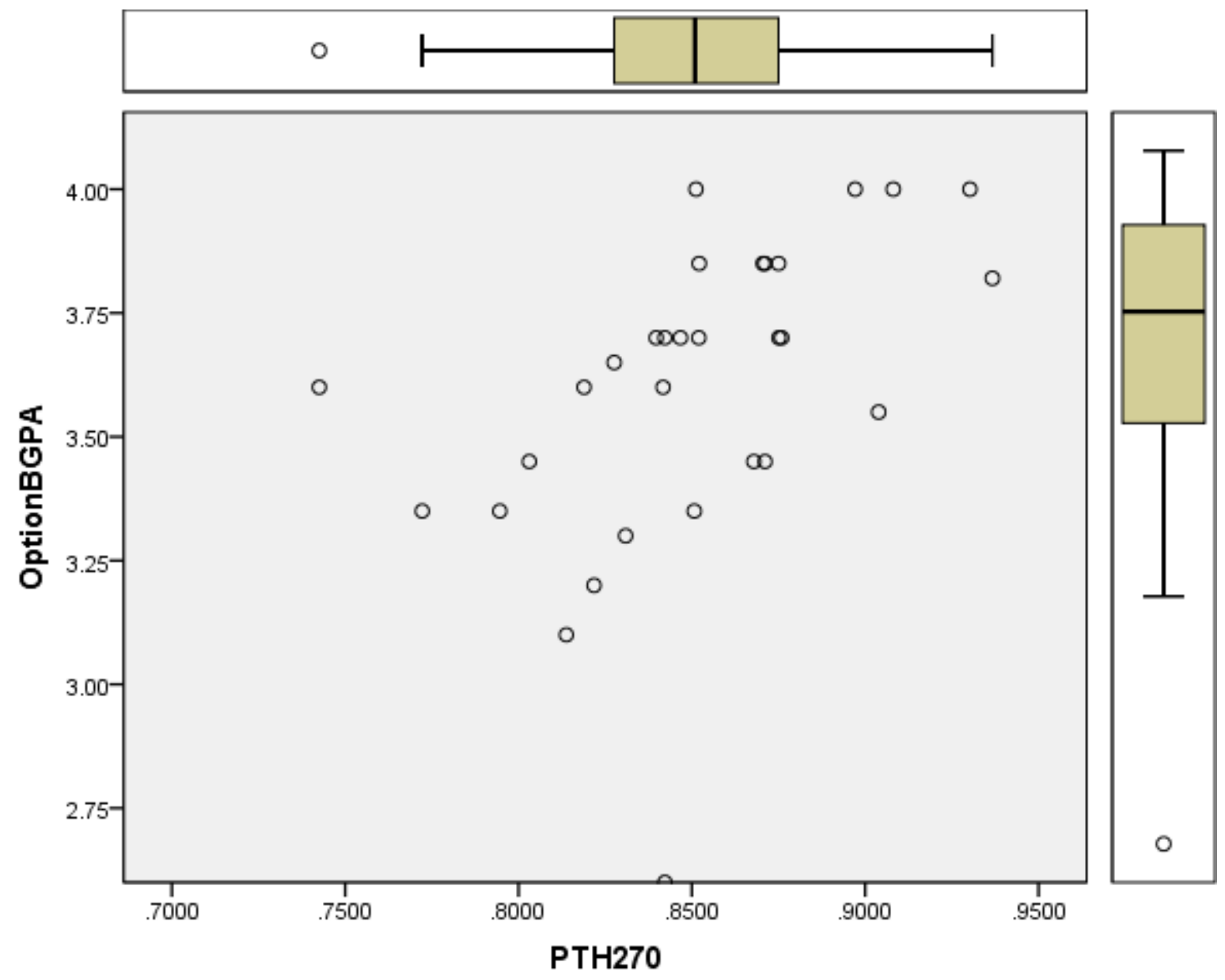

Figure 7: 7-Week Course Format 


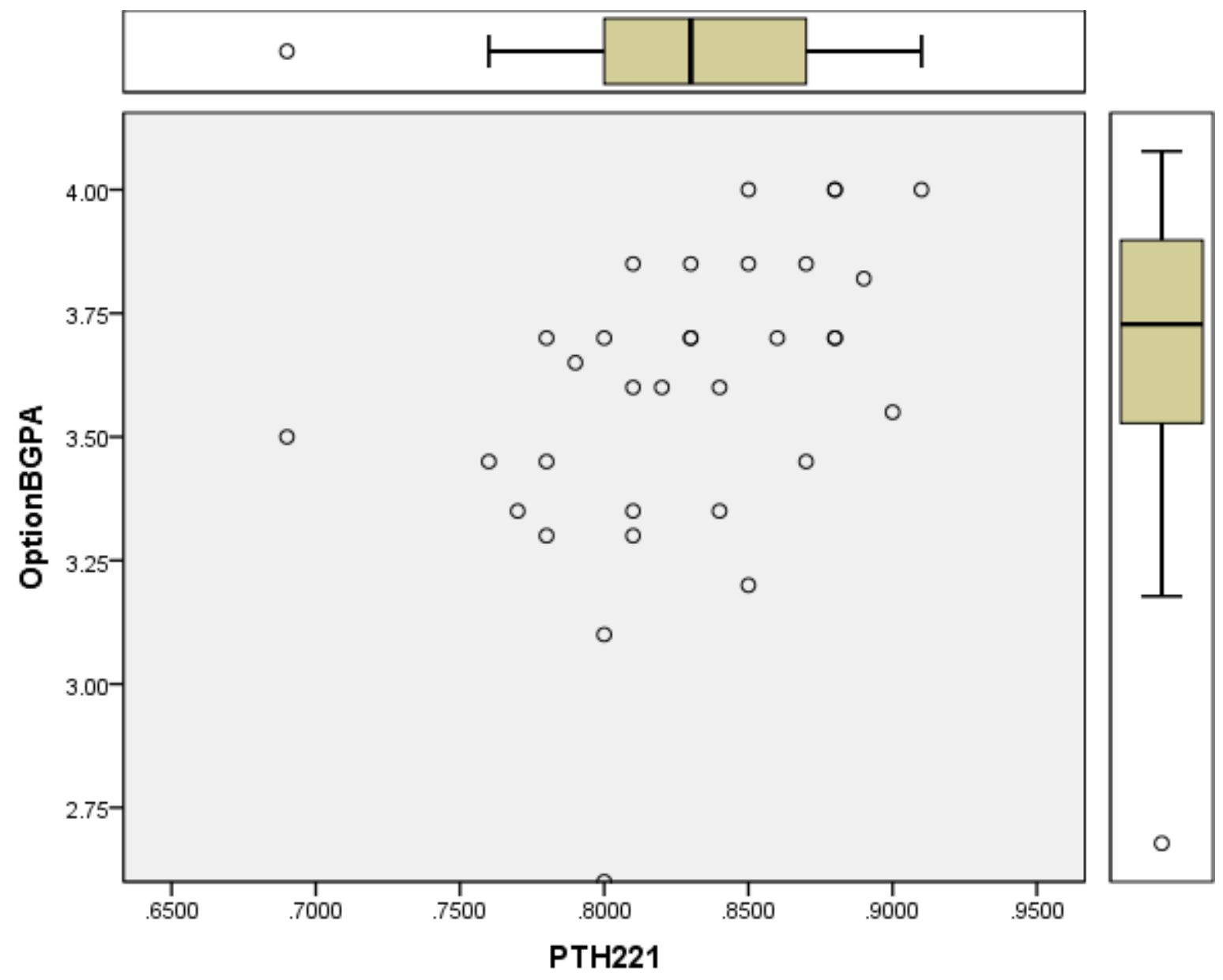

Figure 8: 7-Week Course Format 


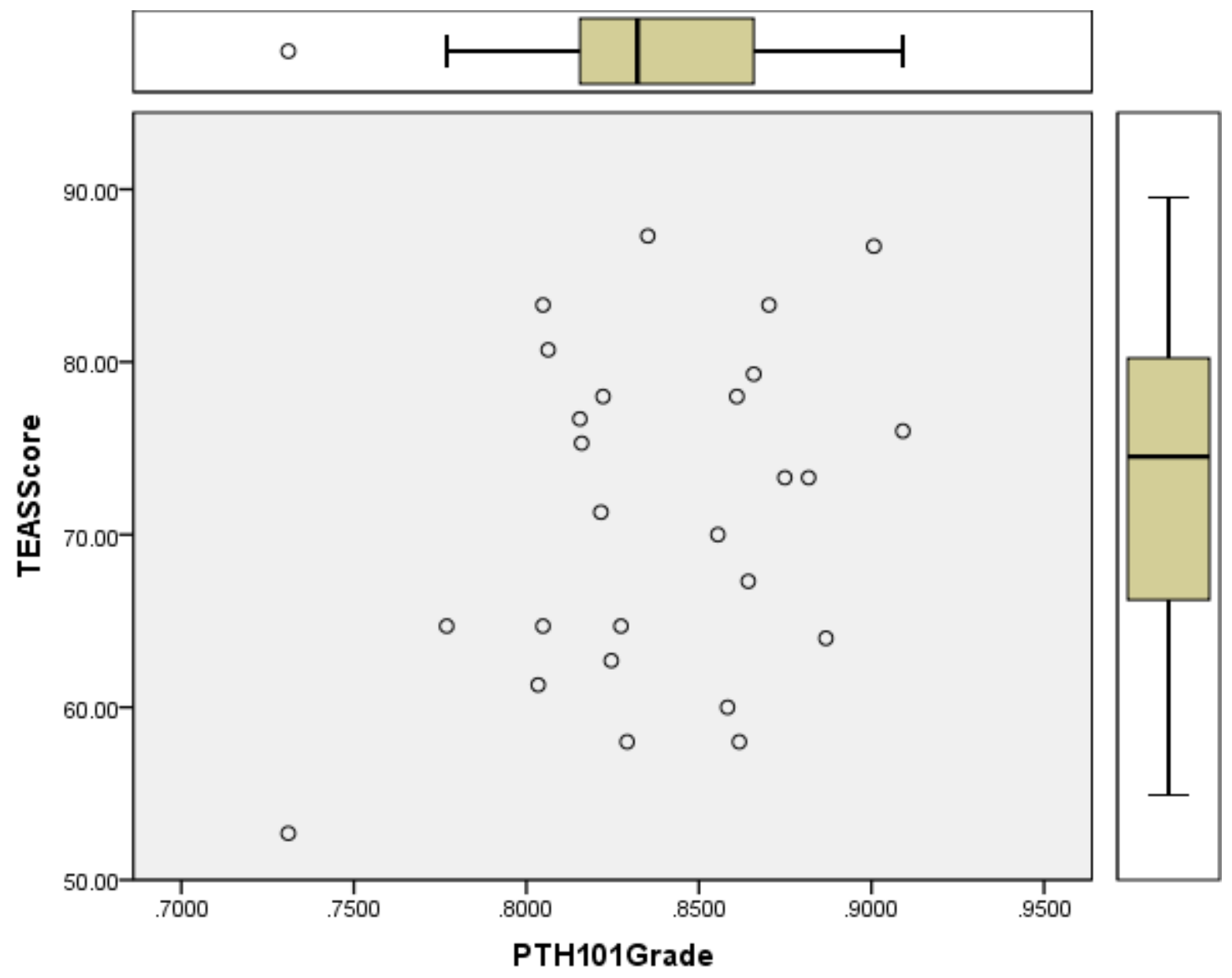

Figure 9: 15-Week Course Format 


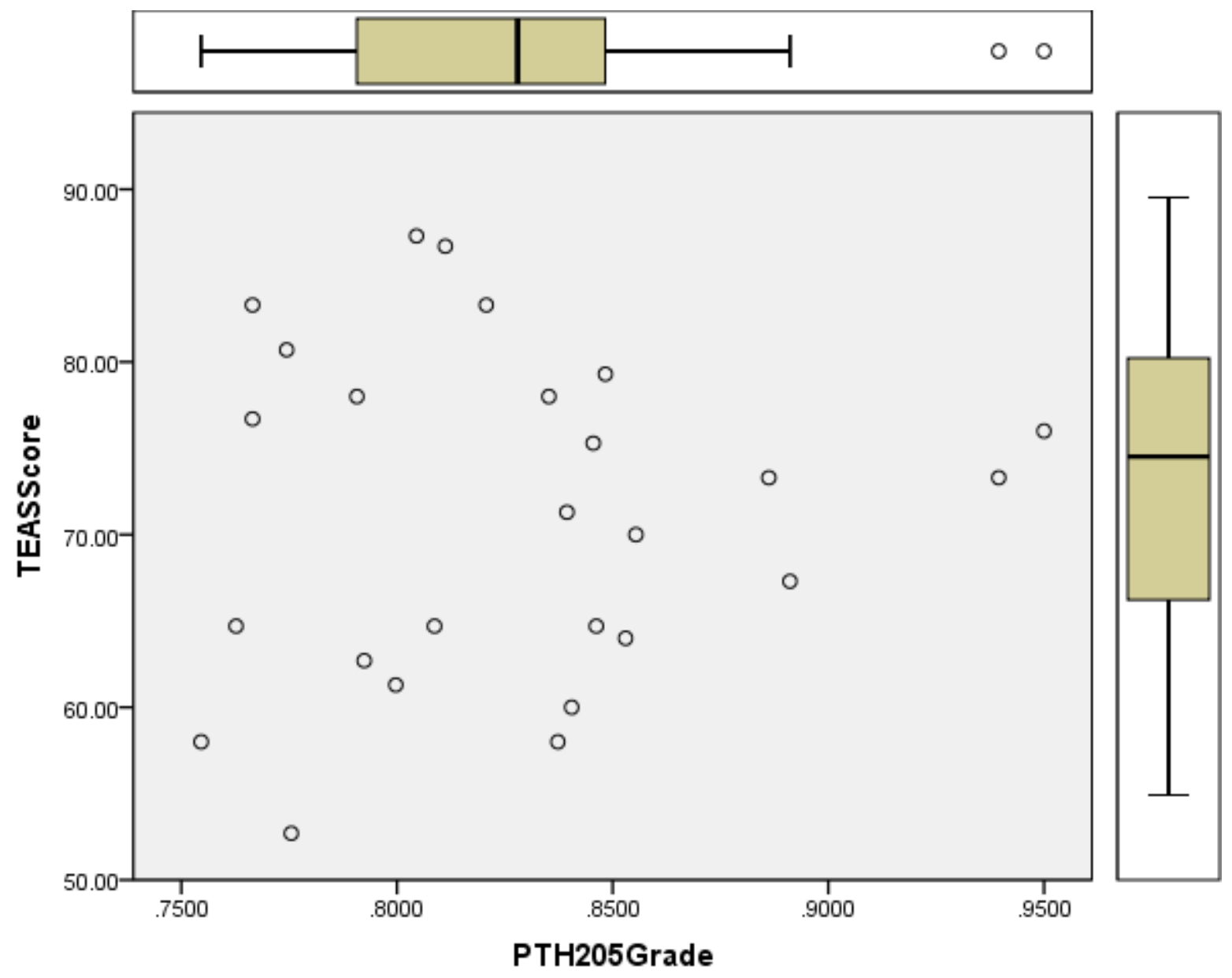

Figure 10: 15-Week Course Format 


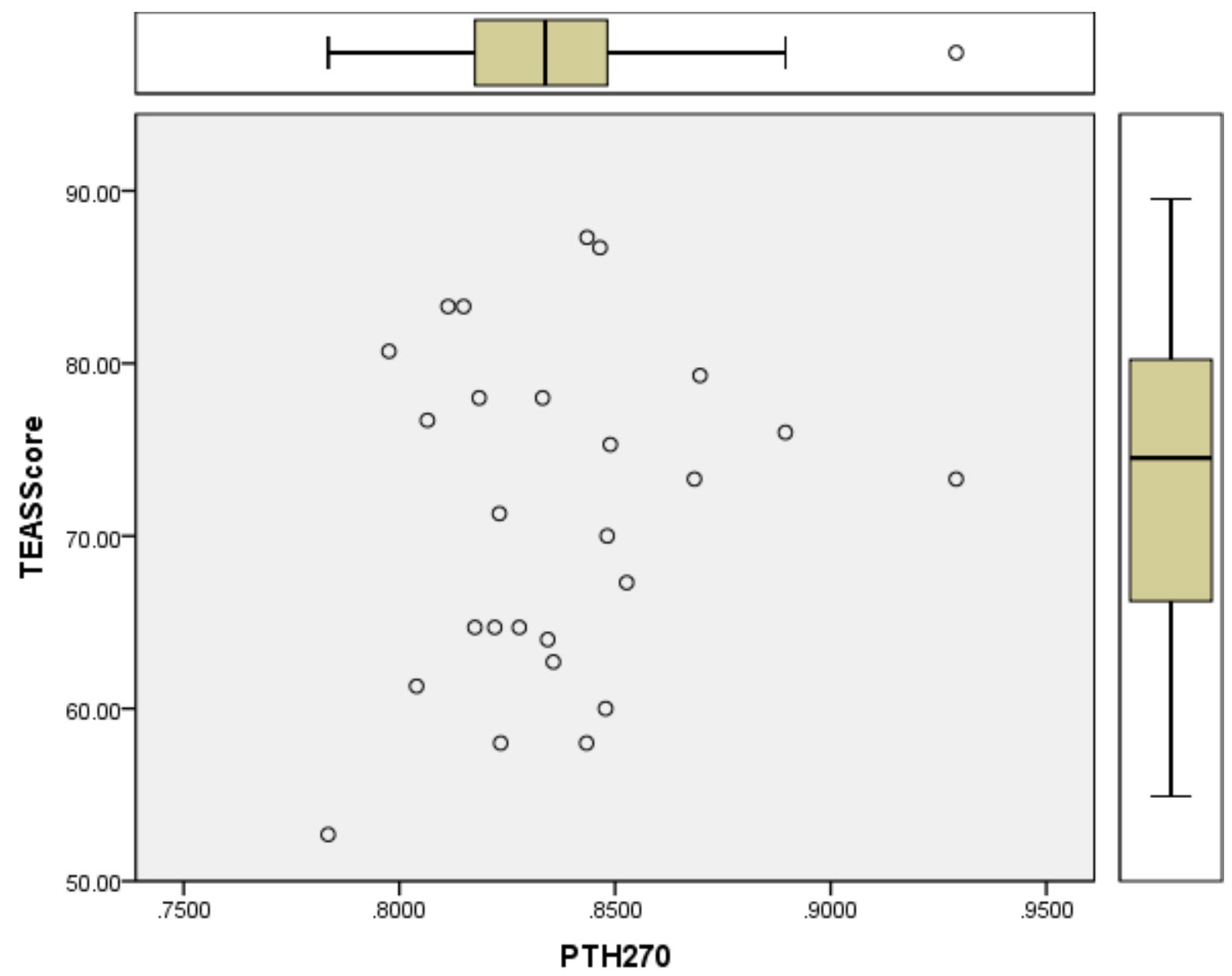

Figure 11: 15-Week Course Format 


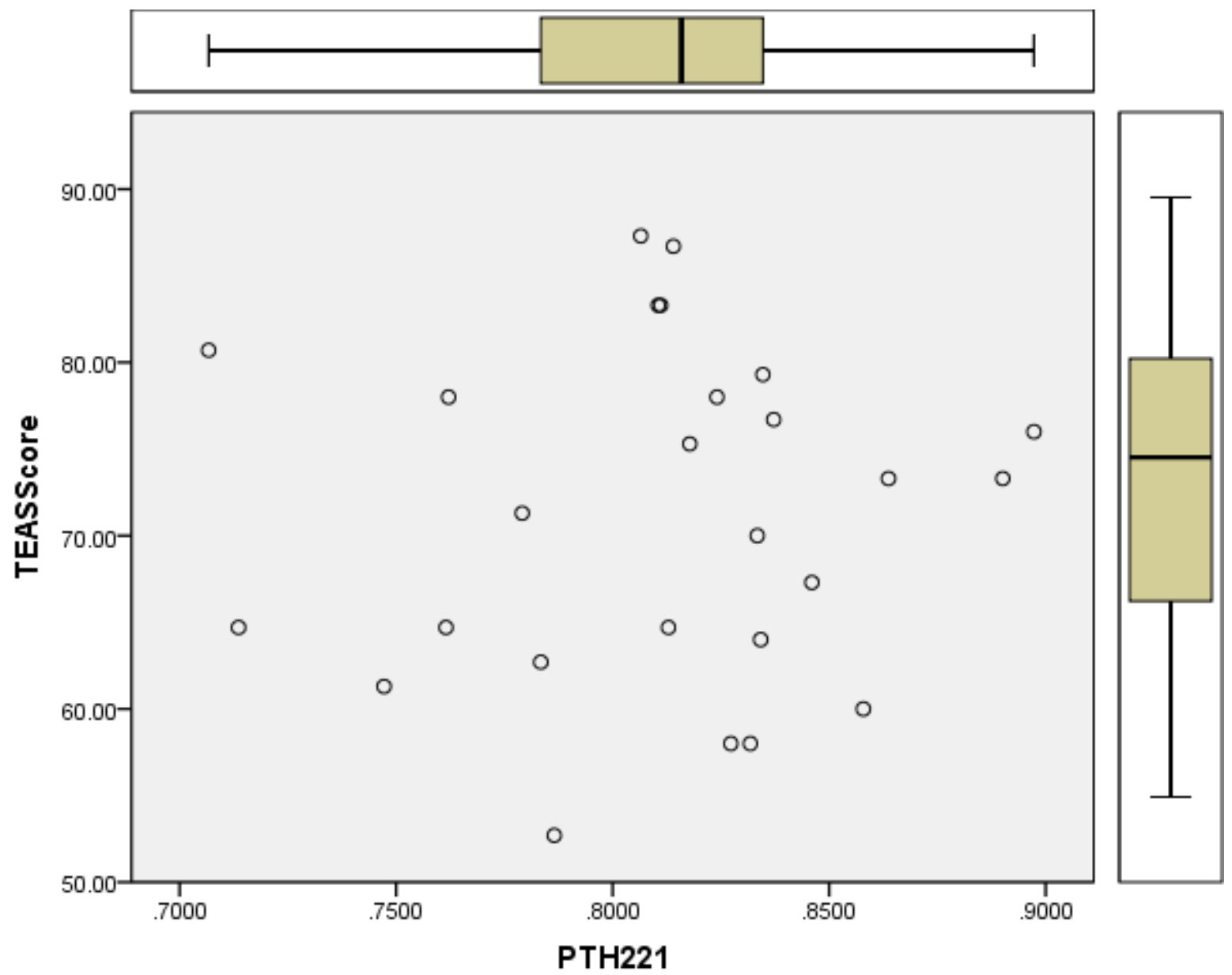

Figure 12: 15-Week Course Format 


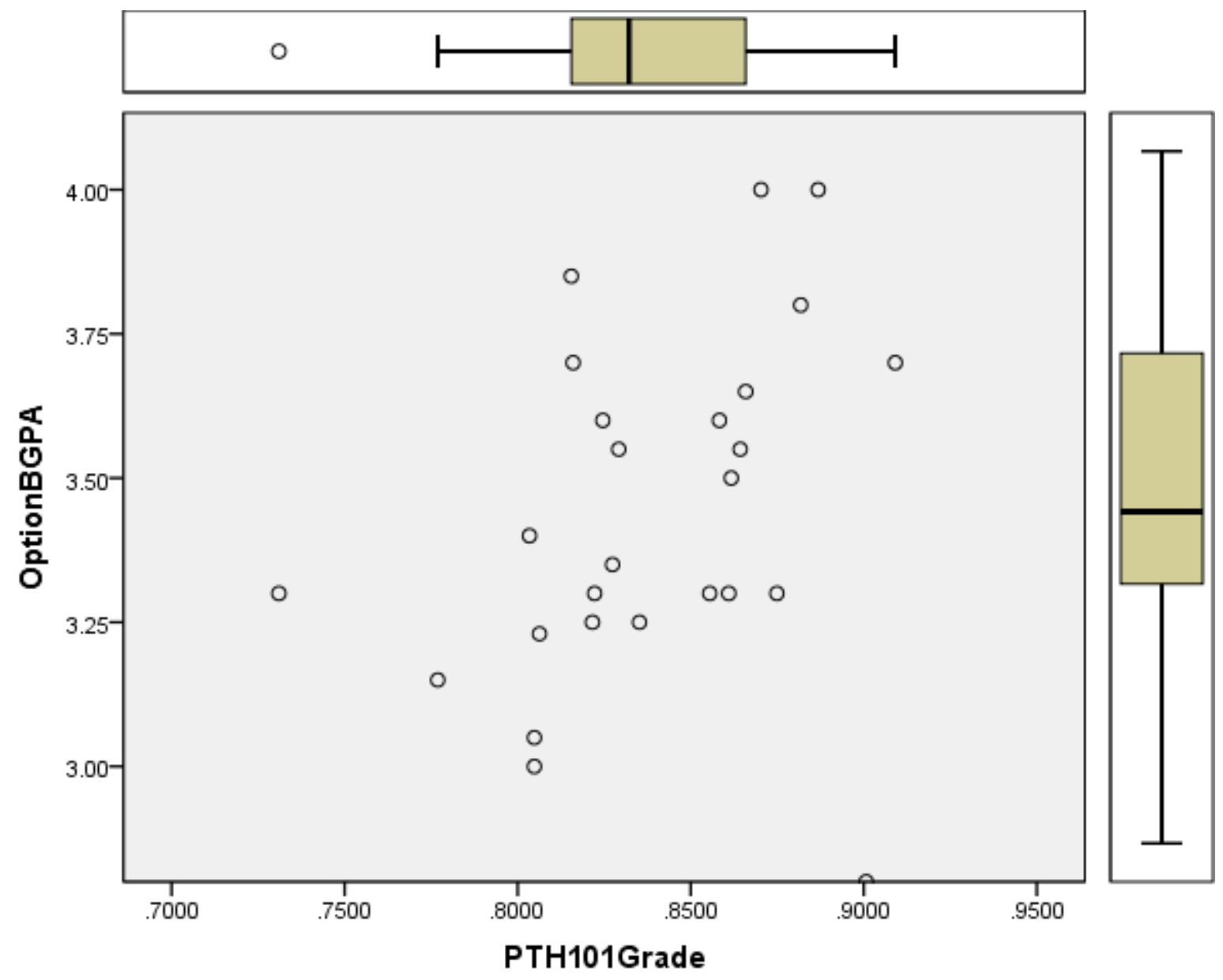

Figure 13: 15-Week Course Format 


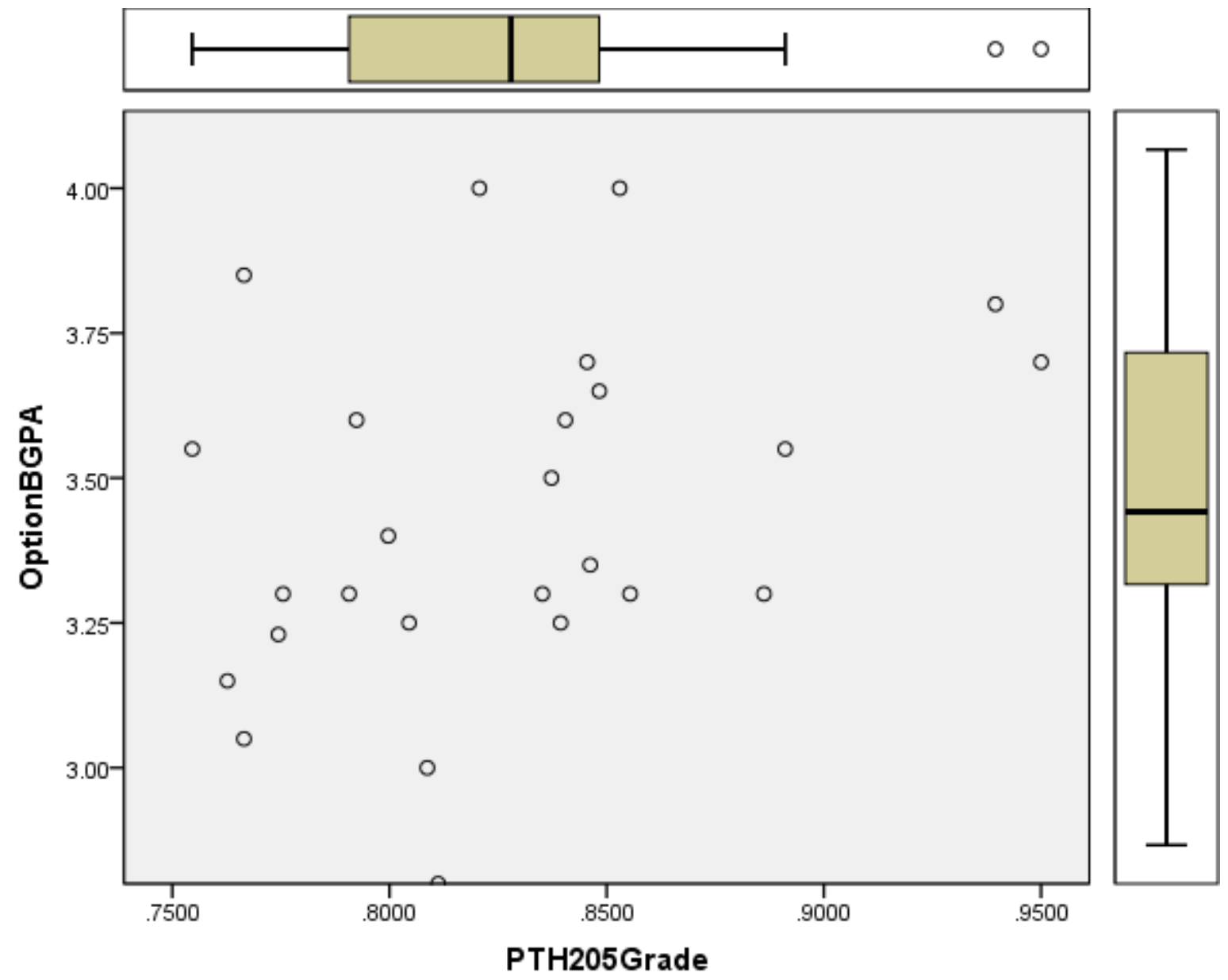

Figure 14: 15-Week Course Format 


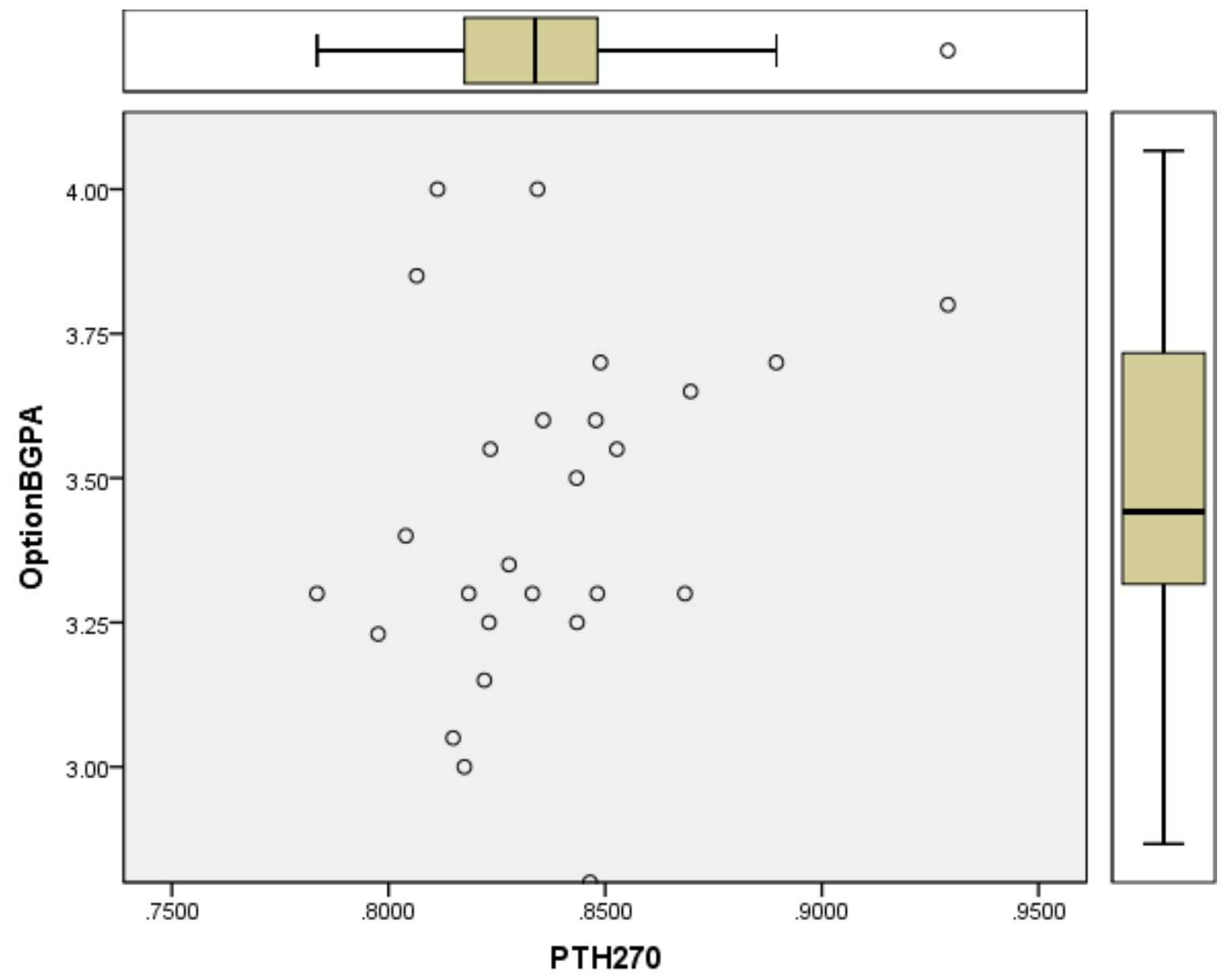

Figure 15: 15-Week Course Format 


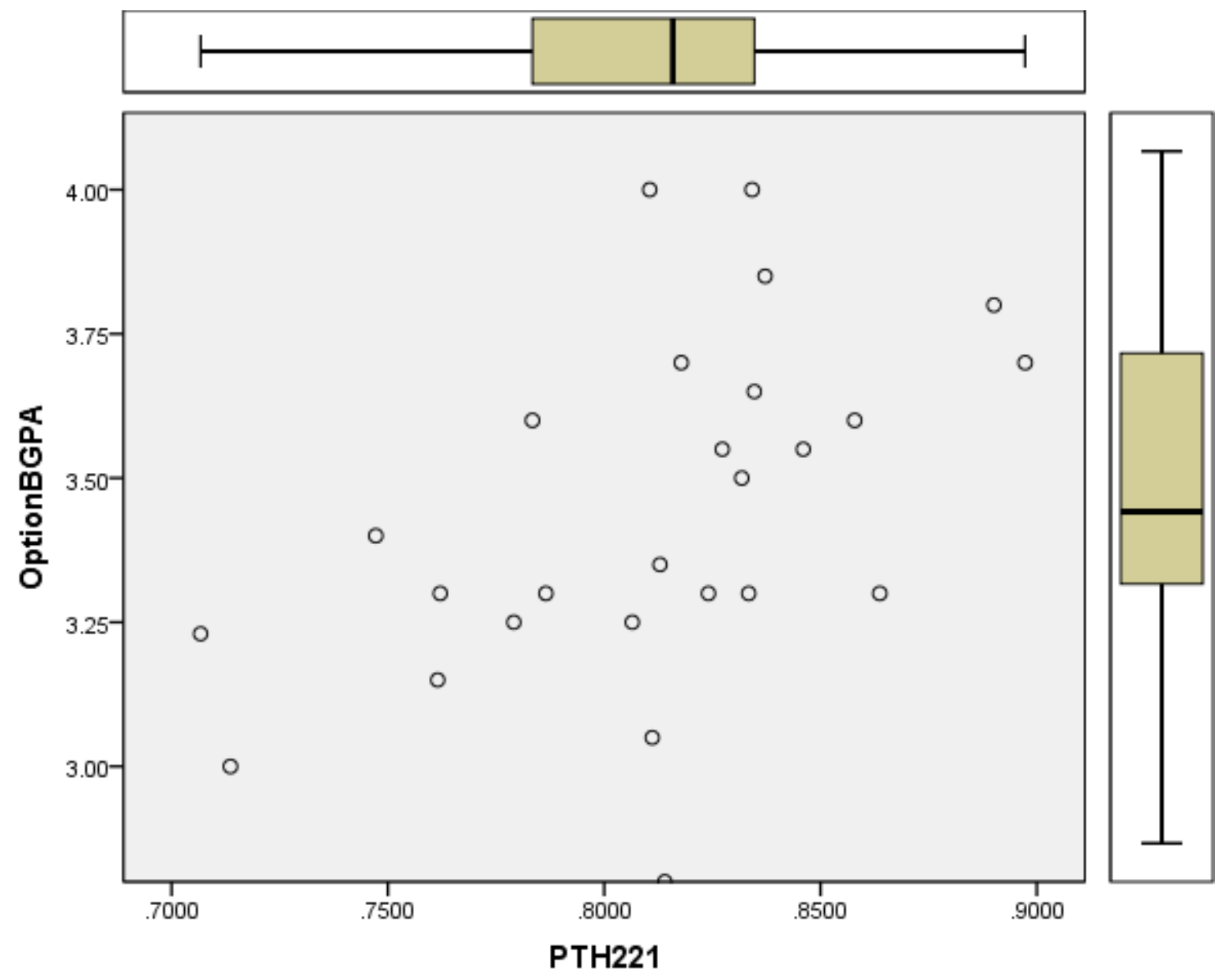

Figure 16: 15-Week Course Format 